\author{
UNIVERSIDADE DE SÃO PAULO \\ INSTITUTO DE ASTRONOMIA, GEOFÍSICA E CIÊNCIAS ATMOSFÉRICAS \\ PROGRAMA DE PÓS GRADUAÇÃO EM GEOFÍSICA
}

Dissertação de Mestrado

\title{
MODELAGEM DE ANOMALIAS DE DADOS HTEM PARA EXPLORAÇÃO MINERAL NO QUADRILÁTERO FERRÍFERO, MG
}

GABRIELA SERÊJO DE OLIVEIRA

São Paulo, Brasil

Junho de 2020 
Gabriela Serêjo de Oliveira

Versão Corrigida. O Original encontra-se disponível na Unidade

\section{MODELAGEM DE ANOMALIAS DE DADOS HTEM PARA EXPLORAÇÃO MINERAL NO QUADRILÁTERO FERRÍFERO, MG}

Dissertação apresentada ao Instituto de Astronomia, Geofísica e Ciências Atmosféricas para obtenção do título de Mestre em Geofísica.

Área de concentração: Geofísica Aplicada à Prospecção de Recursos Naturais, à Geotecnia e a Problemas Ambientais.

Orientador: Prof. Dr. Jorge Luís Porsani

São Paulo

2020 
Os ideais são como as estrelas, você não conseguirá tocá-las com suas mãos. Mas como os marinheiros nas águas desertas, elas podem guiá-lo, e, seguindo as estrelas, você chegará ao seu destino. (Carl Sagan) 


\section{Agradecimentos}

Agradeço a todos as pessoas e instituições, que direta ou indiretamente contribuíram para execução e conclusão desta pesquisa de dissertação de mestrado, e em especial:

○ À Deus por sempre estar ao meu lado e ter me proporcionado a oportunidade de realizar um mestrado na melhor universidade do país ao lado de professores e colegas maravilhosos.

○ Aos meus pais, Francisco Antônio e Joana Serêjo, em especial minha mãe, que sempre me apoiou e me incentivou a lutar por meus objetivos. Também agradeço pelo apoio e por todo o carinho e paciência durante esses anos.

- A agência de fomento CAPES pelo suporte financeiro para esta pesquisa.

- Ao meu orientador Prof. Dr. Jorge Luís Porsani, pelo aprendizado, paciência e incentivo durante todos esses anos de tutoria, desde as iniciações científicas, trabalho final de conclusão de graduação e agora na orientação da minha pesquisa de mestrado.

- Ao meu colega Marco Antônio Couto Jr. pelo apoio e coorientação nesta dissertação. Por sempre estar disponível para discussões e ensinamentos nos mais diversos desafios desta pesquisa.

- A todos os meus colegas, professores e funcionários do IAG. Por todo suporte, ensinamentos e momentos felizes em especial na nossa "salinha do café".

- Às minhas amigas e companheiras durante todo este período de mestrado Alane Neves e Fabiana Lasmar Pereira e ao meu amigo Ualisson Bellon por toda a ajuda nas discussões sobre geologia e na elaboração das imagens e mapas desta pesquisa.

- A CPRM e a ANM pela liberação dos dados para execução desta dissertação de mestrado.

O presente trabalho foi realizado com apoio da Coordenação de Aperfeiçoamento de Pessoal de Nível Superior - Brasil (CAPES) - Código de Financiamento 001. 


\section{Sumário}

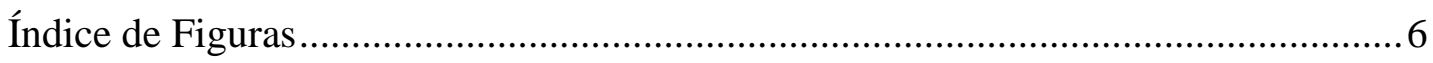

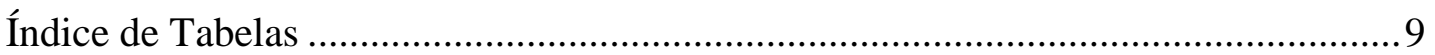

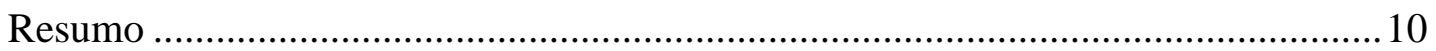

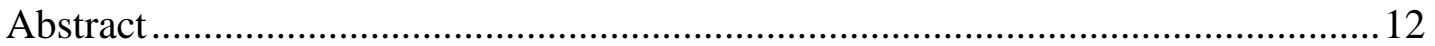

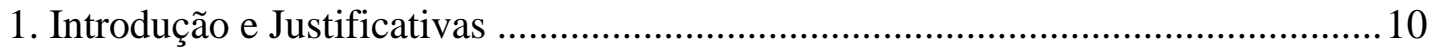

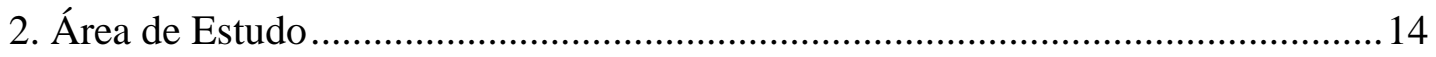

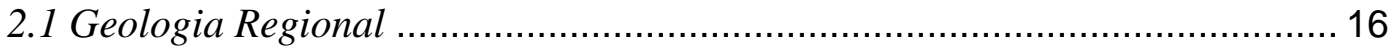

2.2 Evolução Tectônica do GBRV ............................................................... 21

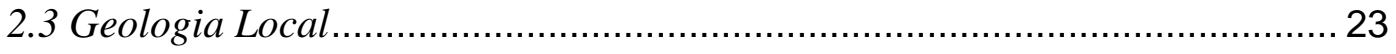

2.4 Depósitos Orogênicos Auríferos .............................................................. 26

3. Método TDEM (Time Domain Electromagnetic) ............................................29

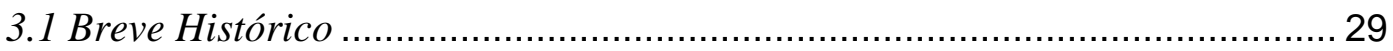

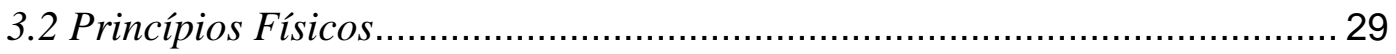

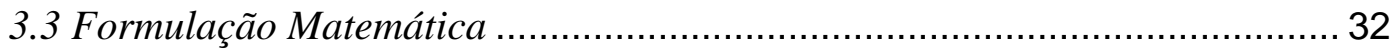

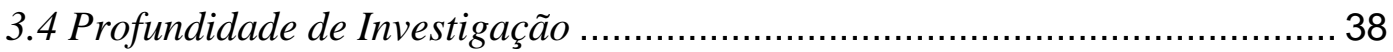

3.5 Fontes de Acoplamentos e Ruídos............................................................. 39

3.6 Sistemas Eletromagnéticos Aerotransportados ........................................... 40

4. Aquisição e Processamento dos Dados.................................................................4 44

5. Modelagem de Dados de Sistemas Eletromagnéticos Aéreos ...............................4 49

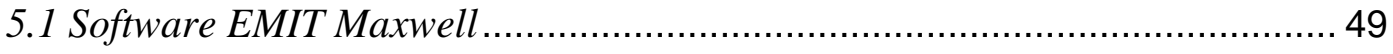

5.2 Características das Anomalias HTEM.................................................... 51

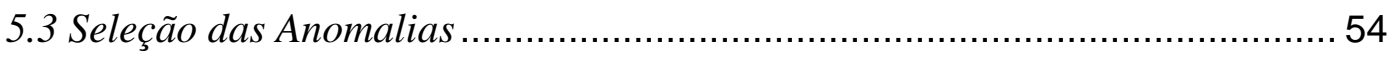

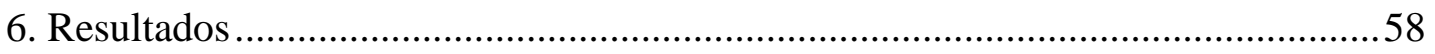

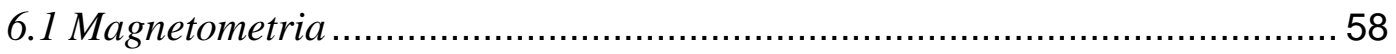

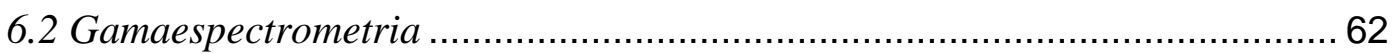

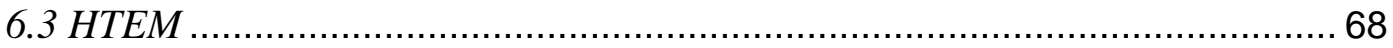




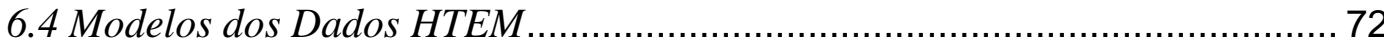

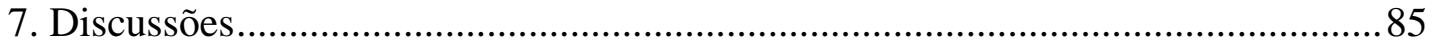

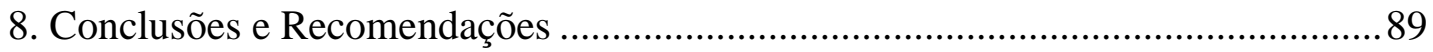

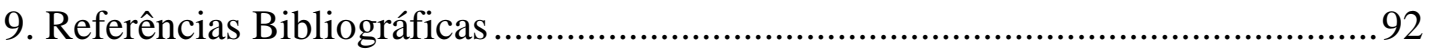




\section{Índice de Figuras}

Figura 1: Localização da área de estudo no Quadrilátero Ferrífero (MG) indicando minas ativas, delimitação da área de estudo e cidades próximas.

Figura 2: Principais depósitos auríferos hospedados no Greenstone Belt Rio das Velhas (retirado de Lobato et al., 2001b).

Figura 3: Mapa geológico simplificado do Quadrilátero Ferrífero com indicação da localização da área de estudo (modificado de Farina et al., 2016).

Figura 4: Coluna estratigráfica do Quadrilátero Ferrífero (Carlos, 2013).

Figura 5: Mapa geológico simplificado do Supergrupo Rio das Velhas na região do QF (retirado de Baltazar \& Zucchetti, 2007).

Figura 6: Domínios Tectônicos do GBRV (Baltazar \& Zucchetti, 2007). .22

Figura 7: Mapa da geologia local da área de estudo (CPRM). .23

Figura 8: Geologia simplificada da região entre Caeté e Santa Barbará e a localização depósitos auríferos (Adaptado de Lobato et al., 2001b). .26

Figura 9: a) Configuração tectônica dos depósitos orogênicos auríferos. b) Níveis de profundidade para formação dos depósitos de ouro (Adaptado de Groves et al., 1998).

Figura 10: a) Eddy currents imediatamente depois do desligamento, conhecido como "early time". b) Eddy currents nos tempos tardios, conhecido como "late time" (Adaptado de McNeill, 1994). 30

Figura 11: Diagrama da sequência de eventos de um levantamento TDEM (Adaptado de McNeill, 1994).

Figura 12: Esquema gráfico dos tipos de acoplamento e suas respostas no dado medido. a) Acoplamento galvânico. b) Acoplamento capacitivo (adaptado de Sørensen et al., 2000).

Figura 13: Evolução dos sistemas AEM (adaptado de Carson, 2003).....................................41

Figura 14: Configuração de um sistema VTEM (Legault et al., 2010). .43

Figura 15: Localização do Projeto Rio das Velhas I e II e Nova Redenção. Os polígonos pretos não representam as áreas cobertas pelos aerolevantamentos.

Figura 16: Sistema AeroTEM ${ }^{\mathrm{HD}}$. (A) bird do magnetômetro (B) loop transmissor e bobinas receptoras (retirado de CPRM, 2012).

Figura 17: Esquemas das formas de onda do transmissor e do receptor 
Figura 18: Modelo direto para uma placa vertical com 100x100 m e $100 \mathrm{~m}$ de profundidade para as componentes $\mathrm{Z}$ (preto) e $\mathrm{X}$ (azul)

Figura 19: Modelo direto para uma placa horizontal com 100x100 m e $100 \mathrm{~m}$ de

profundidade para as componentes Z (preto) e X (azul).

Figura 20: Modelo direto para uma placa sub-vertical com 100x100 m, 100 m de profundidade e $45^{\circ}$ de mergulho para as componentes $\mathrm{Z}$ (preto) e $\mathrm{X}$ (azul).

Figura 21: Modelo direto para uma placa vertical espessa com 100x100 m, 100 m de profundidade para as componentes $\mathrm{Z}$ (preto) e X (azul).

Figura 22: Dados da fase de requerimento para mineração (Retirado de http://www.anm.gov.br/assuntos/ao-minerador/sigmine). .56

Figura 23: Mapa dos "pickings" das anomalias de condutividade dos dados HTEM (Adaptado de Couto Jr. et al., 2017).

Figura 24: a) Geologia da área de estudo (Adaptado de Lobato et al., 2001b). b) Mapa da intensidade do campo magnético total.

Figura 25: a) Mapa da amplitude do sinal analítico (ASA 3D). b) Mapa da fase da amplitude do sinal analítico (TILT Derivative).

Figura 26: Geologia do lineamento Córrego do Sítio e mapa da fase da amplitude do sinal analítico (Adaptado de Lobato et al., 2001b).

Figura 27: a) Mapa da geologia da área de estudo (CPRM). b) Mapa do canal do potássio...63

Figura 28: a) Mapa da geologia da área de estudo. b) Mapa ternário (RGB) dos elementos eU (azul), eTh (verde) e K (vermelho).

Fig. 29: a) Modelo Digital do Terreno (MDT). b) Mapa ternário dos radioelementos eU, eTh

e K da área de estudo. .64

Figura 30: Mapa ternário sobre a topografia (MDT) da área de estudo. .65

Figura 31: a) Mapa da razão entre eTh e K. b) Mapa do Fator F. c) Geologia da região de estudo (CPRM).

Figura 32: Resultado dos dados HTEM para o canal 2 (early times) ...................................68

Figura 33: Resultado dos dados HTEM para o canal 7 (intermediate times)..........................69

Figura 34: Resultado dos dados HTEM para o canal 12 (late times).

Figura 35: a) Geologia da área de estudo (Adaptado de Lobato et al., 2001b). b) Canal 7 (offtime) dos dados HTEM. .71

Figura 36: Anomalias selecionas nos dados HTEM - Canal 7 (off-time) para modelagem destacadas pelo retângulo em preto. 
Figura 37: Resultado da modelagem para as componentes Z e X para os canais 4-9 (off-time).

Figura 38: Resultados da modelagem da componente $\mathrm{Z}$ para os canais 4 a 9 (off-time). a) visão tridimensional do modelo. b) visão NW-SE do modelo.

Figura 39: Resultado da modelagem para as componentes Z e X para os canais 4-10 (offtime).

Figura 40: Resultados da modelagem da componente Z para os canais 4 a 10 (off-time). a) visão tridimensional do modelo. b) visão NW-SE do modelo. .77

Figura 41: Resultado da modelagem para as componentes Z e X para os canais 4-7 (off-time).

Figura 42: Resultados da modelagem da componente $\mathrm{Z}$ para os canais 4 a 7 (off-time). a) visão tridimensional do modelo. b) visão NW-SE do modelo. 80

Figura 43: Resultado da modelagem para os canais 4-8 (off-time) das componentes Z e X...82

Figura 44: Resultados da modelagem da componente Z para os canais 4 a 8 (off-time). a) visão tridimensional do modelo. b) visão NW-SE do modelo. 


\section{Índice de Tabelas}

Tabela 1: Principais características de diferentes sistemas transientes aéreos (Adaptado de Christiansen et al., 2006).

Tabela 2: Característica do sistema utilizado na aquisição dos dados eletromagnéticos (CPRM, 2012)

Tabela 3: Parâmetros para geração de uma placa no software Maxwell (EMIT, 2015). .50

Tabela 4: Parâmetros do modelo 1 .74

Tabela 5: Parâmetros do modelo 2. .77

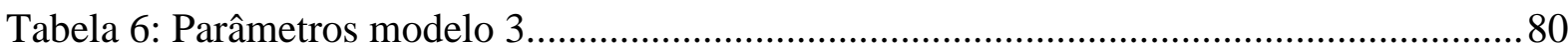

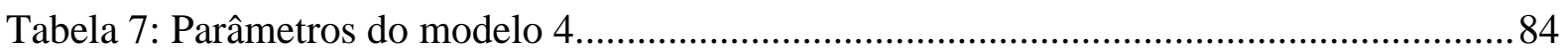

Tabela 8: Lista dos alvos modelados segundo o contexto geofísico e geológico e prioridade para exploração. 


\section{Resumo}

Nesta pesquisa foi realizada a modelagem 2.5D de anomalias de condutividade elétrica de dados HTEM (Helicopter Transient Electromagnetic), utilizando placas finas ou prismas, com o objetivo de determinar parâmetros geométricos, estruturais e físicos de depósitos de ouro associados a sulfetos localizados no Quadrilátero Ferrífero (QF), Estado de Minas Gerais, Brasil. A modelagem foi realizada utilizando o software EMIT Maxwell e os dados são provenientes do aerolevantamento eletromagnético (HTEM) adquirido entre os municípios mineiros de Santa Bárbara e Barão de Cocais (QF), no Projeto Rio das Velhas (PRV) - Etapa 2 (CPRM) - Projeto 1116 na base do GeoSGB. Além disso, para uma interpretação integrada dos resultados foram utilizados dados aéreos de magnetometria, também do PRV - Etapa 2 e dados aéreos radiométricos adquiridos na segunda fase do PRV - Etapa 1 (CPRM/DNPM). Por meio dos filtros de realce como a Amplitude do Sinal Analítico 3D (ASA 3D) e fase do sinal analítico (TILT Derivative) dos dados magnéticos, foi possível identificar lineamentos regionais, associados aos efeitos das Formações Ferríferas Bandadas (Banded Iron Formations - BIF's) fortemente magnéticas localizadas em amplas zonas de cisalhamento presentes na região de estudo. Os dados radiométricos foram utilizados para identificar zonas de possível alteração hidrotermal, principalmente do tipo potássica associada à mineralização do ouro. $\mathrm{O}$ mapa ternário, com as concentrações de potássio (vermelho), urânio (azul) e tório (verde), utilizado especialmente para o mapeamento geológico, destacou corpos graníticos, unidades máficas e ultramáficas e represamentos. A análise conjunta dos mapas da razão Th/K e do Fator $\mathrm{F}$ indicaram extensas anomalias de potássio concentradas ao longo de mineralizações e minas conhecidas, provavelmente formadas devido à lixiviação e acúmulo de potássio através do processo de alteração potássica, gerando os halos de alteração, principalmente na associação ressedimentada. Os mapas dos canais "early" e "intermediate" (off-time) dos dados HTEM exibiram amplas zonas condutoras lineares relacionadas aos sulfetos localizados nas zonas de cisalhamento. Essas anomalias de alta amplitude são orientadas na direção de $\mathrm{N} 45^{\circ} \mathrm{E}$, concordante com a direção do strike geológico regional das estruturas mineralizantes. A modelagem 2.5D como placas condutoras associadas aos depósitos de ouro foi utilizada na interpretação qualitativa dos dados HTEM. A partir dos modelos de placas finas ou prismas foi possível recuperar parâmetros geométricos, estruturais e físicos das mineralizações (condutância ou condutividade elétrica, respectivamente). Os modelos revelaram, em geral, orientação de $\mathrm{N}^{\circ} 5^{\circ} \mathrm{E}$, concordante com as principais estruturas geológicas da região, atitude de $135 / 20-80^{\circ}$, geometrias variáveis e baixas condutâncias/condutividades, corroborando assim 
com os parâmetros e estudos geológicos encontrados na literatura. Os modelos encontrados em áreas já exploradas podem auxiliar na exploração brownfield, como na melhoria do conhecimento das propriedades destas mineralizações e planejamento da mina. Já em áreas não investigadas, exploração greenfield, os parâmetros encontrados servem como guia para novos alvos exploratórios e orientação de furos de sondagem. 


\begin{abstract}
In this research, 2.5D modeling of electrical conductivity anomalies of HTEM data (Helicopter Electromagnetic Transient) was carried out, using thin plates or prisms geometries, with the objective of determining geometrical, structural and physical parameters of gold deposits associated with metallic sulfides in the Quadrilateral Ferrífero, Minas Gerais State, Brazil. The modeling was performed using the EMIT Maxwell software and the data were collected between the municipalities of Santa Bárbara and Barão de Cocais (QF), in the Rio das Velhas Project (PRV) - Stage 2 (CPRM) - Project 1116 (GeoSGB database). In addition, for an integrated interpretation of the results were used airborne magnetometry data, also PRV - Stage 2 and airborne radiometric data acquired in the second phase of the PRV - Stage 1 (CPRM/DNPM). Through enhancement filters, such as 3D Analytical Signal Amplitude (3D ASA) and Analytical Signal Phase (TILT Derivative) of the magnetic data, it was possible to identify regional lineaments, associated with the effects of the strongly magnetic Banded Iron Formations (BIF's) located in wide shear zones within the study region. Radiometric data was used to identify zones of hydrothermal alteration, especially the potassic type, associated with gold mineralization. The ternary map, showing potassium (red), uranium (blue) and thorium (green) highlighted granitic bodies, mafic and ultramafic units and impoundment/daming. A joint analysis of $\mathrm{Th} / \mathrm{K}$ ratio and Factor $\mathrm{F}$ maps detected extensive potassium anomalies concentrated along known mineralizations, probably caused by leaching and accumulation of potassium through the potassic alteration process, generating the alteration halos, especially in Resedimented association. The maps of the "early" and "intermediate" channels (off-time) of the HTEM data showed wide linear conduction zones related to the location of sulfides in the shear zones. These high amplitude anomalies are oriented in the $\mathrm{N} 45^{\circ} \mathrm{E}$ direction, in accordance with the direction of the regional geological strike of mineralizing structures. The $2.5 \mathrm{D}$ modeling of conductive plates associated with gold deposits was used in the qualitative interpretation of HTEM survey. From the thin plate or prism models, it was possible to recover the geometric, structural and physical (conductance or electrical conductivity, respectively) parameters of the mineralizations. The models revealed, in general, structural control to $\mathrm{N} 45^{\circ} \mathrm{E}$, agreeing with the main geological structures of the region, attitude of $130 / 20-80^{\circ}$, variable geometries and low conductances/conductivities, thus corroborating with the parameters and geological studies found in literature. The conductors models in areas already explored can assist in brownfield exploration, such as improving knowledge of the properties of these
\end{abstract}


mineralizations and mine planning. In non-investigated areas, i.e. greenfield exploration, the modeled parameters can be used as a guide for new exploratory targets and drill hole guidance. 


\section{Introdução e Justificativas}

O Quadrilátero Ferrífero (QF) se estende por uma área aproximada de $7.000 \mathrm{~km}^{2}$, na porção central do Estado de Minas Gerais, sendo uma região geologicamente importante do Pré-Cambriano brasileiro, devido às suas riquezas minerais, principalmente ouro e ferro (Lobato et al., 2001a).

A região do QF foi a mais importante área brasileira de produção de ouro desde o início do século XVIII até o final dos anos 1970. Representa uma província aurífera de classe mundial, com produção histórica que supera 1.000 toneladas de ouro, totalizando mais de $40 \%$ da produção total brasileira (Lobato et al., 2001b).

A evolução tectônica e estrutural do QF é complexa e ainda tema de muito debate. A ocorrência de uma sequência de eventos deformacionais influenciou diretamente a formação dos depósitos auríferos no QF. As mineralizações hospedam-se principalmente em formações ferríferas bandadas, vulcânicas máficas e veios de quartzo associados ao grupo Nova Lima, porção basal do Supergrupo Rio das Velhas (Dorr, 1969).

O uso da geofísica na busca por depósitos minerais é reconhecido internacionalmente e têm se tornado cada vez mais rotineiro em programas de exploração de pequenas e grandes empresas no mercado da mineração (Oliveira, 2014). Dentre os métodos geofísicos mais utilizados, destacam-se os métodos eletromagnéticos no domínio do tempo (TDEM - Time Domain Electromagnetic), com maior profundidade de investigação em relação aos métodos eletromagnéticos no domínio da frequência com fonte controlada e sensível à corpos condutores mais profundos.

Segundo (Allard, 2007), a indústria de mineração tem utilizado com sucesso os métodos eletromagnéticos aerotransportados (AEM) há mais de 60 anos, especialmente devido a possibilidade de estudar grandes áreas em um curto período de tempo. Nos anos 2000, o HTEM (Helicopter Transient Electromagnetic ou Transiente Eletromagnético por Helicóptero) ganhou destaque devido à sua boa resolução espacial dos condutores, baixo custo em relação aos sistemas de asa fixa para levantamentos em áreas pequenas e maior profundidade de investigação em relação aos sistemas do domínio da frequência. 
Embora a região esteja coberta por diversos levantamentos geofísicos, tanto aéreos quanto terrestres, realizados por iniciativas pública e privada, nem todos os dados estão públicos, com exceção dos aerolevantamentos da série 1000 do Serviço Geológico do Brasil (SGB-CPRM). Além disso, existem poucos estudos publicados que tratam dos depósitos auríferos do Quadrilátero Ferrífero com o enfoque geofísico. Dentre os trabalhos existentes destacam-se Silva (1999), Rolim (2001), Guimarães (2011), Oliveira (2014), Couto Jr. et al. (2017) e Couto Jr. et al. (2019).

Silva (1999) integrou dados aerogeofísicos magnéticos, gamaespectrométricos e eletromagnéticos no domínio da frequência, também do projeto Rio das Velhas - Etapa 1 e da CODEMGE (Companhia de Desenvolvimento de Minas Gerais) com o objetivo de determinar zonas prospectivas de ouro nas formações ferríferas bandadas do Greenstone Belt Rio das Velhas (Quadrilátero Ferrífero).

Rolim (2001) reprocessou e interpretou os dados aéreos de gamaespectrometria e eletromagnético no domínio da frequência do Projeto Rio das Velhas - Etapa 1 e magnetométricos do CGBA (Convênio Geofísica Brasil-Alemanha) com o objetivo de identificar ambientes favoráveis a mineralização aurífera, além de oferecer subsídios às investigações geológicas e análise metalogenética na porção central do QF.

Guimarães (2011) apresentou os resultados do processo de inversão de dados aéreos eletromagnéticos do levantamento SPECTREM adquirido pela empresa AGBM (Anglo Gold Ashanti Brasil Mineração e de polarização induzida (IP) da Geodatos do Brasil Ltda. O autor levou em consideração a falta de resposta EM (Electromagnetic Method) no caso dos depósitos de ouro em sulfetos disseminados, onde existe a predominância da resposta do efeito IP. Os resultados possibilitaram a caracterização da assinatura de corpos sulfetados conhecidos do depósito Lamego (QF), além da compreensão das profundidades, extensões laterais e controles estruturais de novos corpos condutores.

Oliveira (2014) integrou dados aerogeofísicos de eletromagnetismo (SPECTREM) adquiridos pela empresa Anglo Gold Ashanti e de magnetometria e gamaespectrometria (HELIMAG) adquiridos pela Fugro Airborne Surveys, com o objetivo de desenvolver um modelo exploratório dos depósitos auríferos encontrados nas minas do Complexo do Córrego do Sítio $(\mathrm{QF})$. 
Couto Jr. et al. (2017) apresentam os resultados da integração de dados HTEM, radiométricos e da técnica de inversão chamada "Vetor de Magnetização (MVI)", em áreas do Quadrilátero Ferrífero, com o objetivo de prover um melhor entendimento dos depósitos auríferos, como parte do projeto da CPRM “Geologia e Metalogênese do QF”.

Couto Jr. et al. (2019) apresentam a modelagem IP de sinais AEM (airborne eletrocmagnetic method) adquiridos em áreas com sulfetos disseminados associados à mineralização de ouro na mina de Lamego, propriedade da empresa AngloGold Ashanti, no QF. A modelagem AEMIP (Airborne Electromagnetic Induced Polarization) foi realizada utilizando reparametrização MPA (Maximum Phase Angle) do modelo Cole-Cole.

Nesse contexto, o desenvolvimento de pesquisas utilizando modelagem de dados de aerolevantamentos geofísicos pode contribuir para o melhor entendimento das respostas físicas dos métodos eletromagnéticos nos depósitos auríferos e na determinação de suas geometrias e propriedades físicas, auxiliando assim em futuras campanhas de prospecção mineral.

Um dos modelos mais empregados na modelagem de dados eletromagnéticos é uma placa retangular fina no espaço livre. Uma série de feições geológicas podem ser modeladas através dessa abordagem. Placas finas condutivas têm sido muito utilizadas na exploração mineral para modelar e interpretar respostas EM de corpos finos de minérios condutores, como depósitos de sulfetos maciços hospedados em zonas de fraturas e rochas resistivas (Nabighian et al., 1984). Um exemplo de aplicação de modelagem de dados EM aéreos por placas condutivas finas encontra-se no trabalho de Bournas et al. (2015). Neste trabalho as anomalias causadas por condutores lineares com direção E-W, possivelmente de natureza grafítica, foram modeladas através de placas condutivas finas. Com o auxílio da modelagem foi possível delinear novos alvos favoráveis à exploração e à execução de furos de sondagens para grafita e mineralizações massivas sulfetada de $\mathrm{Cu}-\mathrm{Ni}$.

Portanto, o objetivo desta pesquisa é aplicar a modelagem 2.5D de anomalias de condutividade elétrica, por placas finas e/ou prismas, utilizando o software EMIT Maxwell, para a caracterização de depósitos auríferos compreendidos entre os municípios de Santa Bárbara e Barão de Cocais (QF). Os dados utilizados nessa pesquisa são provenientes do aerolevantamento eletromagnético (HTEM) adquirido na região do Quadrilátero Ferrífero, no Projeto Rio das Velhas - Etapa 2. Adicionalmente, para uma interpretação integrada de 
resultados, serão utilizados dados magnetométricos, gamaespectrométricos e geológicos disponíveis para a região.

Esta pesquisa contribuirá (1) na caracterização de depósitos auríferos, (2) na compreensão dos controles estruturais desses depósitos, (3) na caracterização geoelétrica da região do QF, e (4) na ampliação do conhecimento para o setor minerário do Brasil que utiliza métodos eletromagnéticos aerotransportados. 


\section{2. Área de Estudo}

Á área de estudo está localizada no Quadrilátero Ferrífero (QF), entre os municípios de Santa Bárbara e Barão de Cocais, região do Estado de Minas Gerais (MG). A Figura 1 mostra a localização da área de estudo (destacada pelo polígono em amarelo) e a localização das minas ativas Córrego do Sítio I e II e Pilar.
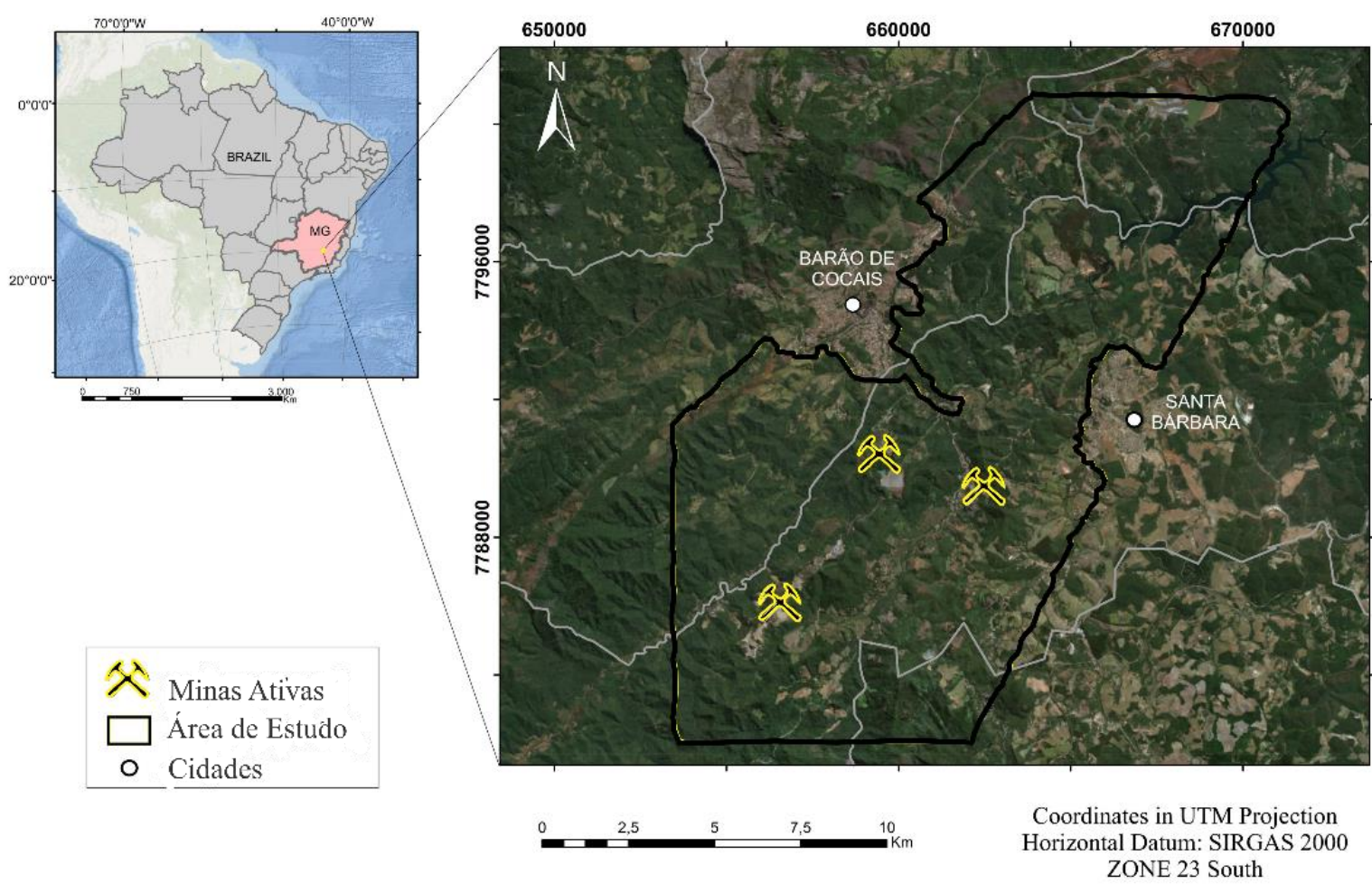

Figura 1: Localização da área de estudo no Quadrilátero Ferrífero (MG) indicando minas ativas, delimitação da área de estudo e cidades próximas.

A região do QF é uma das mais importantes províncias de ouro no Brasil, com produção histórica e reservas de ouro atuais superiores a 1.000 ton, representando $40 \%$ da produção total de ouro no Brasil (Vial et al., 2007a). O depósito aurífero Morro Velho, uma das minas subterrâneas mais importantes da região, produziu cerca de 450 ton ao longo de 100 anos de exploração. Os depósitos auríferos estão hospedados, em sua maioria, em rochas do Grupo Nova Lima, porção basal do Supergrupo Rio das Velhas (Lobato et al., 2001b).

Segundo Baltazar \& Zucchetti (2007), em escala de depósito, os depósitos de ouro no SGRV (Supergrupo Rio das Velhas) são controlados estruturalmente por falhas de empurrão 
de direção NW-SE e falhas transcorrentes com direção NE-SW de segunda e terceira ordem e são do tipo D2. Segundo Baltazar \& Zucchetti (2007) estruturas do tipo D2 são compressivas e de idade Arqueana, com orientação típica NE-SW. Os principais depósitos auríferos no QF (Fig. 2) estão localizados em rochas hidrotermais do tipo Lapa-Seca, que contêm $47 \%$ do ouro da região (mina Morro Velho), e nas Formações Ferríferas Bandadas (BIF’s), que contém outros $49 \%$ do ouro (minas Cuiabá, Raposos, São Bento, Lamego e Brumal). Diversos depósitos menores são hospedados em rochas vulcânicas máficas e ultramáficas, sedimentares, vulcanoclásticas e em pelitos carbonosos representando $4 \%$ do ouro contido. As principais estruturas hospedeiras destes depósitos são falhas transcorrentes, reversas e normais e dobras assimétricas. Já os principais tipos de alteração hidrotermal que ocorrem nesses depósitos são a silicificação, seritização, carbonatação e a sulfetação (Lobato et al., 2001b). 


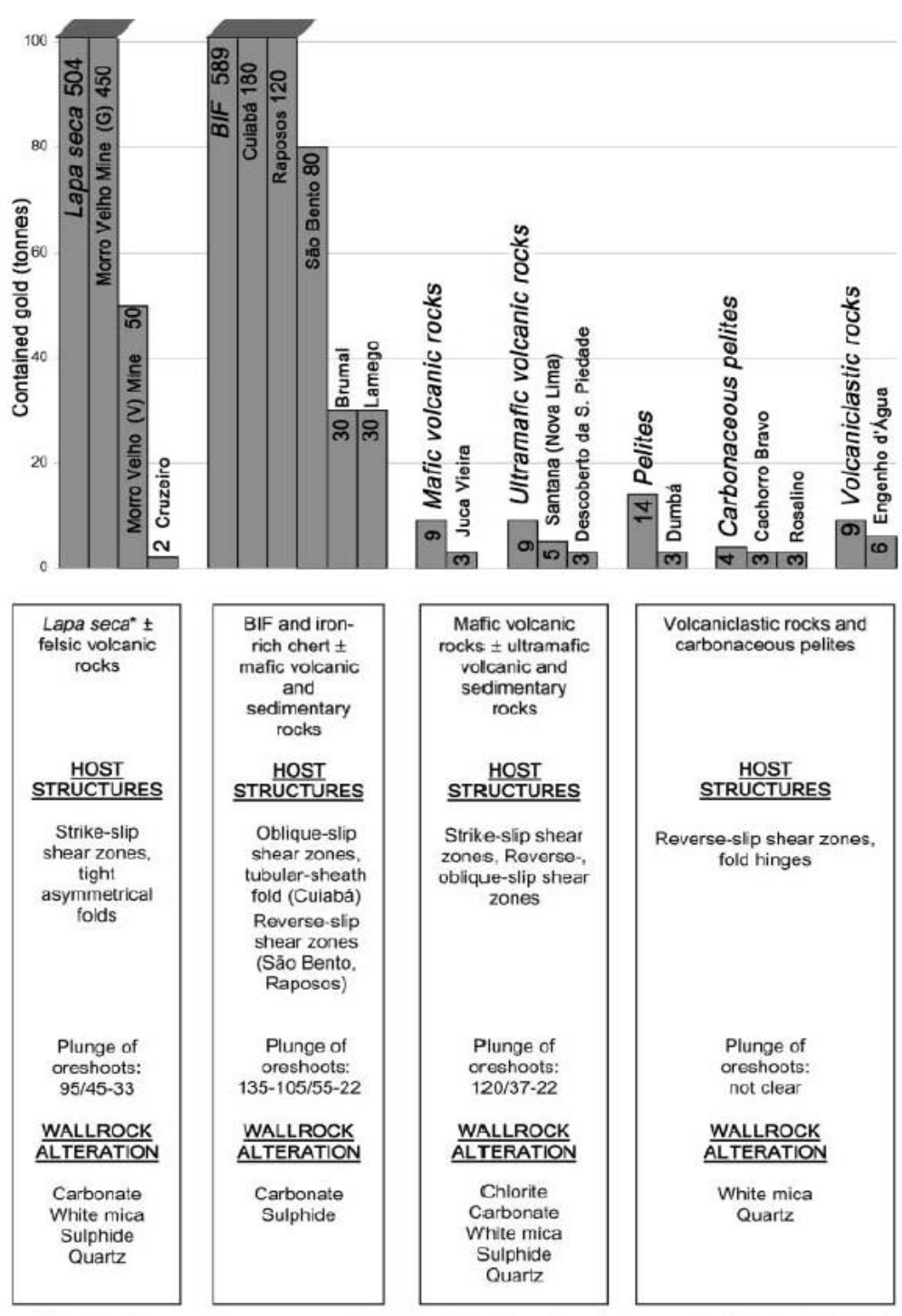

Figura 2: Principais depósitos auríferos hospedados no Greenstone Belt Rio das Velhas (retirado de Lobato et al., 2001b).

\subsection{Geologia Regional}

O QF apresenta um terreno granito-greenstone coberto por sequências supracrustais Proterozóicas e está situado na porção sul do Cráton São Francisco (Almeida, 1967; Almeida \& Hasui, 1984; Marshak et al., 1992).

O QF é composto por quatro principais domínios estruturais: o embasamento cristalino Arqueano, o Supergrupo Rio das Velhas de idade Arqueana, o Supergrupo Minas e o Grupo Itacolomi de idades do Paleoproterozóicas (Alkmin \& Marshak, 1998). Segundo Baltazar \& Zucchetti (2007), a distribuição do Supergrupo Minas define a forma geométrica do QF, uma vez que seus limites são formados por "mega dobras" sinclinais. A Figura 3 sintetiza as 
principais estruturas geológicas presentes no QF e a localização da área de estudo (polígono amarelo):

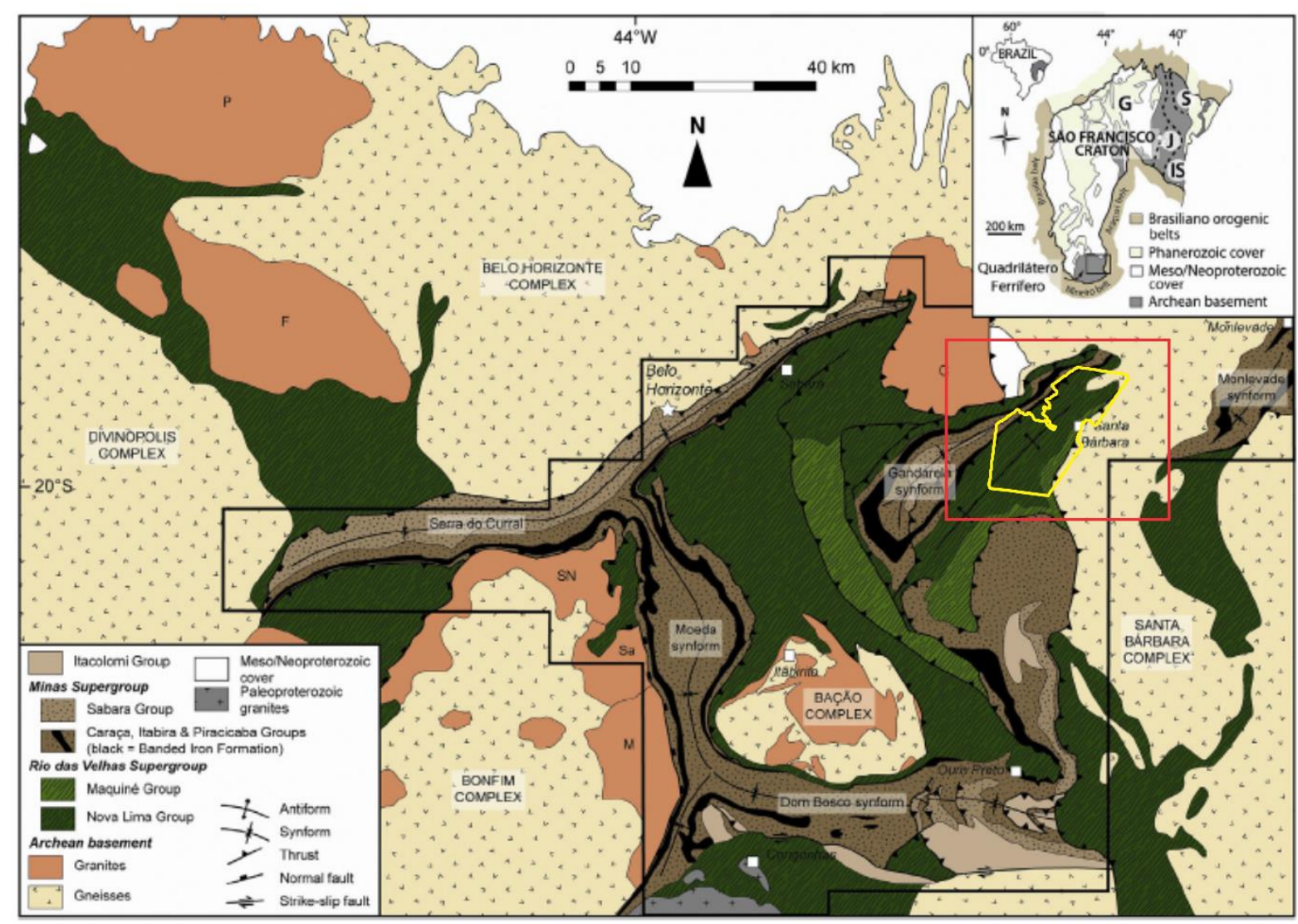

Figura 3: Mapa geológico simplificado do Quadrilátero Ferrífero com indicação da localização da área de estudo (modificado de Farina et al., 2016).

Os complexos metamórficos constituem o embasamento da sequência estratigráfica e são formados, majoritariamente, por ortognaisses do tipo TTG (tonalito-trondhjemitogranodiorito), migmatizados ou não, e apresentam intrusões de granitoides, anfibolitos e pegmatitos. Estudos geocronológicos mostram idades de 2.9 a $3.2 \mathrm{Ga}$ para algumas rochas destes complexos. A unidade é representada pelos complexos Caeté, Belo Horizonte, Bonfim, Santa Bárbara e Bação (Herz, 1970; Noce, 2000).

O SGRV é caracterizado por uma sequência greenstone belt conhecido como Greenstone Belt Rio das Velhas (GBRV) (Schorscher, 1976) e compreende os Grupos Nova Lima e Maquiné. O Grupo Nova Lima é constituído por rochas vulcânicas e metassedimentares químicas e clásticas e é umas das unidades mais estudadas mundialmente devido aos seus depósitos e ocorrências auríferas em BIF’s. Já o Grupo Maquiné é constituído basicamente por 
quartzitos, conglomerados e filitos. O Grupo Maquiné recobre o Grupo Nova Lima ao longo de uma desconformidade angular.

Segundo Dorr (1969), o Supergrupo Minas constitui uma unidade metassedimentar que assenta em discordância angular sobre o SRV. O supergrupo é dividido em quatro grupos: Sabará, Piracicaba, Itabira e Caraça. O grupo Itabira é dividido entre as formações Cauê e Ganderela. Na formação Cauê estão localizados os maiores depósitos de ferro do QF e é composta por formações ferríferas bandadas e rochas do tipo itabirito e mármore dolomítico.

Dorr (1969) considera o Grupo Itacolomi como constituído de duas fácies, uma de quartzitos e outra predominantemente composta por filitos. A Figura 4 sintetiza na coluna estratigráfica do QF as informações litológicas mencionadas acima. 


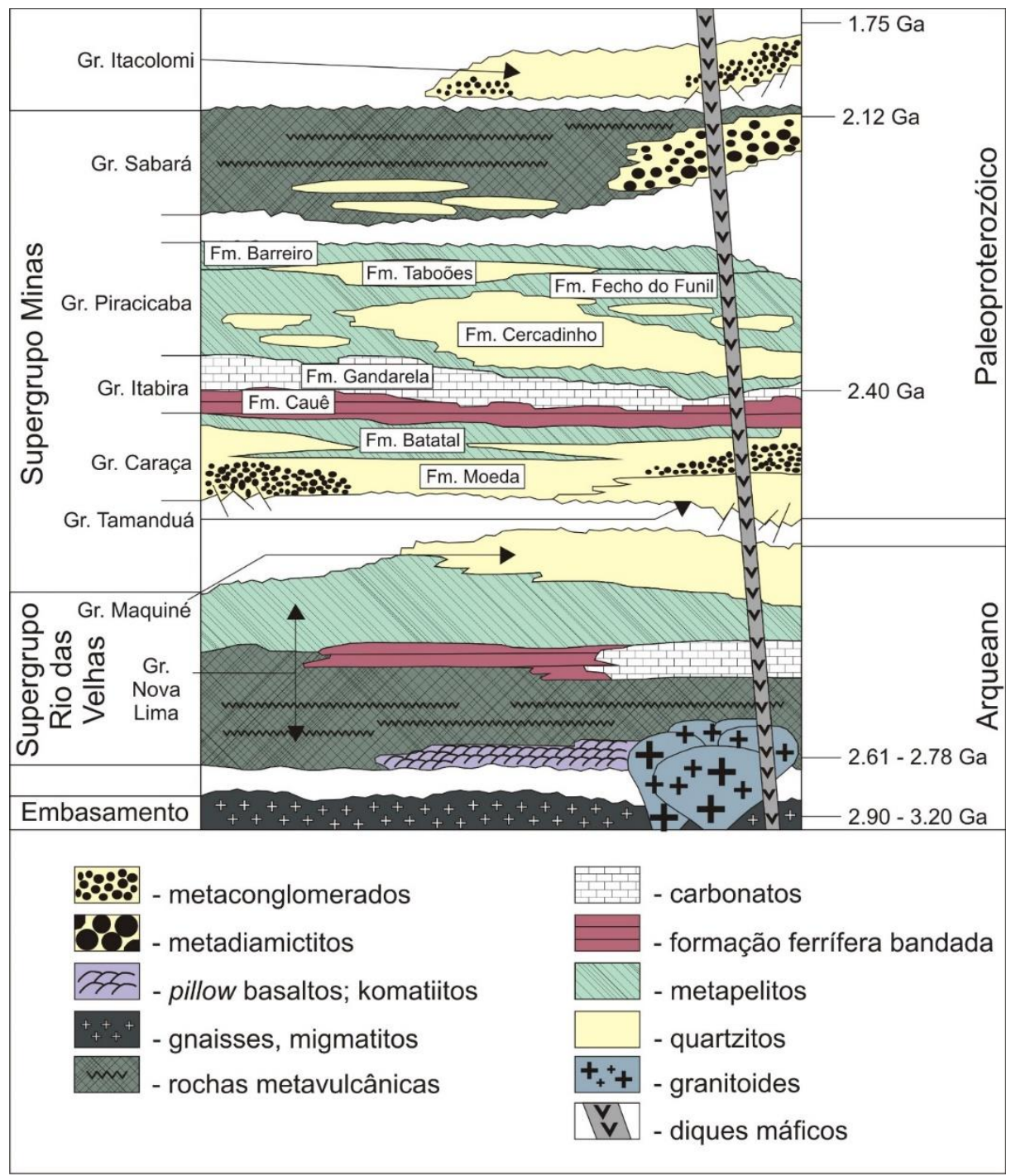

Figura 4: Coluna estratigráfica do Quadrilátero Ferrífero (Carlos, 2013).

Baltazar \& Zucchetti (2007) propuseram uma nova divisão tectônica-estratigráfica para o Supergrupo Rio das Velhas, utilizando o conceito de litofácies, onde cada associação é definida por uma estratigrafia e um sistema tectônico diferente, resultando em quatro ciclos deposicionais para o GBRV (Fig. 5). 

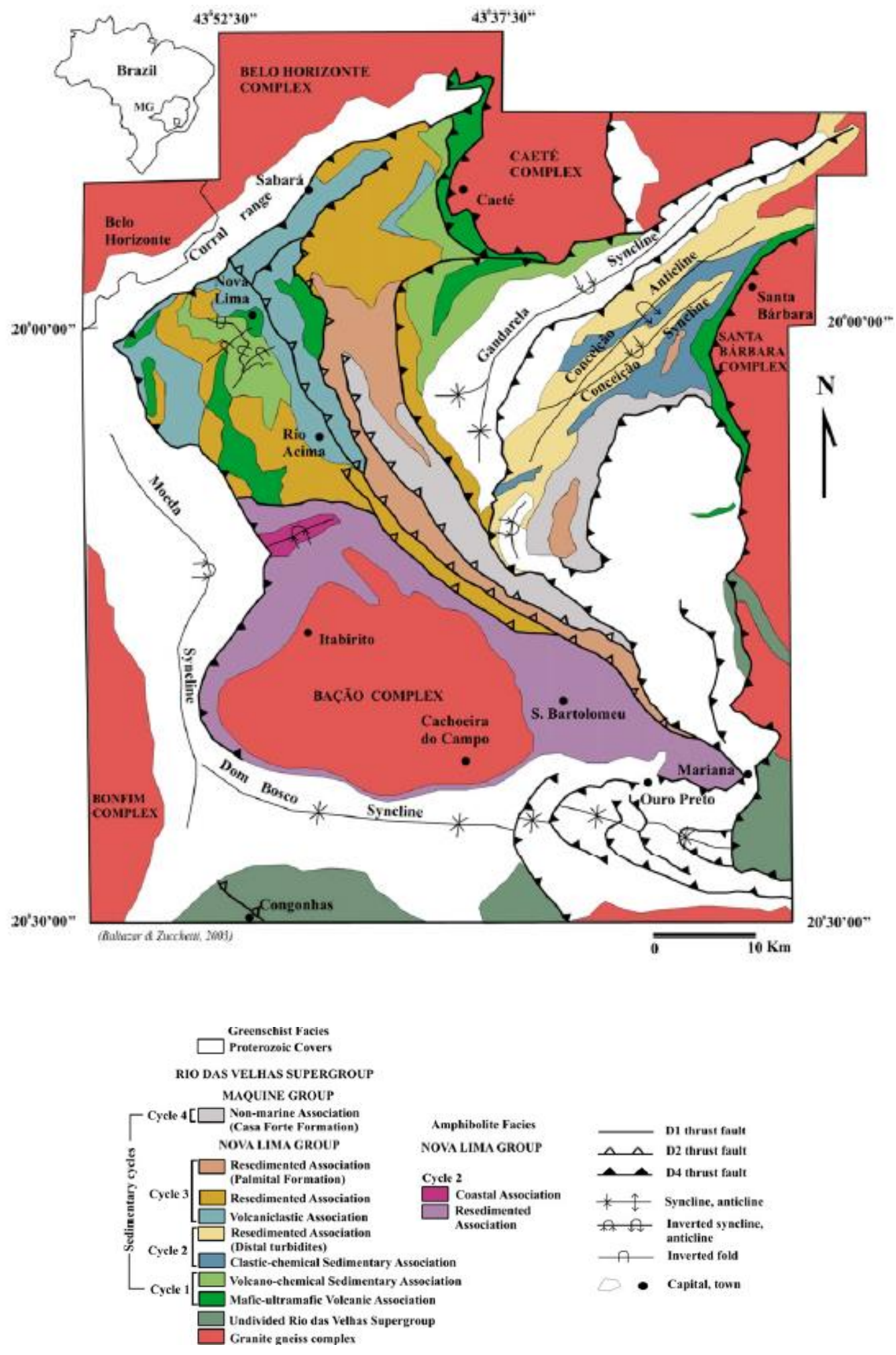

Figura 5: Mapa geológico simplificado do Supergrupo Rio das Velhas na região do QF (retirado de Baltazar \& Zucchetti, 2007). 
Segundo os autores, a distribuição espacial desses ciclos é controlada por zonas de cisalhamento que justapõem blocos tectônicos com características litoestruturais diferentes, impossibilitando assim definir apenas uma coluna estratigráfica para toda a sequência greenstone belt. Portanto, Baltazar \& Zucchetti (2007) sugerem uma subdivisão em três colunas estratigráficas distintas para o GBRV. O Ciclo 1 é composto por rochas vulcânicas máficas e ultramáficas com intercalações de rochas sedimentares químicas, geradas em um regime tectônico extensional de bacias de espalhamento oceânico. O Ciclo 2 é composto por rochas sedimentares clásticas e químicas, associadas a um estágio inicial de vulcanismo félsico, sendo interpretado como o estágio final da bacia extensional oceânica e a fase de subducção. O Ciclo 3 compreende rochas sedimentares e está associado ao ambiente transicional de leques aluviais submarinos e sucessões não marinhas. Já o Ciclo 4 é formado por rochas sedimentares clásticas provenientes de depósitos de leques aluviais gerados em bacias de retroarco e é representado pela associação de litofácies não marinhas.

\subsection{Evolução Tectônica do GBRV}

A evolução tectônica-estrutural do QF é complexa e ainda é tema de muito debate entre pesquisadores. O GBRV apresenta uma evolução policíclica e foi submetido a uma série de eventos tectônicos subsequentes. Diversos autores propuseram modelos para explicar a evolução tectônica do GBRV como Dorr (1969), Vieira \& Oliveira (1988), Junqueira (1997), Chemale Jr. et al. (1994), Baltazar (1998a), entre outros. Para esta pesquisa foi utilizado o modelo de evolução proposto por Baltazar \& Zucchetti (2007) por ser usualmente adotado pelo SGB-CPRM e nas atividades de exploração mineral aurífera no QF. Os autores dividem o GBRV em quatro domínios estruturais, definidos de acordo com os seus estilos estruturais e o trend de suas principais estruturas megascópicas (Fig. 6). Em cada domínio, um certo grupo de estruturas planares e lineares são bem preservadas e relacionadas à quatro geração de estruturas resultantes de três eventos deformacionais que afetaram o greenstone belt. 


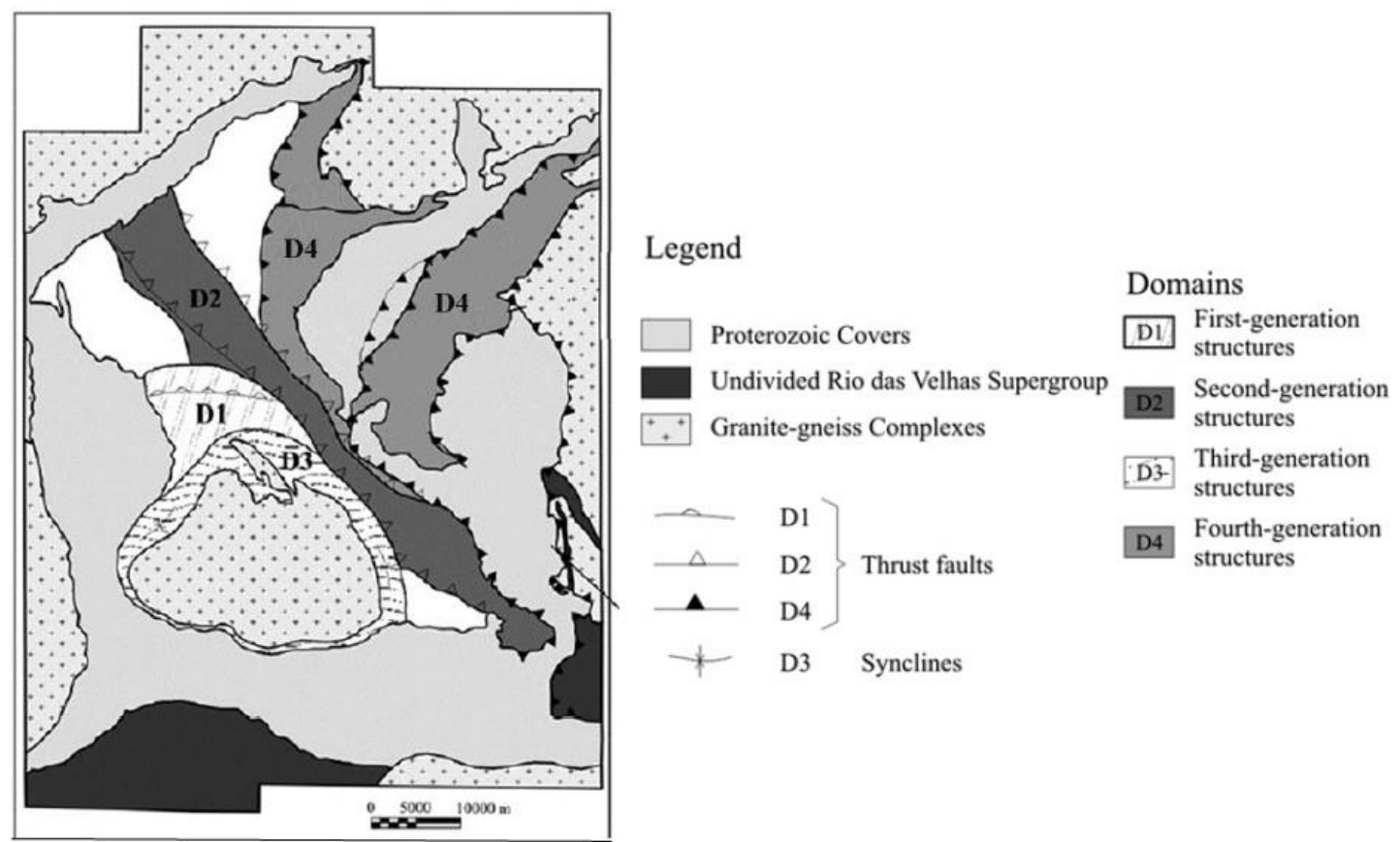

Figura 6: Domínios Tectônicos do GBRV (Baltazar \& Zucchetti, 2007).

A primeira fase, denominada de domínio estrutural D1, ocorreu no Arqueano e possui um regime do tipo compressivo com transporte tectônico de N para S. As estruturas resultantes são falhas de empurrão com direção E-W e vergência para $S$ e também dobras isoclinais e abertas com eixos mergulhando para ENE. As principais estruturas geradas nesta fase são bem preservadas na porção sul do QF como, por exemplo, a falha Bem-Te-Vi.

A segunda fase (D2) possui estruturas bem preservadas na parte central do QF, tem idade Arqueana, constitui um regime compressivo e houve transporte tectônico de NE para SW. As principais estruturas são falhas de empurrão com direção NW, representadas pelas falhas Araçuruí, Córrego do Areão, Tapera, São Vicente e Raposo, e dobras isoclinais e apertadas com vergência para SW e direção NW.

Já a terceira fase (D3) possui um regime extensional com transporte tectônico de WNW para ESE e está relacionada ao evento Transamazônico. Dois principais grupos de estruturas são relacionados a esta fase. O primeiro grupo são as estruturas que definem a forma quadrangular do QF e são representadas pelos sinclinais Serra do Curral, Moeda, Dom Bosco e Santa Rita. Estes sinclinais são formados pelas rochas sedimentares do Supergrupo Minas, depositados em um ambiente intracratônico durante a extensão (Chemale et al., 1994). O segundo grupo está relacionado a forma de "domo e quilhas" do embasamento granito- 
gnaíssico que compreende os complexos Belo Horizonte, Bonfim, Bação, Caeté, Santa Rita e Santa Bárbara. Estas estruturas estão associadas ao soerguimento do embasamento e consequente nucleação dos sinclinais regionais.

Por fim, a última fase (D4) domina a parte nordeste do QF, com uma direção geral N-S. Regionalmente, a fase D4 é representada por zonas de cisalhamento bem desenvolvidas como, por exemplo, a zona Fundão-Cambotas. As estruturas representam um regime compressivo, de idade Neoproterozóica e relacionado ao Ciclo Orogênico Brasiliano (Chemale et al., 1991; Alkmim et al., 1994; Schrank \& Machado, 1996a).

\subsection{Geologia Local}

Segundo a classificação determinada por Baltazar \& Zucchetti (2007), na área de estudo estão presentes parte do complexo Santa Bárbara e do Granito Peti (embasamento granitognáissico) e os grupos Quebra Osso, Nova Lima (unidades químico-pelítica e ressedimentada), Caraça e Itabira. A Figura 7 apresenta as litologias presentes na área de estudo (definida pelo polígono preto):
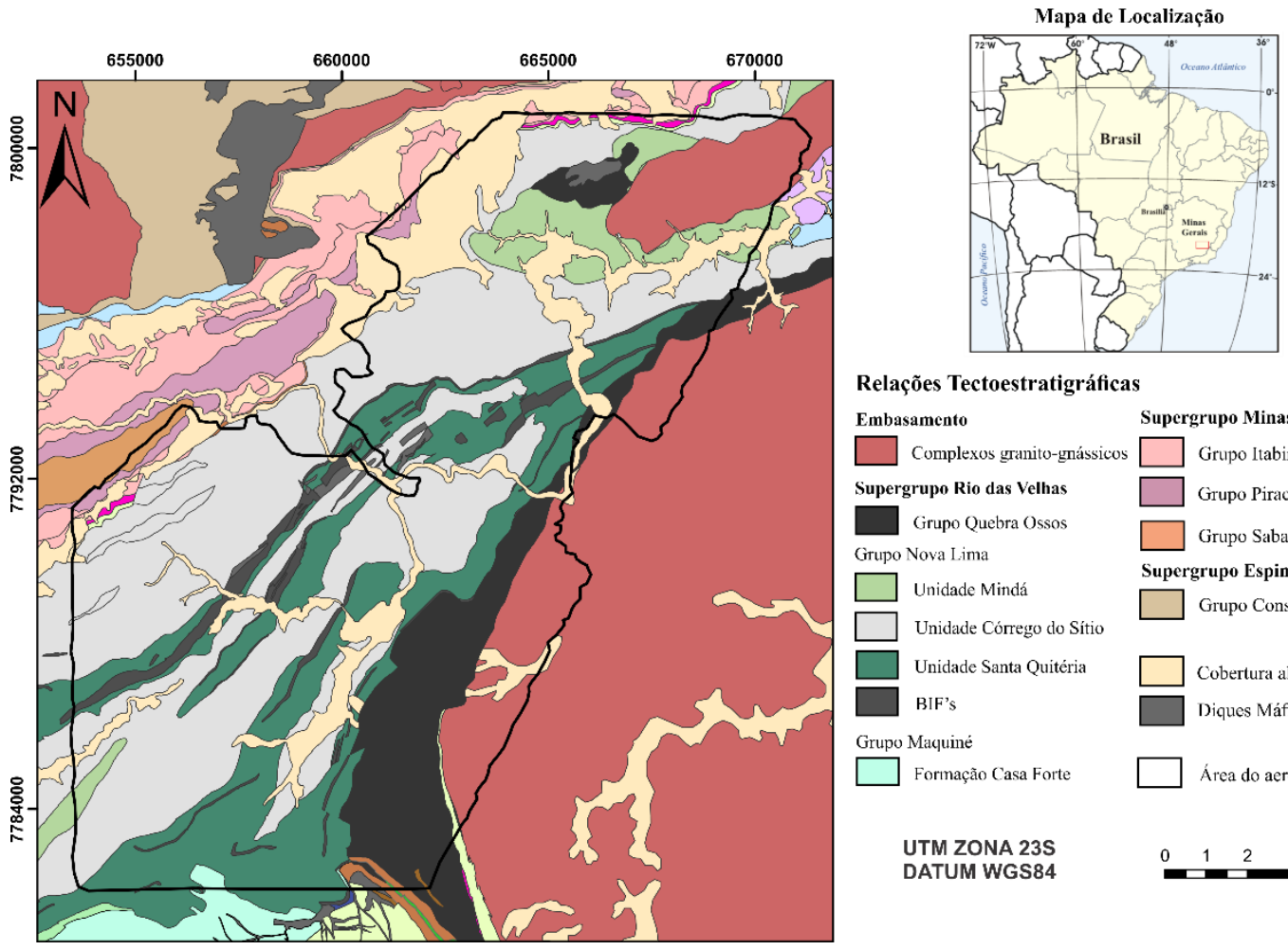

Relações Tectoestratigráficas

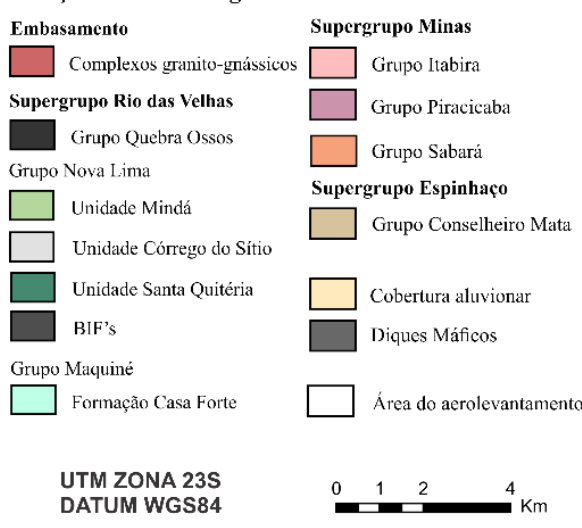

Figura 7: Mapa da geologia local da área de estudo (CPRM). 
O complexo granito-gnáissico Santa Bárbara e o granito Peti encontram-se na parte NE e $\mathrm{N}$ da área de estudo, respectivamente. O embasamento cristalino é formado por rochas de complexos gnáissicos-graníticos e migmatíticos com idades entre 3380 a 2900 Ma (Teixeira et al., 1996). Estes complexos são formados por rochas gnáissicas polideformadas de composição tonalítica a granítica e, subordinadamente, por granitos, granodioritos, anfibolitos e intrusões máficas a ultramáficas (Herz, 1970; Ladeira et al., 1983; Teixeira et al., 1996).

O Grupo Quebra-Ossos, definido por Baltazar \& Zuchetti (2007) como uma associação máfica-ultramáfica, é constituído por lavas máficas e ultramáficas com pequenas intrusões de gabros, anortositos, peridotitos com intercalações de BIF's, chert ferruginoso, pelitos carbonosos, turbiditos e raras rochas vulcanoclásticas félsicas.

A Associação Clástico-Química é caracterizada por alternância de rochas sedimentares clásticas e químicas, de granulometria fina. Pelitos são intercalados com finas camadas de FFB (formação ferrífera bandada) (i.e., BIF) e, subordinadamente, chert e xistos carbonosos. Esta associação corresponde a unidade Santa Quitéria, presente na área de estudo.

Já a Associação Ressedimentada, amplamente distribuída pelo QF, é formada por três diferentes sequências de grauvaca-argilito. Duas metamorfizadas nas fácies xisto verde e uma na fácies anfibolito. Na área de estudo, essa associação corresponde à unidade Córrego do Sítio.

O Supergrupo Minas é representado na área de estudo Itabira e Piracicaba. O grupo Itabira é composto pelas formações Cauê e Gandarela formados em um provável ambiente de margem continental, em subsidência. A Formação Cauê hospeda os principais depósitos de minério de ferro do QF em suas BIF's do tipo Lago Superior. A Formação Gandarela é uma sequência predominantemente carbonática e é recoberta por rochas formadas em um ambiente deltaico do Grupo Piracicaba.

As principais estruturas presentes na área de estudo são os sistemas de cisalhamento Fundão-Cambotas e Água-Quente e o anticlinal Conceição (Fig. 8).

Do ponto de vista estrutural, a área de estudo destaca-se pela inversão estratigráfica devido ao cavalgamento do Complexo Santa Bárbara sobre as rochas do SGRV, consequência da movimentação tectônica de leste para oeste segundo o sistema de cisalhamento FundãoCambotas. Este sistema de cisalhamento é representado por uma frente de empurrões e dobras 
compreendidas pelas falhas de Fundão e das Cambotas, que se uniram ao sul do sinclinal Gandarela (Chemale Jr., 1994).

Segundo Chemale Jr. (1994) o sistema de cisalhamento Fundão-Cambotas é uma zona de empurrão, com direção N-S, transporte tectônico de E-W e mergulho de 30-50 para leste. É um típico sistema de falhas com rampas frontais, laterais e oblíquas, formado durante o evento Brasiliano em um regime compressivo com vergência para oeste.

O sistema Água Quente se estende ao longo de cerca de $50 \mathrm{~km}$ de extensão, entre os municípios de Mariana e Santa Bárbara. É formado por dobras de estilos e escalas variadas e falhas reversas que se ramificam ao sistema principal que possui direção geral N-S (RibeiroRodrigues, 1992). No entanto, zonas de cisalhamento com direções E-W e NW-SE também foram mapeadas. Tem por característica estrutural sobrepor o Complexo Santa Bárbara, a leste e às rochas supracrustais, a oeste. Esta falha, ao adentrar as rochas máficas e ultramáficas do Grupo Quebra Ossos, ao norte, desaparece (Ferreira Filho \& Fonseca, 2001).

O anticlinal Conceição, uma estrutura formada pelo dobramento do Supergrupo Minas, foi definido por Malouf \& Corrêa Neto (1996) com eixo orientado para SW-NE, fechamento para NE e flanco sudeste invertido, com antiformes e sinformes menores e parasitas no seu flanco sudeste. Já Dorr (1969) define a estrutura como um anticlinal invertido e menciona que seu eixo foi erodido durante todo o período Terciário, deixando aflorar os xistos, filitos e BIF's do Grupo Nova Lima. Além disso, as bordas da anticlinal estão topograficamente elevadas em relação ao eixo e são sustentadas por itabiritos, quartizitos e crostas ferruginosas.

Na porção nordeste do QF, onde encontra-se a área de estudo, as principais estruturas estão orientadas a direção NE-SW (Fig. 8). O ouro no QF é controlado estruturalmente e está hospedado em pequenas estruturas localizadas dentro de grandes zonas de deformação. $\mathrm{Na}$ escala de depósito, o ouro é controlado por falhas de empurrão de segunda e terceira ordem com direção NW-SE e falhas transcorrentes dúcteis-rúpteis de direção NE-SW geradas durante a fase D2 (Baltazar \& Zuchetti, 2007). 


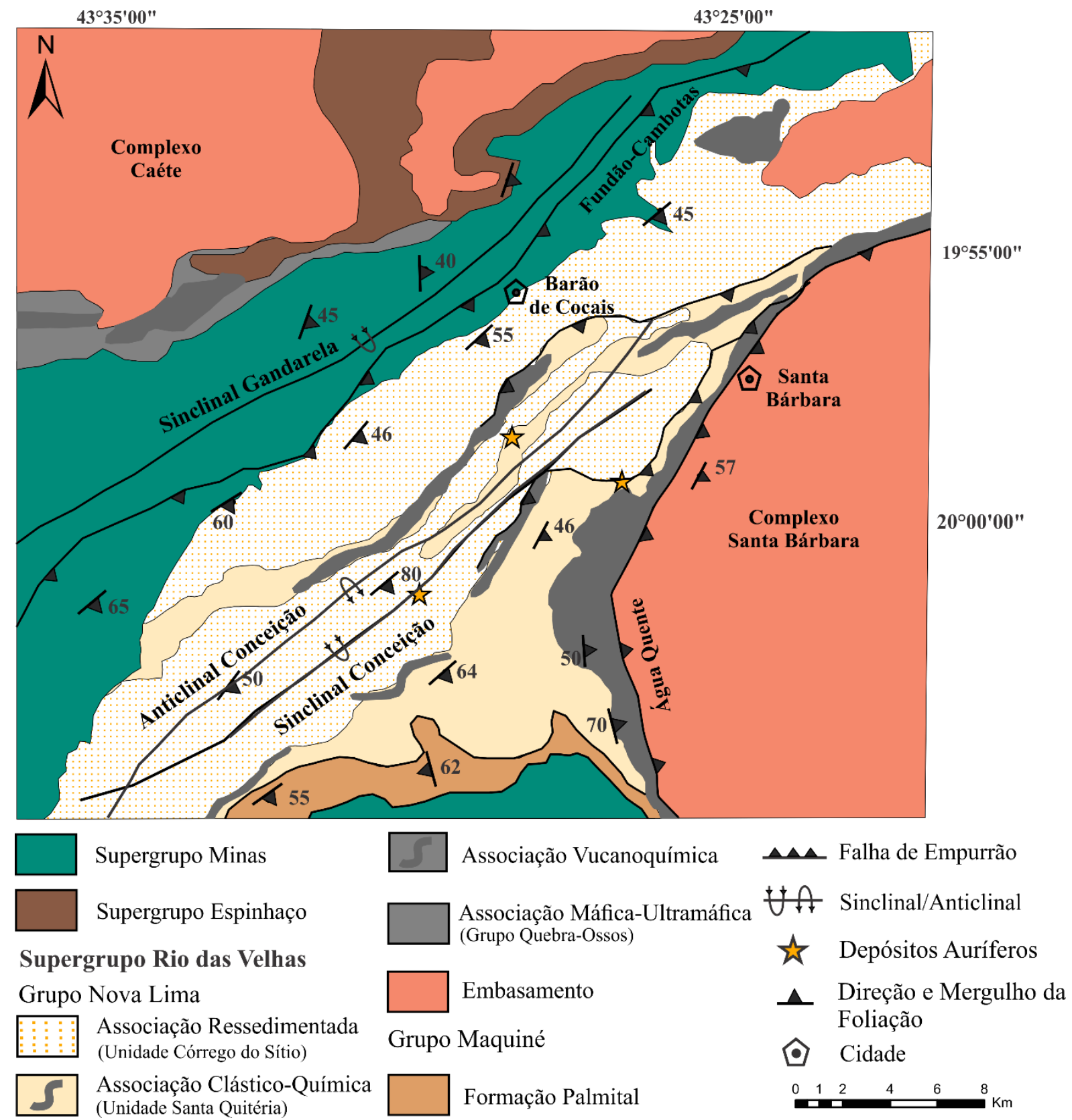

Figura 8: Geologia simplificada da região entre Caeté e Santa Barbará e a localização depósitos auríferos (Adaptado de Lobato et al., 2001b).

\subsection{Depósitos Orogênicos Auríferos}

Os depósitos de ouro (Au) do QF foram originados durante a deformação e metamorfismo de idade Arqueana do GBRV e ocorrem em sua maioria no Grupo Nova Lima, na porção basal da sequência máfica-ultramáfica (Lobato et al., 2001b; Noce et al., 2007). 
De acordo com Baltazar \& Zuchetti (2007), os depósitos de ouro podem ser classificados em dois principais grupos baseados na rocha hospedeira. $\mathrm{O}$ primeiro grupo está hospedado no Greenstone Belt Rio das Velhas de idade Arqueana. O segundo grupo está principalmente hospedado nas rochas dos Grupos Minas e Caraça de idade Paleoproterozóica.

O primeiro grupo pode ser subdividido em seis tipos:

(1) Ouro associado a BIFs, composto por alternações de sulfeto e carbonato, com predominância de pirita ou pirrotita, acompanhados de arsenopirita;

(2) Ouro associado a "Lapa Seca", caracterizado por corpos de sulfeto maciço juntamente com veios de quartzo;

(3) Ouro associado a veios de quartzo, geralmente mostrando zonas simétricas de alteração hidrotermal;

(4) Ouro associado a sulfetos disseminados em veios de quartzo;

(5) Ouro associado a anfibólios no qual o minério é composto por camadas alternadas de sulfeto e anfibólio;

(6) Ouro associado a sulfetos disseminados com gradação para maciços;

Já o segundo grupo pode ser dividido em três tipos:

(1) Ouro associado a turmalina e arsenopirita em veios de quartzo;

(2) Depósitos de ouro-paládio associados com os Itabiritos do Grupo Minas;

(3) Depósitos de ouro hospedados em sedimentos Proterozóicos;

Depósitos orogênicos de ouro (Groves et al., 1998) estão hospedados nas rochas do Grupo Nova Lima, unidade basal do Greenstone Belt Rio das Velhas. Historicamente, elas foram a fonte da principal produção de ouro no QF. Esses depósitos são associados com lineamentos regionais, com os maiores depósitos controlados por falhas transcorrentes, subverticais e com direção de mergulho predominantemente E-W. Já os menores, em sua maioria são controlados por falhas de empurrão relacionadas às zonas de cisalhamento. $\mathrm{O}$ ouro é anedral e está incluso em sulfetos, principalmente pirita $\left(\mathrm{FeS}_{2}\right)$, calcopirita $\left(\mathrm{CuFeS}_{2}\right)$ e arsenopirita $\left(\mathrm{FeAsS} \mathrm{A}_{2}\right)$, ou ocorre como finos filmes preenchendo fraturas nesses minerais. Nos 
depósitos dominados por pirita, há um aumento na quantidade de ouro com o enriquecimento de arsênio na pirita e/ou com o surgimento de arsenopirita. Os grãos de ouro com tamanho entre 50 e $120 \mu \mathrm{m}$ são geralmente encontrados na pirrotita, com os mais finos (10 a $50 \mu \mathrm{m})$ inclusos na pirita. Quando incluso na arsenopirita e associado com quartzo e carbonato, o ouro possui tamanho menor que $10 \mu \mathrm{m}$ (Lobato et al., 2001b).

Segundo Groves et al. (1998), os depósitos orogênicos são formados durantes processos deformacionais em regimes de esforços compressivos à transpressionais, em orógenos colisionais ou acrescionários. Estes depósitos podem ser divididos de acordo com a profundidade de formação em: epizonal (<6 km), mesozonal $(6-12 \mathrm{~km})$ e hipozonal $(>12 \mathrm{~km})$. A Figura 9 apresenta a configuração tectônica dos vários tipos de depósitos de ouro e suas profundidades de formação. O processo de formação dos depósitos orogênicos auríferos é destacado pelo círculo vermelho.

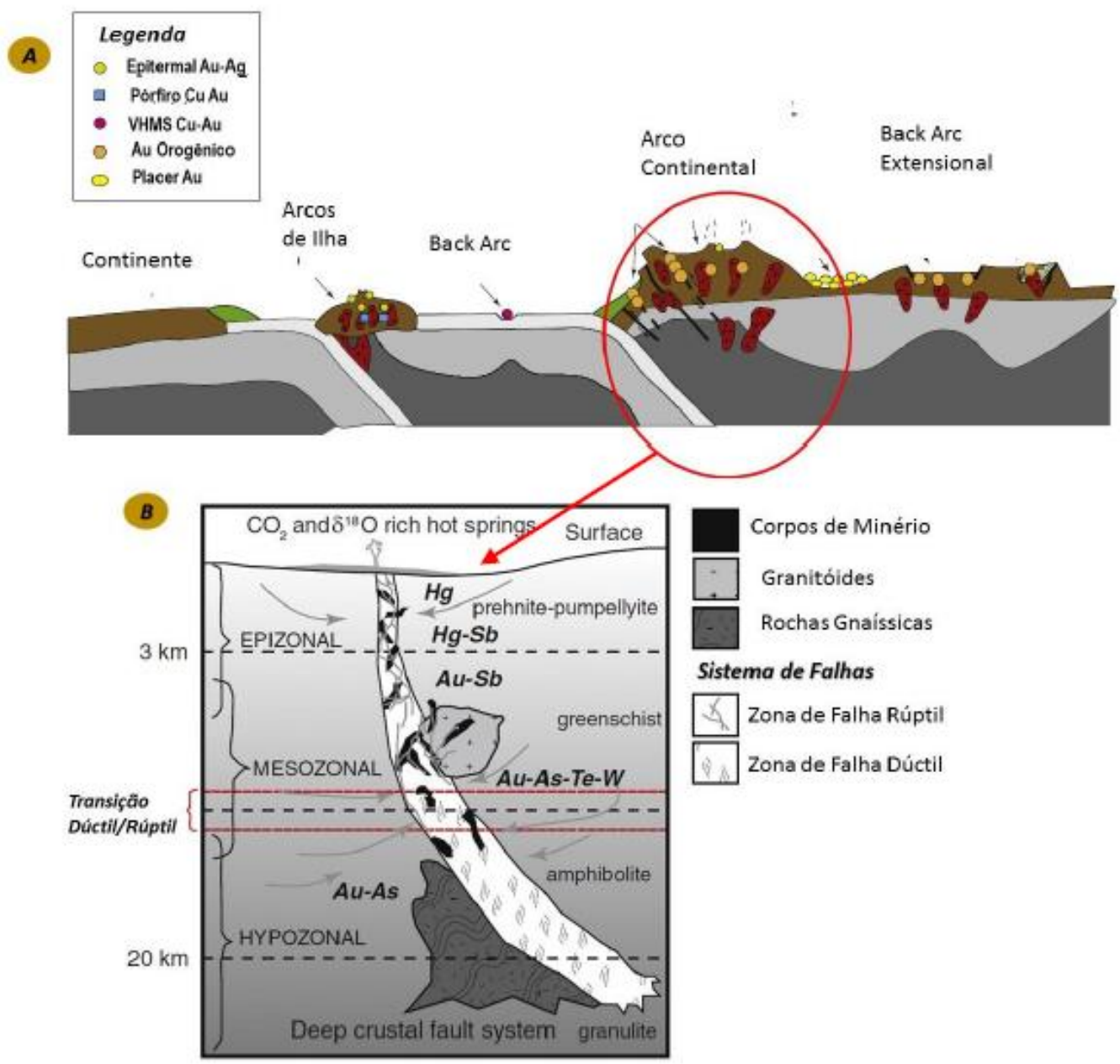

Figura 9: a) Configuração tectônica dos depósitos orogênicos auríferos. b) Níveis de profundidade para formação dos depósitos de ouro (Adaptado de Groves et al., 1998). 


\section{Método TDEM (Time Domain Electromagnetic)}

\subsection{Breve Histórico}

O método TDEM (método eletromagnético no domínio do tempo) surgiu na União Soviética em meados dos anos 60 (Telford, 1990). Porém, só começou a ser mais refinado e desenvolvido nos anos 80, principalmente devido a modernização dos computadores que levaram a uma interpretação mais rápida dos resultados (Kirsch, 2006).

Os métodos indutivos TDEM e FDEM (método eletromagnético no domínio da frequência) foram originalmente construídos para exploração mineral. Entre as décadas de 60 e 70 o método eletromagnético no domínio da frequência era muito utilizado na investigação de depósitos minerais hospedados em rochas muito resistivas, configuração mineral muito comum na América do Norte, região onde o método obteve grande sucesso. Porém, o FDEM teve dificuldades em penetrar regiões com espessas camadas de baixa resistividade, situação encontrada na Austrália, que possui uma espessa camada de riolito, o que impulsionou o desenvolvimento do TDEM neste país (Christiansen et al., 2006).

Desde então, o método TDEM tem sido aplicado também com grande sucesso na exploração de água subterrânea (Fitterman \& Stewart, 1986; Sørensen et al., 2003; Auken et al., 2003; Porsani et al., 2012a; Porsani et al., 2012b; Bortolozo et al., 2014; Couto Jr., 2015; Almeida et al., 2017; Campaña et al., 2017; Leite et al., 2018; Hamada et al., 2018; Rangel et al., 2018), exploração mineral (McNeill, 1994; Couto Jr. et al., 2019), mapeamentos estratigráficos de bacias sedimentares, prospecção de hidrocarbonetos (Cardador et al., 2003), entre outros.

\subsection{Princípios Físicos}

O TDEM é utilizado para se obter a variação da resistividade (ou condutividade) elétrica em função da profundidade. Para obtenção deste parâmetro são utilizados um loop transmissor (Tx) e uma bobina receptora $(\mathrm{Rx})$. Uma corrente elétrica contínua é injetada no loop transmissor (Tx) e abruptamente interrompida, repetindo-se este processo periodicamente com inversão de polaridade da corrente. Segundo a Lei de Ampère, toda corrente elétrica possui um campo magnético associado, no entanto, esse campo não induz correntes elétricas no substrato enquanto for constante. Para que correntes elétricas sejam induzidas em subsuperfície é necessário provocar uma variação do campo magnético. Logo, a corrente elétrica em Tx é 
interrompida em um instante de tempo (turn-off time), fazendo com que o campo magnético primário (gerado em Tx) varie. Segundo a Lei de Faraday, uma variação do campo eletromagnético no tempo induz uma força eletromotriz (f.e.m.) em um meio com resistividade definida. No método TDEM, essa força eletromotriz induz correntes no substrato geológico, definidas como "Eddy currents" ou correntes de indução. Devido às perdas ôhmicas em subsuperfície, as correntes de indução sofrem atenuação e, consequentemente, seu campo magnético (campo secundário) é atenuado num processo de difusão em regime de transiente em profundidade. Esta atenuação é amostrada em termos da f.e.m. gerada em Rx.

A Figura 10 apresenta um esquema de difusão em subsuperfície das "Eddy currents" em uma geometria definida por "anéis de fumaça" ou "smoke rings", conforme demonstrado por Nabighian (1979).

a)

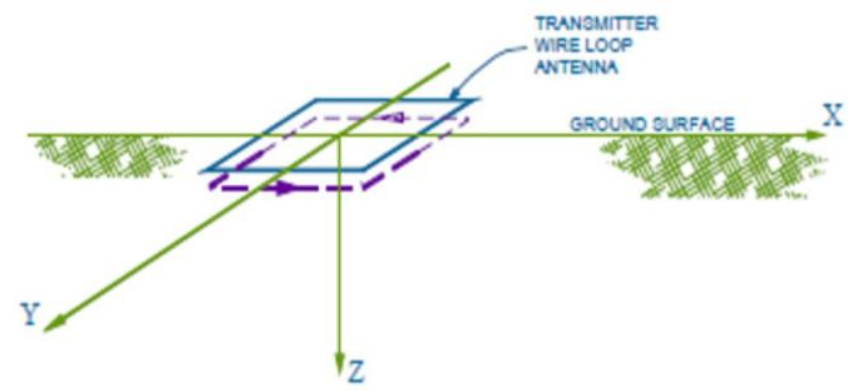

b)

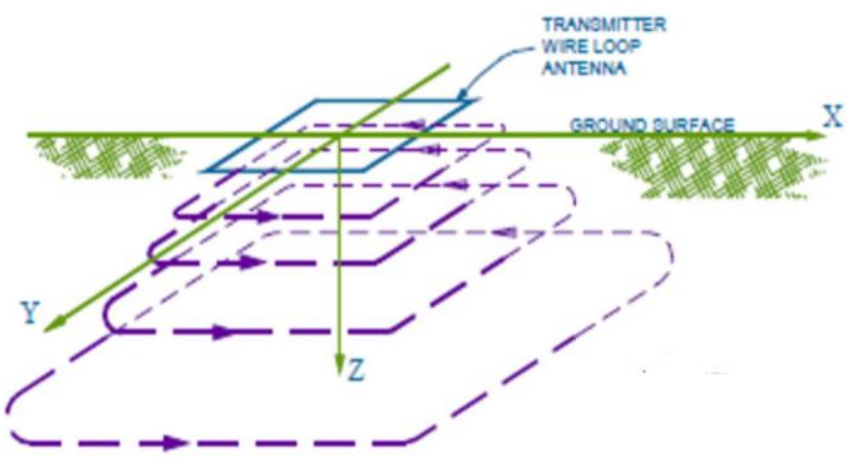

Figura 10: a) Eddy currents imediatamente depois do desligamento, conhecido como "early time”. b) Eddy currents nos tempos tardios, conhecido como "late time” (Adaptado de McNeill, 1994). 
Logo após o "turn-off" (Fig. 10-a), fortes correntes ficam concentradas abaixo do loop transmissor. Com o passar do tempo, as correntes se difundem através de um processo de difusão dos "smoke rings". A magnitude e a taxa de decaimento desta corrente dependem da condutividade/resistividade elétrica do meio e da geometria das camadas condutoras (Nabighian, 1991). O efeito é mostrado na (Fig. 10-b). Quanto mais resistivo o meio, maior será a perda de energia na forma de calor e mais rápida as correntes se difundirão. Já quanto mais condutivo o meio, menor será a perda de energia e as correntes se difundirão mais lentamente, concentrando-se no corpo condutor. Todo o processo descrito acima é resumido na Figura 11, abaixo.

a)

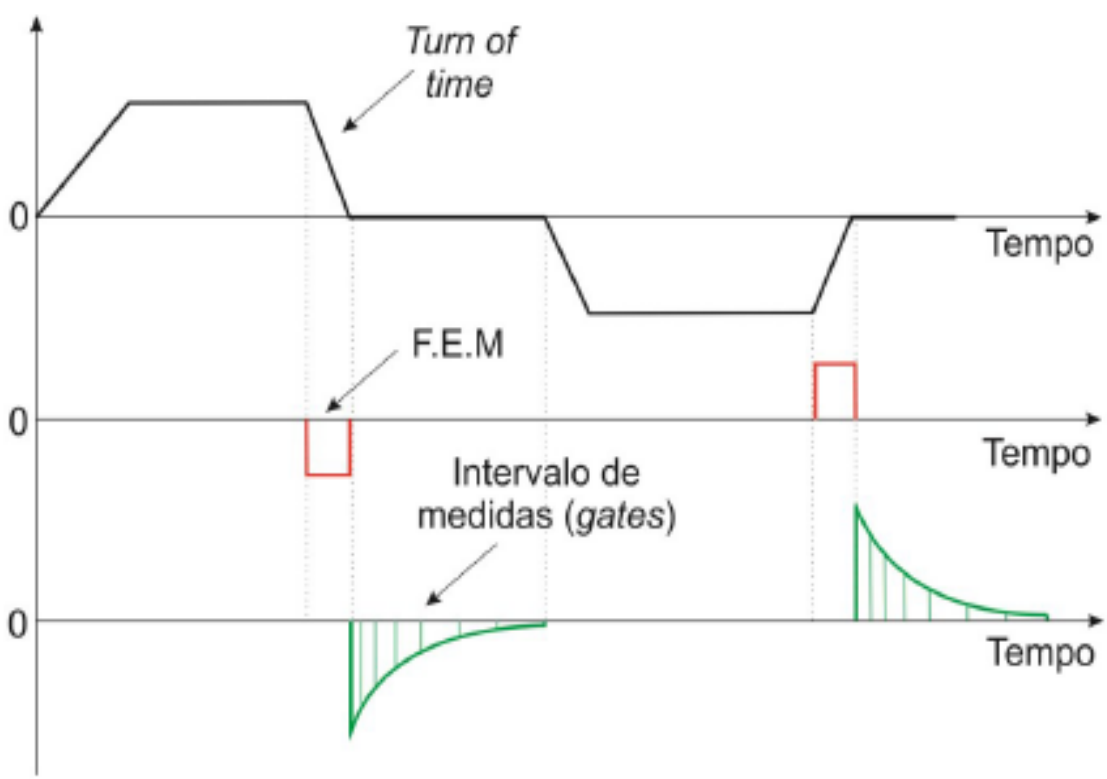

Figura 11: Diagrama da sequência de eventos de um levantamento TDEM (Adaptado de McNeill, 1994).

O sinal captado pela bobina receptora é registrado e convertido em uma curva da taxa de decaimento do campo magnético secundário pelo tempo, através de janelas ou canais de amostragem no tempo que demarcam os registros dos sinais ("gates times"). Esses intervalos aumentam conforme o sinal decai, pois, como a intensidade diminui, é necessário um maior intervalo de tempo para que a razão sinal/ruído seja mensurável (Leite, 2013). 


\subsection{Formulação Matemática}

O método TDEM, assim como outros métodos eletromagnéticos, está fundamentado nas Equações de Maxwell. A seguir, será mostrada a dedução matemática da Equação da resistividade aparente empregada no método TDEM, segundo Kaufman \& Keller (1983), Nabighian (1988) e Kirsch (2006). Todas as unidades estão de acordo com o Sistema Internacional de Unidades (S.I.).

Considerando as Equações de Maxwell:

$$
\begin{gathered}
\nabla \times \boldsymbol{E}=-\frac{\partial \boldsymbol{B}}{\partial t} \\
\nabla \times \boldsymbol{H}=\boldsymbol{j}+\frac{\partial \boldsymbol{D}}{\partial t} \\
\nabla \cdot \boldsymbol{B}=0 \\
\nabla \cdot \boldsymbol{D}=\rho
\end{gathered}
$$

onde, $\mathbf{E}$ é a intensidade do campo elétrico $\left(\mathrm{V} / \mathrm{m}^{2}\right), \mathbf{H}$ é a intensidade do campo magnético $(\mathrm{A} / \mathrm{m}), \mathbf{j}$ é a densidade de corrente elétrica $\left(\mathrm{A} / \mathrm{m}^{2}\right), \mathbf{B}$ é o vetor indução magnética $\left(\mathrm{Wb} / \mathrm{m}^{2}\right), \mathrm{D}$ é a densidade de fluxo magnético $\left(\mathrm{C} / \mathrm{m}^{2}\right)$ e $\rho$ é a densidade volumétrica de carga elétrica $\left(\mathrm{C} / \mathrm{m}^{3}\right)$.

Os campos vetoriais $\mathbf{E}, \mathbf{D}, \mathbf{B}$ e $\mathbf{H}$ se relacionam através das relações constitutivas do meio:

$$
\begin{aligned}
& \boldsymbol{D}=\varepsilon \boldsymbol{E} \\
& \mathbf{B}=\mu \boldsymbol{H} \\
& \mathbf{j}=\sigma \boldsymbol{H}
\end{aligned}
$$

Sendo $\varepsilon$ a permissividade dielétrica, $\mu$ a permeabilidade magnética e $\sigma$ a condutividade elétrica do meio. 
Substituindo as relações constitutivas do meio nas equações (3.3.1) e (3.3.2) e aplicando a Transformada de Fourier nas mesmas, obtém-se as equações de Maxwell no domínio do tempo:

$$
\begin{gathered}
\nabla \times \boldsymbol{E}+i \omega \mu_{0} \boldsymbol{H}=0 \\
\nabla \times \boldsymbol{H}-(\sigma+i \varepsilon \omega) \boldsymbol{E}=0
\end{gathered}
$$

em que $\hat{z}=i \omega \mu_{0}$ representa a impeditividade e $\hat{y}=\sigma+i \varepsilon \omega$ representa a admissividade do meio. Para problemas geoelétricos normalmente utiliza-se $\mu \approx \mu_{0}=4 \pi \times 10^{-7}$ Henry/ m (valor da permeabilidade magnética no vácuo).

As equações (3.3.8) e (3.3.9) são válidas apenas para regiões livres de fontes de correntes elétricas. Para regiões com presença de cargas são utilizadas as equações não-homogêneas:

$$
\begin{gathered}
\nabla \times \boldsymbol{E}+\hat{z} \boldsymbol{H}=-\boldsymbol{J}_{m}^{S} \\
\nabla \times \boldsymbol{H}-\hat{y} \boldsymbol{E}=\boldsymbol{J}_{e}^{S}
\end{gathered}
$$

em que $J_{m}^{S}$ é a corrente de fonte magnética e $J_{e}^{S}$ é a corrente de fonte elétrica.

Se $\boldsymbol{J}_{m}^{S}$ e $\boldsymbol{J}_{e}^{S}$ forem definidos, pode-se resolver as equações não-homogêneas no domínio da frequência (3.3.10) e (3.3.11) para regiões homogêneas. A fim de simplificar a resolução das equações, pode-se representar os campos $\boldsymbol{E}$ e $\boldsymbol{H}$ através dos potenciais de Schelkunoff $\boldsymbol{A}$ e $\boldsymbol{F}$. Estes potenciais tornam a resolução das equações diferenciais mais amigáveis, pois são paralelos às fontes de corrente (campos geradores), diferente dos campos elétrico e magnético.

No método TDEM é utilizado apenas a fonte magnética $\boldsymbol{J}_{m}^{S}$, onde é transmitido um campo elétrico vertical. Portanto, apenas o potencial $\boldsymbol{F}$ é necessário, facilitando assim o cálculo. O potencial de Sckelkunoff $\boldsymbol{F}$ é definido como:

$$
\boldsymbol{E}_{\boldsymbol{m}}=\nabla \times \boldsymbol{F}
$$


onde $\boldsymbol{E}_{\boldsymbol{m}}$ é o campo elétrico produzido pela fonte magnética. Substituindo a Equação (3.3.12) na Equação (3.3.11), obtêm-se:

$$
\nabla \times(-\nabla \times \boldsymbol{F})+\hat{z} \boldsymbol{H}=-\boldsymbol{J}_{m}^{S}
$$

Com a Equação (3.3.13) é possível derivar a Equação não-homogênea de Helmholtz, dada por:

$$
\nabla^{2} \boldsymbol{F}+\boldsymbol{k}^{2} \boldsymbol{F}=-\boldsymbol{J}_{m}^{S}
$$

onde $\boldsymbol{k}$ é o número de onda definido como $k^{2}=\mu_{0} \varepsilon \omega^{2}-i \omega \mu_{0} \sigma=-\hat{z} \hat{y}$.

Para materiais geológicos e frequências menores que $10^{5} \mathrm{~Hz}$, a corrente de deslocamento $\left(\mu_{0} \varepsilon \omega^{2}\right)$ é desprezível quando comparada a corrente de condução $\left(\omega \mu_{0} \sigma\right)$, isto é, $\mu_{0} \varepsilon \omega^{2} \ll$ $\omega \mu_{0} \sigma$ e, portanto, $k^{2} \approx-i \omega \mu_{0} \sigma$. Esta é a chamada aproximação quasi-estática.

Os campos elétrico e magnético totais produzidos por uma fonte magnética podem ser derivados utilizando o potencial $\boldsymbol{F}$ :

$$
\begin{gathered}
\boldsymbol{E}_{\boldsymbol{m}}=\nabla \times \boldsymbol{F} \\
\boldsymbol{H}_{\boldsymbol{m}}=-\hat{y} \mathbf{F}+\frac{1}{\hat{z}} \nabla(\nabla \cdot \boldsymbol{F})
\end{gathered}
$$

Assumindo-se uma terra estratificada horizontalmente (1D), o potencial $\boldsymbol{F}$ possui apenas a componente vertical $z$ :

$$
\boldsymbol{F}=F_{z} \boldsymbol{u}_{z}=T E_{z}
$$

sendo $F_{z}$ uma função escalar de $x, y$ e $z$ e $\boldsymbol{u}_{z}$ um vetor unitário na direção $z$. $T E_{z}$ representa $o$ campo magnético transversal propagando-se no plano $x$ - $y$. Substituindo a Equação (3.19) nas equações (3.3.17) e (3.3.18), tem-se as expressões das componentes dos campos:

$$
\mathbf{H}_{\mathbf{x}}=\frac{1}{\hat{z}} \frac{\partial^{2} F_{z}}{\partial \mathbf{x} \partial \mathrm{z}}
$$




$$
\begin{gathered}
\mathbf{E}_{\mathbf{x}}=-\frac{\partial F_{z}}{\partial \mathrm{y}} \\
\mathbf{H}_{\mathbf{y}}=\frac{1}{\hat{z}} \frac{\partial F_{\mathbf{z}}}{\partial \mathrm{y} \partial \mathrm{z}} \\
\mathbf{E}_{\mathbf{y}}=\frac{\partial F_{\mathbf{z}}}{\partial \mathrm{x}} \\
\boldsymbol{H}_{\mathbf{z}}=\frac{1}{\hat{z}}\left(\frac{\partial^{2}}{\partial z^{2}}+k^{2}\right) F_{z} \\
\boldsymbol{E}_{\mathbf{z}}=0
\end{gathered}
$$

No método TDEM o campo elétrico é paralelo ao loop transmissor e transmitido em subsuperfície. O campo magnético é transversal ao campo elétrico. Dessa forma, é preciso obter o campo magnético vertical no centro do loop, sendo necessário apenas o potencial F. Portanto, o campo magnético no centro do loop pode ser calculado como uma integração de dipolos magnéticos verticais sobre sua área. Assim, segundo Nabighian \& Macnae (1991) o potencial de Schelkunoff $\mathbf{F}$ para um dipolo magnético vertical pode ser deduzido como segue:

$$
F(\rho, z)=\frac{\hat{z}_{0} m}{4 \pi} \int_{0}^{\infty}\left[e^{-u_{0}|z+h|}+R_{T E}^{u_{0}(z+h)}\right] \frac{\lambda}{u_{0}} J_{0}(\lambda r) d \lambda
$$

onde $m$ é o momento magnético do dipolo, $J_{0}$ é a função de Bessel de ordem $0, \lambda=\sqrt{k_{x}^{2}+k_{y}^{2}}$ e $k_{x}$ e $k_{y}$ as frequências espaciais nas direções $x$ e $y, u_{n}=\sqrt{\lambda^{2}-k_{n}^{2}}$, em que $k_{n}^{2}$ é o número de onda da enésima camada, que segundo a aproximação quase-estática é dado por $k^{2} \approx$ $-i \omega \mu_{0} \sigma_{n}, r$ é a distância radial da fonte ao receptor dada por $r=\sqrt{x^{2+} y^{2}}$ e $R_{T E}$ é definido como o coeficiente de reflexão e expressa como o substrato modifica o campo primário.

Integrando a Equação (3.3.26) sobre um loop circular de raio $a$ e corrente elétrica $I$ :

$$
F(r, z)=\frac{\hat{z}_{0} I a}{2} \int_{0}^{\infty} \frac{1}{\mu_{0}}\left[e^{-u_{0}|z+h|}+R_{T E}^{u_{0}(z+h)}\right] J_{1}(\lambda a) J_{0}(\lambda r) d \lambda
$$


onde $J_{1}$ é a função de Bessel de primeira ordem. Substituindo a Equação (3.3.27) na Equação (3.3.18) e simplificando para situação onde o receptor está no centro do loop transmissor (arranjo loop central), temos a componente vertical do campo magnético dada por:

$$
H_{Z}=\frac{I a}{2} \int_{0}^{\infty}\left[e^{-u_{0}|z+h|}+R_{T E}^{u_{0}(z+h)}\right] \frac{\lambda^{2}}{u_{0}} J_{1}(\lambda a) d \lambda
$$

A Equação (3.3.28) está expressa no domínio da frequência, já que $R_{T E}$ depende da frequência. Logo, é necessário utilizar a Transformada Inversa de Laplace ou de Fourier para obtenção da componente vertical do campo magnético no domínio do tempo (resposta transiente). A Equação acima é chamada transformada de Henkel e só pode ser resolvida através de métodos numéricos devido à complexidade da função de Bessel e da própria integral. No entanto, para configuração loop central na superfície de um substrato homogêneo $R_{T E}$ é descrito da seguinte forma:

$$
R_{T E}=\frac{\lambda-u}{\lambda+u}
$$

logo, a Equação (3.3.28) pode ser escrita como:

$$
H_{Z}=\operatorname{Ia} \int_{0}^{\infty} \frac{\lambda^{2}}{\lambda-u} J_{1}(\lambda a) d \lambda
$$

Utilizando a relação constitutiva do meio (3.3.6) e aplicando a Transformada Inversa de Laplace, temos:

$$
B_{Z}=\frac{\mu_{0} I}{2 a}\left[\frac{3}{\pi^{1 / 2} \theta a} e^{-a^{2} \theta^{2}}+\left(1-\frac{3}{2 \theta^{2} a^{2}}\right) \operatorname{erf}(\theta a)\right]
$$

onde $\theta=\sqrt{\frac{\mu_{0} \sigma}{4 t}}$, erf é a função erro e $t$ é a variação temporal. Para $t \rightarrow 0$, temos que $B_{Z}=\frac{\mu_{0} I}{2 a}$, ou seja, é o valor da intensidade do campo magnético antes do desligamento da corrente.

A resposta impulsiva $\frac{\partial B_{Z}}{\partial t}$ pode ser calculada por diferenciação: 


$$
\frac{\partial B_{Z}}{\partial t}=-\frac{I}{\sigma a^{3}}\left[3 \operatorname{erf}(\theta a)-\frac{2}{\pi^{1 / 2}} \theta a\left(3+2 \theta^{2} a^{2}\right) e^{-a^{2} \theta^{2}}\right]
$$

A resposta do impulso, dada pela Equação (3.3.32) é a grandeza física medida no método TDEM. Portanto, as medidas são feitas nos chamados "tempos tardios" (late-times), isto é, para $t \rightarrow \infty \Rightarrow \theta \rightarrow 0$, a Equação (3.3.32) pode ser reescrita como:

$$
\frac{\partial B_{Z}}{\partial t} \approx \frac{I \sigma^{\frac{3}{2}} \mu_{0}^{\frac{5}{2}} a^{2}}{20 \pi^{\frac{1}{2}}} t^{-\frac{5}{2}}
$$

em que I é a intensidade da corrente, a é $a$ distância do loop transmissor a bobina receptora e $t$ é o tempo de medida.

Portanto, a partir da variação temporal do campo magnético secundário pode-se obter a resistividade elétrica aparente $\rho_{a}$ (medida física de interesse do método) por meio de manipulação algébrica, sendo expressada por:

$$
\rho_{a}=\left(\frac{I a^{2}}{20 \frac{\partial B_{Z}}{\partial t}}\right)^{1 / 2} \frac{\mu_{0}^{\frac{5}{3}}}{\pi^{\frac{1}{3}}} t^{-\frac{5}{3}}
$$

Segundo Kaufman e Keller (1983), a Equação (3.3.34) pode ser reescrita da seguinte maneira:

$$
\rho_{a}=k\left(\frac{M}{V(t)}\right)^{2 / 3} \frac{1}{t^{\frac{5}{2}}}
$$

em que $M$ é o momento magnético, $V(t)$ é a f.e.m (força eletromotriz) induzida na bobina receptora e $k$ é uma constante que depende dos parâmetros geométricos do loop transmissor e é dado por:

$$
k=-\frac{\mu}{\pi}\left(\frac{a_{e f} n}{20}\right)^{\frac{2}{3}}
$$

onde $a_{e f}$ é a área efetiva da bobina, $n$ é o número de espiras da bobina receptora e $V(t)$ é dado por: 


$$
V(t)=-a_{e f} n\left(\frac{\partial B_{Z}}{\partial t}\right)
$$

\subsection{Profundidade de Investigação}

A profundidade de investigação do método TDEM é dada pelo Skin Depth, definido para o domínio do tempo em Spies (1989). O Skin Depth determina a profundidade de penetração da densidade de corrente em um particular "delay time" (t), tempo em que as medidas da amplitude do $\mathrm{dB} / \mathrm{dt}$ são realizadas. No método TDEM ele depende da condutividade do meio $(\sigma)$ ou da resistividade $(\rho)$, da permeabilidade magnética $(\mu)$ e pelo tempo transiente do campo eletromagnético (t), sendo expresso pela Equação 3.4.1 abaixo:

$$
\delta_{T D}=\sqrt{\frac{2 t}{\mu \sigma}} \cong 1,26 \sqrt{\rho t}
$$

Onde t é dado em segundos, $\sigma$ dado em S/m, $\rho$ em Ohm.m e para a maioria das rochas a permeabilidade magnética $\mu$ é igual à do vácuo dada por $\mu_{0}=4 \pi \times 10^{-7} \mathrm{Henry} / \mathrm{m}$.

Nabighian \& Macnae (1989) e Spies (1989) também propuseram a profundidade de investigação para tempos tardios, tanto para aquisições terrestre, quanto aéreas, nomeada de DOI (Depth of Investigation). A Equação (3.4.2) relaciona a profundidade de investigação a condutividade média do meio $(\sigma)$, a corrente $(I)$ e a área efetiva do loop transmissor $(A)$ e ao nível médio de ruído $\left(N_{V}\right)$ definido por Spies (1989) como $0,5 \mathrm{nV} / \mathrm{m}^{2}$.

$$
D O I \cong 0,55\left[\frac{I A}{\sigma N_{V}}\right]^{1 / 5}
$$




\subsection{Fontes de Acoplamentos e Ruídos}

As maiores fontes de ruído no método TDEM são artefatos produzidos pelo homem e são conhecidos como acoplamentos. As principais fontes do acoplamento são linhas de transmissão de energia, cabos e tubulações enterradas e cercas metálicas.

Uma vez que um só ciclo de medição é afetado significativamente, cada curva resultante corresponde a um empilhamento de muitas repetições do mesmo ciclo durante um período de tempo escolhido pelo operador. A repetição deste ciclo melhora a medida e diminui o nível de ruído. O número de curvas individuais que são empilhadas pode variar dependendo do objetivo e da área de estudo, porém, uma curva final pode ter aproximadamente entre 1.000 e 10.000 curvas empilhadas. O acoplamento ocorre em função das correntes induzidas por outras fontes eletromagnéticas (linhas de transmissão, geradores, rede elétrica de construções, etc) dentro do volume em que o campo eletromagnético se propaga, gerando distorções da resposta eletromagnética do substrato. No método TDEM, o acoplamento pode ser classificado em duas formas: galvânico e capacitivo (Sørensen et al., 2005). No acoplamento galvânico (Fig. 12-a) o transmissor (TDEM) induz correntes em estruturas como linhas de transmissão e cercas metálicas, constituindo assim um circuito LR (indutor-resistor) com o solo. Assim, o decaimento do campo magnético medido é uma soma dos campos induzidos pelo transmissor e pelo indutor (campo induzido nas linhas de transmissão ou cercas metálicas). Logo, esse tipo de interferência é de difícil identificação, pois o sinal apresenta apenas decaimentos do campo magnético menores. Já o acoplamento capacitivo (Fig. 12-b) está associado às medidas realizadas próximas a cabos envoltos por algum material isolante, como por exemplo, fiações de cobre encapadas no subsolo. Esses cabos atuam como um capacitor, formando um circuito RLC (resistor-indutor-capacitor). O método TDEM induz correntes em subsuperfície e no corpo condutor isolado que atua como um capacitor que é descarregado de forma oscilante. Logo, a resposta obtida é oscilante, sendo facilmente detectável em campo. 


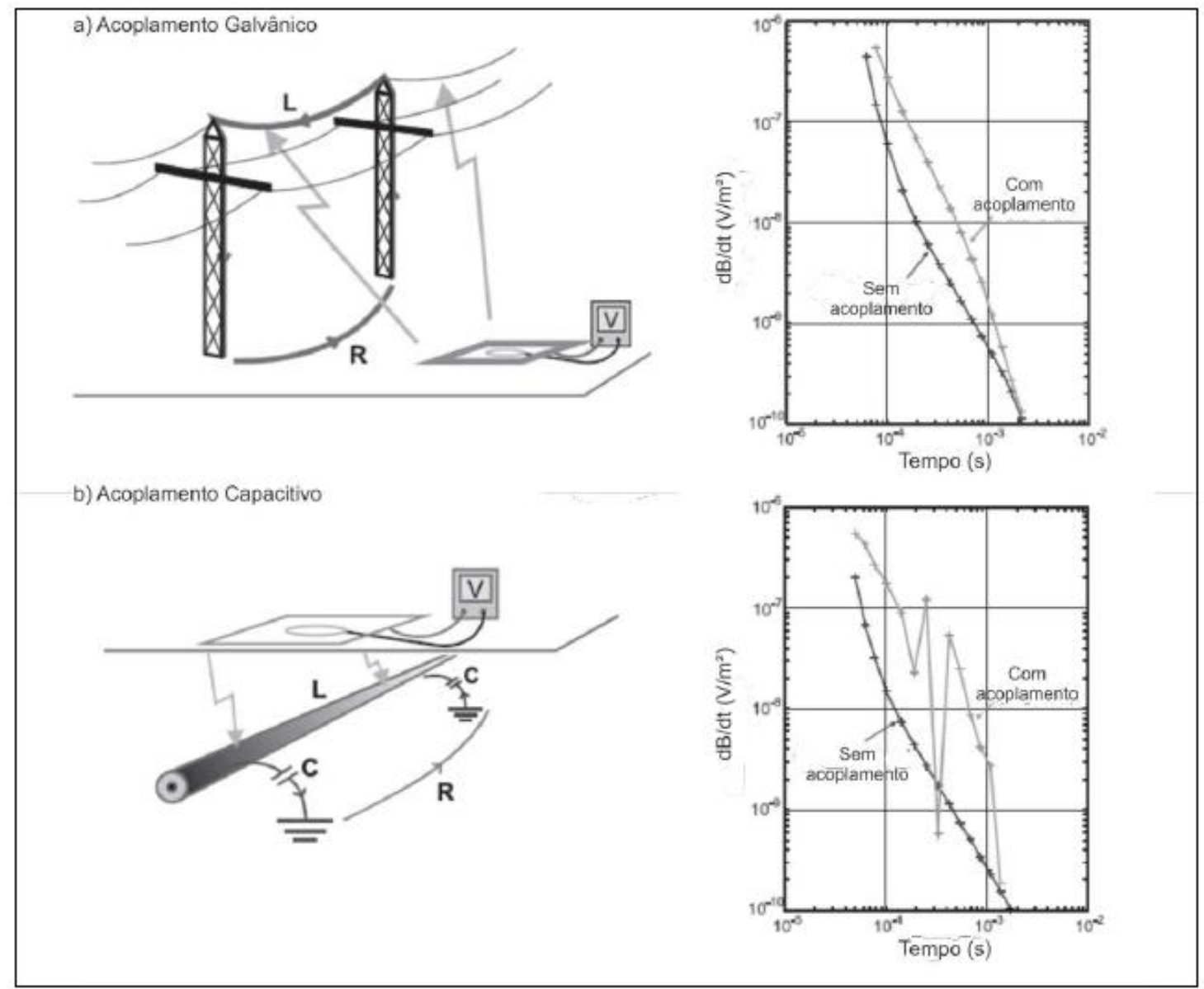

Figura 12: Esquema gráfico dos tipos de acoplamento e suas respostas no dado medido. a) Acoplamento galvânico. b) Acoplamento capacitivo (adaptado de Sørensen et al., 2000).

\subsection{Sistemas Eletromagnéticos Aerotransportados}

Os métodos eletromagnéticos aerotransportados (AEM - Airborne Electromagnetic Methods) têm sido desenvolvidos e muito utilizados nos últimos 60 anos. A evolução da tecnologia AEM e sua aplicação comercial estão relacionadas principalmente às oscilações dos preços das commodities ou ciclos de metais, mas também a programas de mapeamento realizado por iniciativas públicas e privadas, incentivos fiscais, corridas de exploração após grandes descobertas, e, finalmente, aos avanços tecnológicos (Allard, 2007).

Carson (2003) identificou quatro fases de evolução dos sistemas AEM. A primeira fase ocorreu no início da década de 50 e foi marcada pelo desenvolvimento de sistemas internos. A segunda fase ocorreu nos anos 1970 e ficou conhecida como a "era dos sistemas de asa fixa". 
O sistema INPUT, um sistema eletromagnético no domínio do tempo, dominou os levantamentos aéreos, mas sua participação diminuiu nos anos 1980 quando a demanda por metais base e urânio caiu. Com a crescente exploração de ouro, diamante e água subterrânea nos anos 1980 surgiu a necessidade de sistemas mais versáteis que pudessem mapear geologias complexas com alta resolução. Assim, ocorreu o desenvolvimento dos sistemas eletromagnéticos no domínio da frequência transportados por helicóptero (HFEM). A terceira fase foi marcada pelo amadurecimento destes sistemas. Entre os anos 1998 e 2000, diante do período econômico, as companhias de exploração e de serviços geofísicos perceberam a necessidade de se adaptar ao mercado. Dois tipos de sistemas dominavam o mercado na época: HFEM e AEM de asa fixa. Os sistemas AEM de asa fixa possuem um alto momento magnético e alta profundidade de investigação, voam com alta velocidade e maior altitude. Já os sistemas HFEM possuem alta resolução espacial em terrenos acidentados, porém voam com menor velocidade. Logo, os geofísicos combinaram o melhor de cada um deles para criar um novo sistema: o sistema eletromagnético no domínio do tempo transportado por helicóptero (HTEM). A quarta fase é representada pelo desenvolvimento e refinamento dos sistemas HTEM. Macnae \& Nabighian (2005) argumentam que os sistemas HTEM superaram em atividades os sistemas HFEM e os sistemas de asa fixa com o passar dos anos. A Figura 13 mostra a evolução dos sistemas AEM e as principais atividades que marcaram seu desenvolvimento:

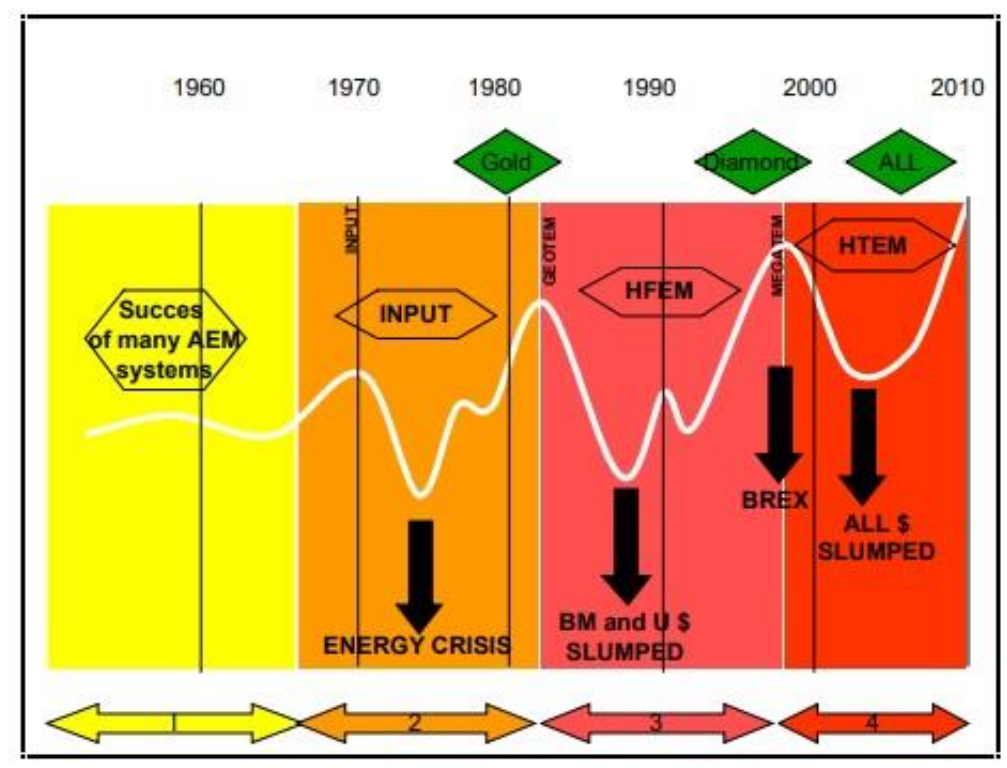

Figura 13: Evolução dos sistemas AEM (adaptado de Carson, 2003). 
Os sistemas HTEM (Tab. 1) mais conhecidos e desenvolvidos nas duas últimas décadas são o AeroTEM (Aeroquest Ltda. - Canadá), VTEM (Geotech Airborne Geophysical Services - Canadá), NEWTEM (Newmont Mining Corporation - Austrália), HoisTEM (Newmont Mining Inc - Austrália) e SkyTEM (SkyTEM Aps - Dinamarca). Todos foram desenvolvidos especialmente para exploração mineral, com exceção do SkyTEM que foi inicialmente desenvolvido para exploração de água subterrânea. Atualmente, as companhias também estão desenvolvendo sistemas híbridos para aplicação em ambos os campos de estudo e também em estudos de solos e estudos ambientais.

Tabela 1: Principais características de diferentes sistemas transientes aéreos (Adaptado de Christiansen et al., 2006).

$\begin{array}{cccc}\text { NOME DO } & \text { MOMENTO } & \text { FORMA DE ONDA DO } & \text { CONFIG.ÇÃO E } \\ \text { SISTEMA } & \left(\text { KAM }^{2}\right) & \text { TRANSMISSOR } & \text { COMPONENTES }\end{array}$

\begin{tabular}{|c|c|c|c|}
\hline AEROTEM & 40 & Triangular & $\begin{array}{c}\text { Loop-Central, Coplanar, } \\
\text { Componente Z e X }\end{array}$ \\
\hline VTEM & 400 & Trapezoidal & $\begin{array}{c}\text { Loop-Central, Coplanar, } \\
\text { Componente Z e X }\end{array}$ \\
\hline HOISTEM & 120 & Trapezoidal & $\begin{array}{c}\text { Loop-Central, Coplanar, } \\
\text { Componente } \mathrm{Z}\end{array}$ \\
\hline SKYTEM & 120 & Trapezoidal & $\begin{array}{c}\text { Loop-Central, Coplanar, } \\
\text { Componente Z e X }\end{array}$ \\
\hline
\end{tabular}

Um típico sistema eletromagnético VTEM (Versatile TEM) transportado por helicóptero (Fig. 14) consiste em um: loop transmissor circular (Tx), bobina receptora (Rx) localizada no centro do loop transmissor, magnetômetro em forma de "bird", GPS e um altímetro. 


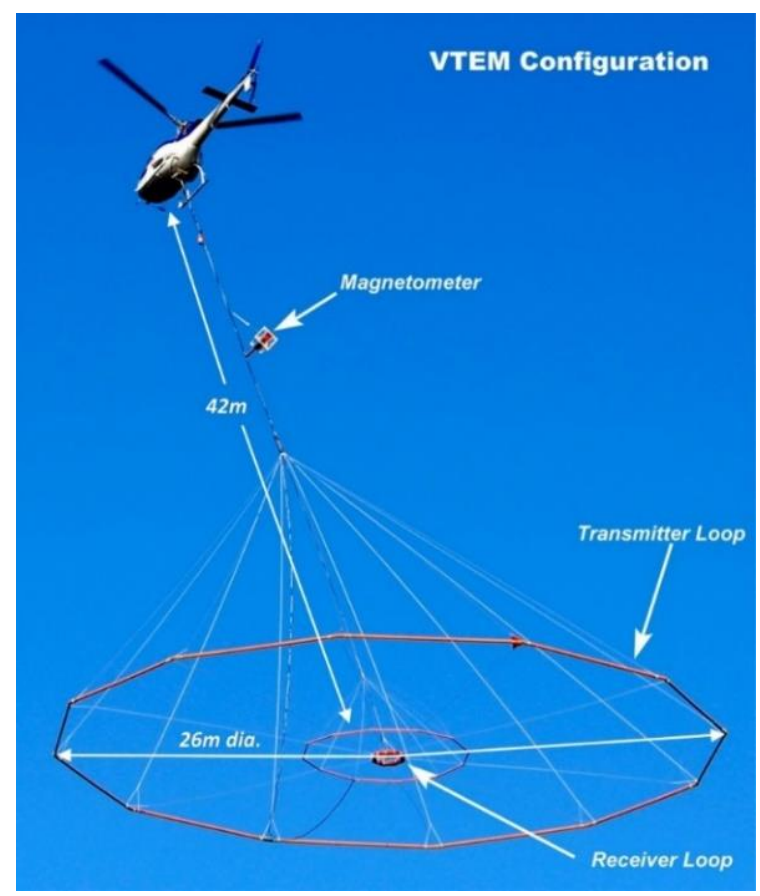

Figura 14: Configuração de um sistema VTEM (Legault et al., 2010).

O AeroTEM ${ }^{\mathrm{HD}}$, sistema HTEM utilizado nesta pesquisa, começou a ser desenvolvido em 1996 pela empresa canadense Aeroquest. O sistema é baseado em um loop circular rígido, com a bobina receptora localizada dentro do loop transmisso. Segundo Balch et al. (2003) as vantagens desta configuração são: máximo acoplamento para todos os alvos geométricos independente da profundidade abaixo da superfície, anomalias mais nítidas com formas mais simples em comparação com sistemas de asa fixa e formas de anomalia independentes da direção da linha de voo. Além disso, bobinas receptoras e transmissoras coincidentes têm menor sensibilidade à sobrecarga condutiva do que sistemas separados transmissor-receptor. As componentes $\mathrm{Z}$ e $\mathrm{X}$ são medidas tanto off-time quanto on-time. A medida do campo magnético secundário on-time pode melhorar a detecção de alvos com alta condutância. Uma bobina de compensação é utilizada para remoção da maior parte do campo magnético primário da medida on-time. Neste trabalho não foram utilizadas as medidas on-time devido ao alto nível de ruído nos dados. 


\section{Aquisição e Processamento dos Dados}

O projeto Rio das Velhas, base de dados geológica para esta pesquisa, foi um projeto cooperativo entre a CPRM e o DNPM concebido em 1992. O objetivo deste projeto foi a caracterização geológica do GBRV, proporcionando um grande avanço científico-tecnológico quanto ao conhecimento do GBRV e assim fomentando a prospecção mineral na região do Quadrilátero Ferrífero (DNPM, 1992).

Adicional e independentemente a este projeto, ocorreu entre 17 de julho a 4 de outubro de 1992, um aerolevantamento geofísico por helicóptero na região do GBRV, numa cooperação entre o governo (executado pelo DNPM e fiscalizado pela CPRM) e um consórcio de empresas de mineração operantes na região do QF, composto por dados eletromagnéticos no domínio da frequência, magnéticos e gamaespectrométricos (DNPM, 1992). Este aerolevantamento corresponde ao número (3007 da série 3000) e, usualmente, é denominado pela CPRM como projeto aerogeofísico Rio das Velhas - Etapa I. Sua execução foi dividida em quatro áreas, com diferentes orientações das linhas de voo.

Entre 28 de junho a 27 de setembro de 2011, numa área menor do GBRV, foi executado integralmente pela CPRM um segundo aerolevantamento geofísico por helicóptero, composto por dados eletromagnéticos no domínio do tempo e magnetometria. Este segundo aerolevantamento corresponde ao número 1116 da série 1000 (CPRM, 2012), disponível no GeoSGB (http://geosgb.cprm.gov.br/). Em trabalhos da CPRM e nesta pesquisa, convencionou-se identificar este aerolevantamento como Rio das Velhas - Etapa II.

Os aerolevantamentos do projeto Rio das Velhas - Etapa II foram realizados em duas regiões (Fig. 15): Nova Redenção (BA) e Rio das Velhas Área 1 e 2 (MG). Nesta pesquisa foram utilizados os dados radiométricos do bloco IV da Etapa 1 e os dados eletromagnéticos e magnéticos da Etapa 2, adquiridos entre os municípios de Santa Bárbara e Barão de Cocais (Área 2), no Quadrilátero Ferrífero, Estado de Minas Gerais. Os dados radiométricos foram adquiridos com espaçamento entre as linhas de voo de 250 m e direção N40W. Já os dados eletromagnéticos e magnéticos o espaçamento foi de $250 \mathrm{~m}$ e direção $\mathrm{N} 45^{\circ} \mathrm{W}$, cortando as principais estruturas geológicas da região. A Figura 16 apresenta o polígono da área do aerolevantamento e as coordenadas geográficas dos dados HTEM e de magnetometria. Os dados gamaespectrométricos foram janelados do Bloco IV para este polígono. 


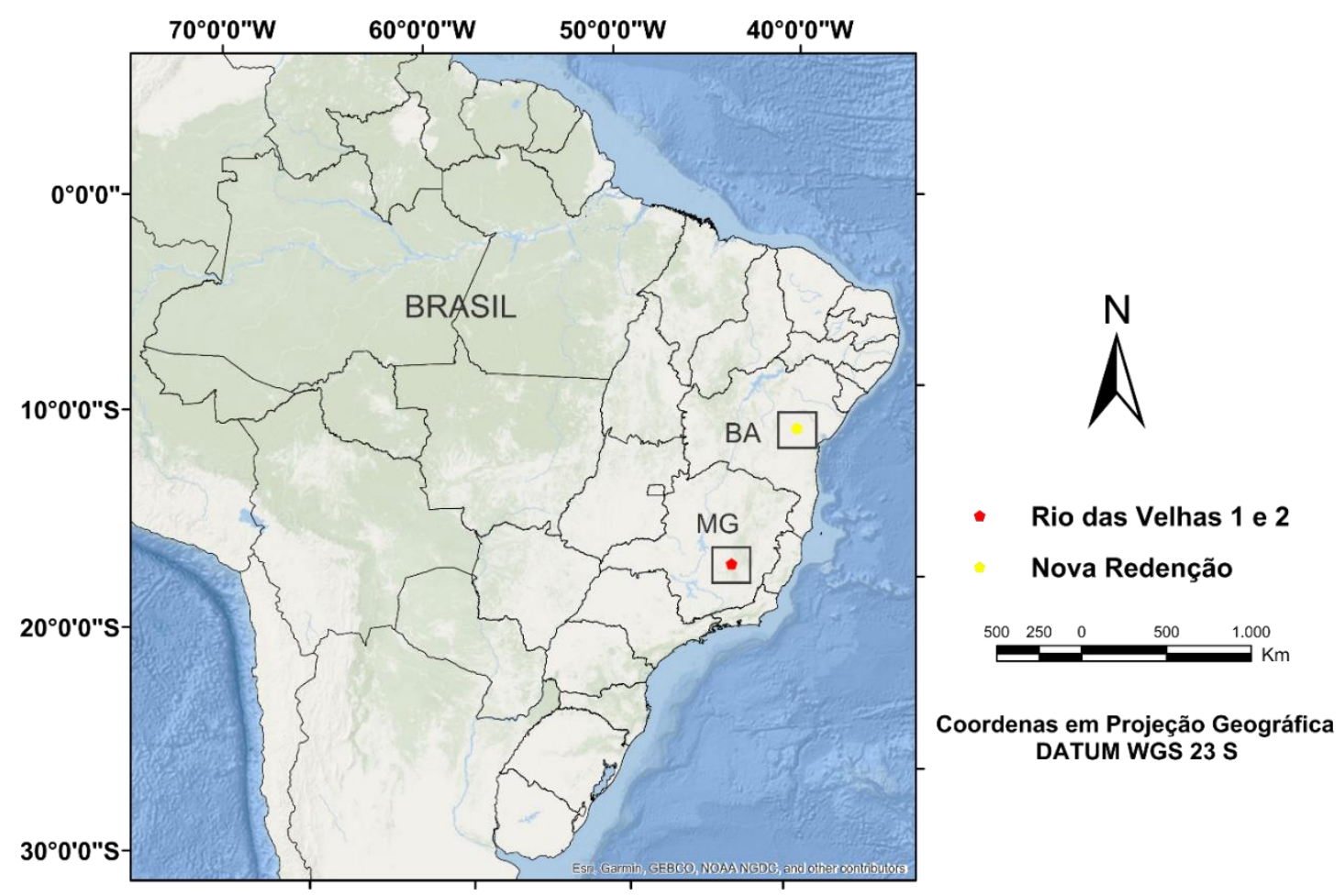

Figura 15: Localização do Projeto Rio das Velhas I e II e Nova Redenção (os polígonos pretos não representam as áreas cobertas pelos aerolevantamentos).

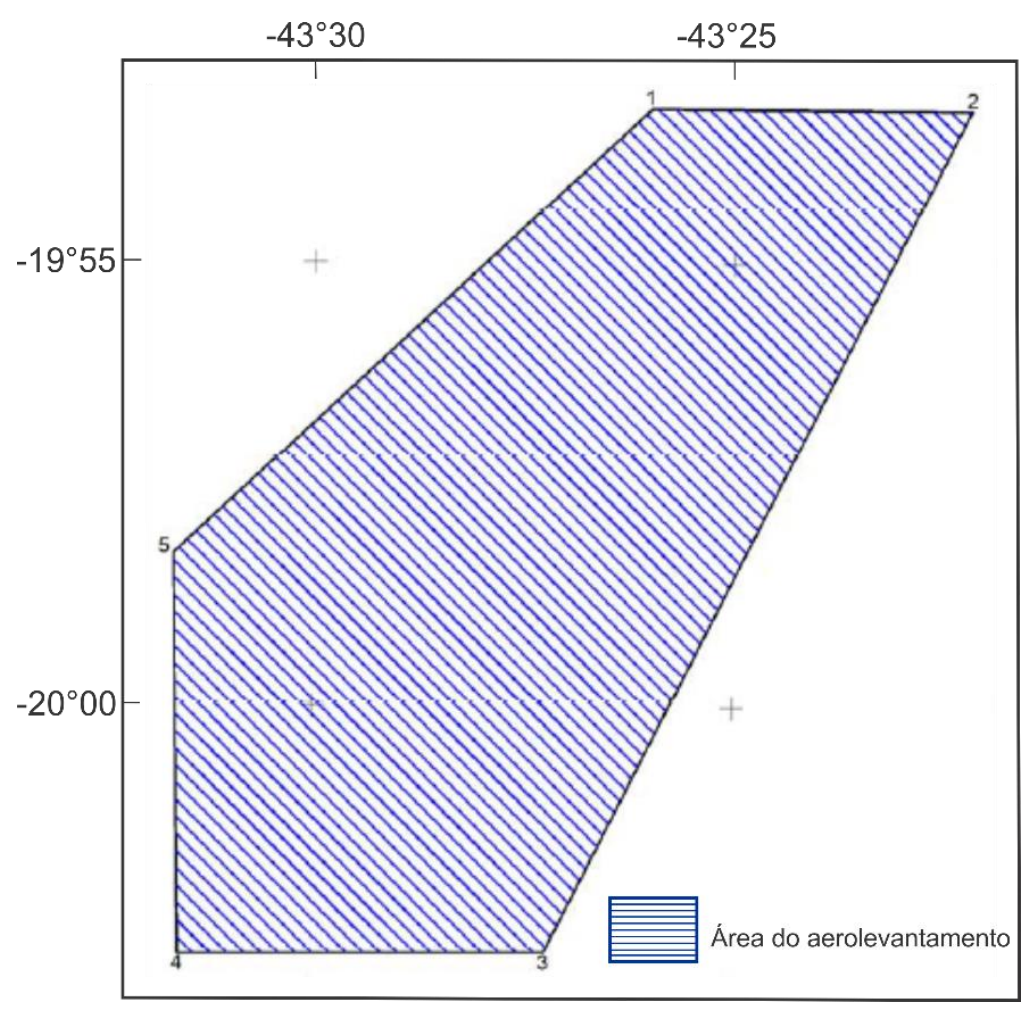

Figura 16: Polígono do aerolevantamento Rio das Velhas - Etapa II que cobre a área de estudo (retirado de CPRM, 2012). Os dados radiométricos da Etapa I foram janelados para este polígono. 
Os equipamentos utilizados na aquisição dos dados eletromagnéticos no domínio do tempo e magnéticos foram: o sistema eletromagnético no domínio do tempo transportado por helicóptero (HTEM), denominado AeroTEM ${ }^{\mathrm{HD}}$, exclusivo da empresa AEROQUEST à época de execução do aerolevantamento e o sensor magnético (Geometrics G823-A) de alta sensibilidade de vapor de césio. As características do sistema eletromagnético AeroTEM ${ }^{\mathrm{HD}}$ e do magnetômetro utilizados na aquisição estão resumidos na Tabela 2. O equipamento AeroTEM $^{\mathrm{HD}}$ é composto por um loop transmissor (Tx), duas bobinas receptoras (Rx) orientadas nos eixos $\mathrm{X}$ e $\mathrm{Z}$ e um sistema de aquisição AeroDAS que fica localizado dentro da aeronave (Fig. 17). A forma de onda triangular (Fig. 18) enviada pelo loop transmissor (Tx), possui um pulso simétrico on-time de $4.509 \mu$ s (frequência base de $30 \mathrm{~Hz}$ ). Durante todo o ciclo on-off o monitor de corrente efetua a leitura de 600 canais (60 leituras por segundo). As medidas on-time foram adquiridas em 16 canais e as medidas off-time em 17 canais resultando em 33 canais de aquisição.

Tabela 2: Característica do sistema utilizado na aquisição dos dados eletromagnéticos (CPRM, 2012).

\begin{tabular}{|l|l|}
\hline Tipo de Aeronave & Esquilo AS350B3 (prefixo PT-YOY) \\
\hline Frequência Base do Transmissor & $30 \mathrm{~Hz}$ \\
\hline Diâmetro do Loop Transmissor & $20 \mathrm{~m}$ \\
\hline Pico de Corrente do Transmissor & $323 \mathrm{~A}$ \\
\hline $\begin{array}{l}\text { Pico do Momento do Dipolo } \\
\text { Magnético }\end{array}$ & 711000 NIA \\
\hline Altura Nominal da Aeronave & $120 \mathrm{~m}$ (terrenos acidentados) / 90 m (demais \\
\hline Altura do Sistema Eletromagnético & $60 \mathrm{~m}$ abaixo da aeronave \\
\hline Altura do Bird do Magnetômetro & $34 \mathrm{~m}$ abaixo da aeronave \\
\hline
\end{tabular}




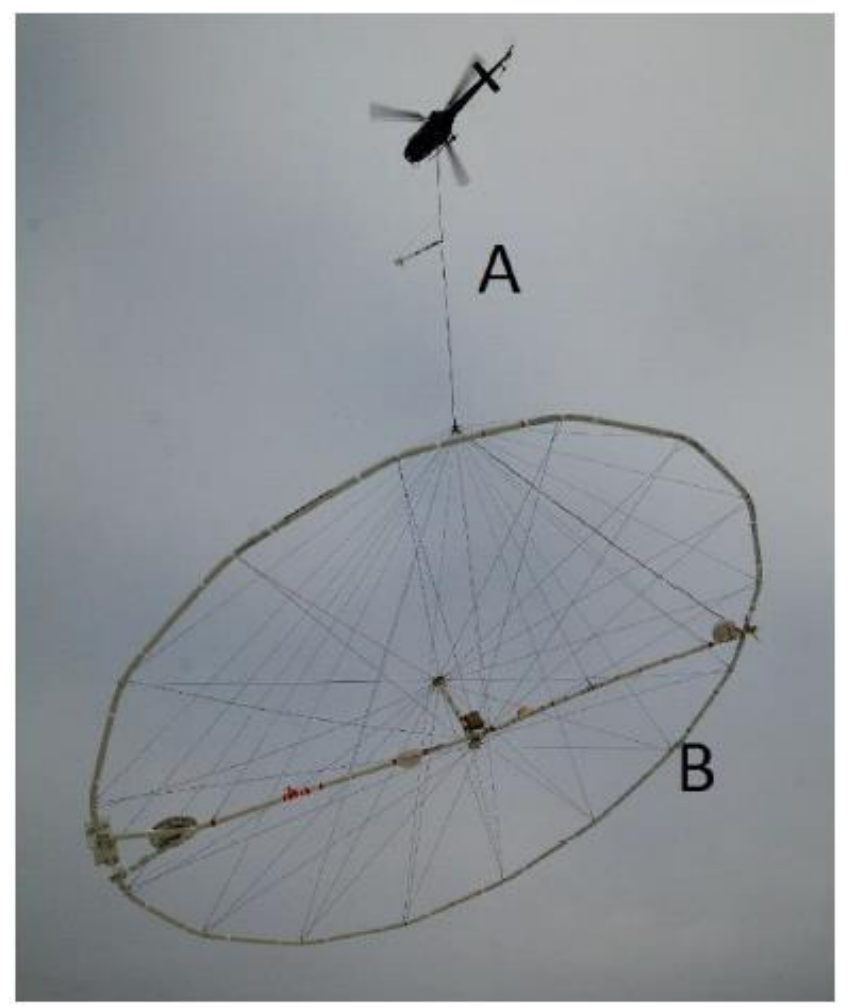

Figura 16: Sistema AeroTEM ${ }^{\mathrm{HD}}$. (A) bird do magnetômetro (B) loop transmissor e bobinas receptoras (retirado de CPRM, 2012).

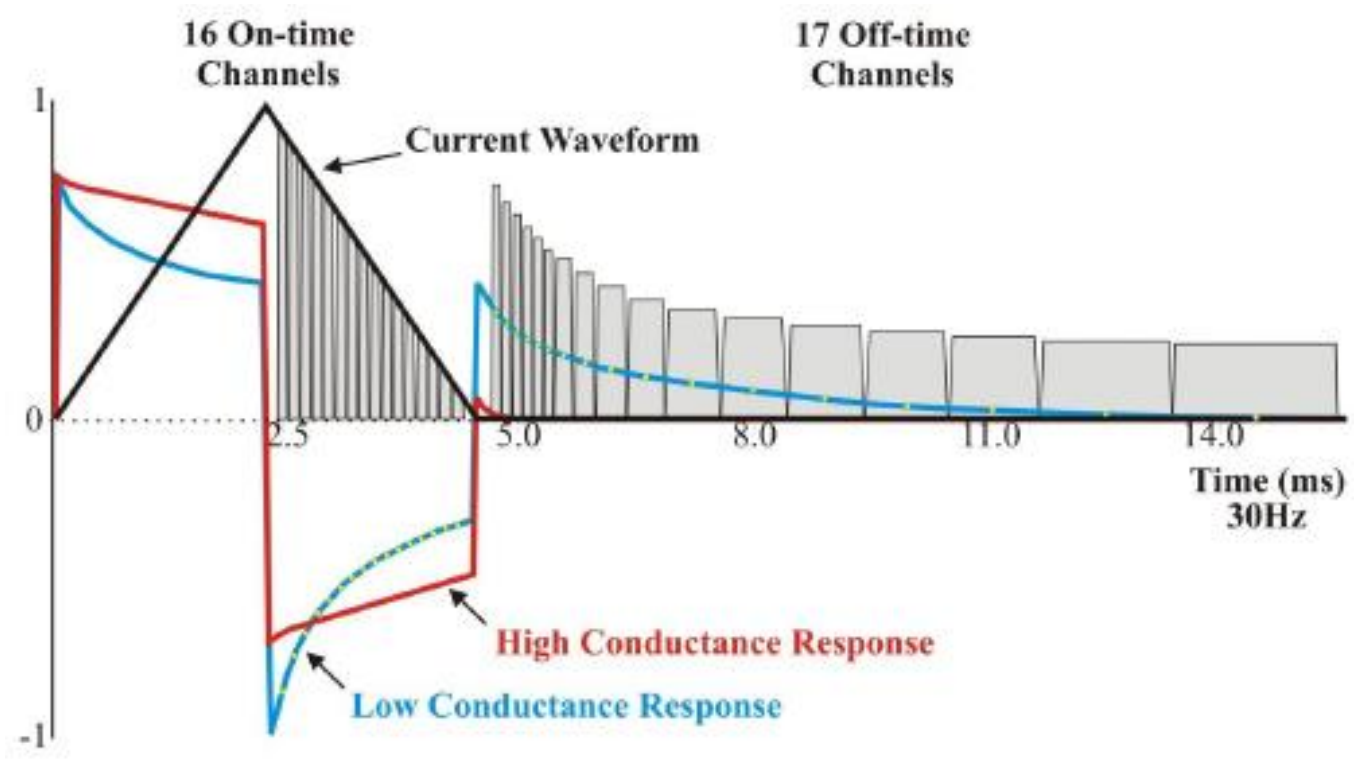

Figura 17: Esquemas das formas de onda do transmissor e do receptor (retirado de CPRM, 2012). 
O processamento dos dados foi realizado pela empresa (Aeroquest) no software ATP PRO e consistiu nas seguintes etapas:

a) compensação das componentes $\mathrm{Z}$ e X para forma de onda do campo primário;

b) empilhamento: Os dados eletromagnéticos brutos foram amostrados a uma taxa de $36.000 \mathrm{~Hz}$ (600 canais, 60 vezes por segundo) e reamostrados a uma taxa de $10 \mathrm{~Hz}$, com amostras a cada $1.5-25 \mathrm{~m}$;

c) filtragem: os dados empilhados foram filtrados para remoção ou minimização de ruídos de alta frequência que não representam feições geológicas.

d) compartimentalização: os dados foram divididos em 33 canais (16 on-time e 17 offtime);

e) nivelamento;

f) distribuição em linhas de voo.

Os dados de gamaespectrometria utilizados nesta pesquisa foram recortados do Bloco IV que abrange a área de estudo. Este levantamento foi realizado pela empresa PROSPEC S.A. - Geologia, Prospecção e Aerolevantamentos. As medições foram realizadas com um espectrômctro EXPLORANIUM, modelo GR-820, de 256 canais espectrais, associado a um detector EXPLORANIUM GPX-1 024, com volume total de 1024 polegadas cúbicas de Nal (TI), instalado a bordo do helicóptero. Foram medidos cinco canais: contagem total, urânio, potássio, tório e radiação cósmica. $\mathrm{O}$ intervalo de amostragem foi de 1 segundo. $\mathrm{O}$ préprocessamento também foi realizado pela empresa que adquiriu os dados e foram executados os seguintes passos:
a) remoção de spikes e ruídos;
b) remoção do background;
c) cálculo das constantes;
d) correção do efeito Compton;
e) correção altimétrica;
f) distribuição em linhas de voo.

Com o objetivo de corrigir efeitos causados pelo desnivelamento entre as linhas de voo adjacentes no dado pré-processado, foi empregada a técnica de processamento do micronivelamento, com a utilização de filtros no software Oasis Montaj (Sequeent). Foram 
aplicados os filtros passa-alta do cosseno direcional e Butterworth, propostos em Geosoft (1997a). As filtragens amenizaram o ruído causado pelo desnivelamento.

\section{Modelagem de Dados de Sistemas Eletromagnéticos Aéreos}

A modelagem direta é uma ferramenta amplamente utilizada na interpretação de dados eletromagnéticos aéreos e fornece informações para, por exemplo, construção de novos sistemas aéreos, comparação das respostas entre diferentes sistemas, como base para interpretação qualitativa de feições selecionadas, entre outros (Nabighian \& Macnae, 1991).

Os modelos disponíveis hoje em dia, são simplificações físicas e geológicas das propriedades da Terra. Diversos modelos são utilizados em programas de modelagem como: semiespaços homogêneos ou em camadas, "uniform conductive overburdens", condutores esféricos em camadas ou placas retangulares finas.

Desde os trabalhos de Lamontagne \& West (1971), Annan (1974) e Dyck et al. (1980), a modelagem eletromagnética de uma placa condutora tem sido amplamente utilizada na indústria de exploração mineral. Esta abordagem ganhou popularidade e hoje em dia é aplicada rotineiramente na indústria.

Uma placa fina condutiva no espaço livre é um dos modelos mais comuns empregados na interpretação dos métodos eletromagnéticos. Placas condutivas são uma boa aproximação para uma série de feições geológicas como diques intrusivos, camadas horizontais com tamanho finito, veios mineralizados ou até mesmo corpos condutivos de minério isolado (Johansson, 2017). Diversos depósitos minerais possuem como característica uma extensão vertical muito maior do que sua espessura, tornando-a desprezível em algumas situações, como no caso dos depósitos de ouro da região de estudo. Placas são normalmente modeladas usando uma aproximação por "single wire loop" ou pelo método da decomposição espectral desenvolvido por Annan (1974) (Lamontagne et al., 1988).

\subsection{Software EMIT Maxwell}

A interpretação qualitativa dos dados foi realizada através do software EMIT Maxwell, utilizando modelos de placas retangulares finas (thin sheet plate modeling) ou prismas retangulares, que permitem a modelagem direta em 3D, com o objetivo de determinar a geometria e as propriedades físicas (condutância ou condutividade) dos corpos condutores. $\mathrm{O}$ 
software EMIT Maxwell, desenvolvido pela empresa australiana EMIT (Eletromagnetic Imaging Technology) permite a visualização, processamento e modelagem de dados aéreos ou terrestres, no domínio do tempo e da frequência.

A resposta para uma placa fina retangular depende apenas do produto condutividadeespessura ou condutância. Dessa forma, a condutividade e a espessura não podem ser resolvidas separadamente. Esta aproximação é válida para quando a espessura for metade da profundidade de difusão, no domínio do tempo (EMIT, 2015). Para uma placa condutiva "fina", as correntes de difusão ficarão confinadas no plano da placa, enquanto o campo primário irá permanecer contínuo ao longo da placa.

As correntes de difusão são simuladas nas placas através dos ribbons. Os ribbons são circuitos fechados com resistência elétrica que varia linearmente com o comprimento e a largura dos ribbons e inversamente com a condutância da placa. A corrente elétrica flui apenas dentro dos ribbons e cada um é eletricamente isolado do outro. O software assume um meio resistivo, sem nenhuma interação com as rochas hospedeiras, porém os efeitos de indutância da interação entre placas são considerados quando mais de uma placa é utilizada para o ajuste do modelo (EMIT, 2015).

Segundo Grant \& West (1965) o problema de calcular a resposta EM de uma placa fina corresponde a calcular a resposta de cada ribbon. Se cada ribbon for substituído por um fio formando um loop, com auto-indutância e resistência definidas, o problema se reduz a calcular a resposta EM para um número independente de loops no espaço livre.

Para geração das placas no software Maxwell, parâmetros geométricos e propriedades físicas devem ser especificados. Além disso, um arquivo com as configurações do sistema de aquisição utilizado deve ser adicionado ao programa. A Tabela 3 abaixo contém os principais parâmetros que são especificados na modelagem.

Tabela 3: Parâmetros para geração de uma placa no software Maxwell (EMIT, 2015).

\begin{tabular}{|c|c|c|}
\hline Abreviação & Parâmetro & Unidade \\
\hline $\mathbf{X}$ & Coordenada espacial no eixo X & Metros \\
\hline $\mathbf{Y}$ & Coordenada espacial no eixo Y & Metros \\
\hline
\end{tabular}




\begin{tabular}{|c|c|c|}
\hline $\mathbf{Z}$ & Coordenada espacial no eixo Z & Metros \\
\hline $\mathbf{D}$ & Mergulho & Graus \\
\hline DD & Direção de Mergulho & Graus \\
\hline SL & Comprimento na direção do strike & Metros \\
\hline DE & Comprimento na direção do mergulho & Metros \\
\hline Th & Espessura & Metros \\
\hline CT & Condutância & Siemens \\
\hline Cond & Condutividade & Siemens/Metro \\
\hline $\boldsymbol{\eta}$ & Número de ribbons & \\
\hline
\end{tabular}

\subsection{Características das Anomalias HTEM}

As anomalias eletromagnéticas HTEM apresentam formas características que podem servir como um guia para modelagem. Os modelos abaixo (Figs. 18, 19, 20 e 21) foram calculados para os canais 5-9 (off-time), para uma placa com condutância de $100 \mathrm{~S}$ (placa fina) ou $2 \mathrm{~S} / \mathrm{m}$ de condutividade (placa espessa) e com dimensão igual a 100x100 m a $100 \mathrm{~m}$ de profundidade do sistema de aquisição. As mesmas configurações do sistema de aquisição utilizado nesta pesquisa foram aplicadas nestes dados sintéticos.

Uma placa fina e vertical (Fig. 18) produz uma anomalia simétrica com dois picos na componente $\mathrm{Z}$ e um dipolo do positivo para o negativo na componente $\mathrm{X}$ na direção do voo. Já uma placa fina e horizontal (Fig. 19) produz uma única anomalia positiva na componente $\mathrm{Z}$ e um dipolo com um pico negativo e outro positivo na direção da linha de voo. Os sistemas HTEM produzem respostas com maiores amplitudes para placas condutoras horizontais devido ao ótimo acoplamento do transmissor. Por outro lado, placas condutoras na vertical produzem anomalias com amplitudes menores (Allard, 2007). Uma placa sub-vertical (Fig. 20) com mergulho de $45^{\circ}$ produz uma anomalia assimétrica. É importante ressaltar que um aumento no 
mergulho da placa não aumenta necessariamente a amplitude da resposta do modelo devido as condições da aproximação por placas finas (Johansson, 2017). Para uma placa vertical com espessura de 50 m, como no caso do modelo da Figura 21, a resposta é uma anomalia com um único pico para a componente $\mathrm{Z}$, semelhante a uma placa fina e vertical, porém para a componente $\mathrm{X}$ a anomalia resultante possui a forma de um dipolo do negativo para o positivo. Esta diferença pode ser usada para definir se um condutor horizontal é fino ou espesso. Porém quando existe uma série de condutores muito próximos, ou quando a fonte tem um mergulho raso, pode ser difícil determinar qual o tipo de espessura do condutor.

A forma das anomalias também fornece informações sobre o número de placas necessárias para modelar o dado. Uma anomalia com uma forma simples pode ser normalmente ajustada com apenas uma placa. No entanto, anomalias com formas complexas podem precisar de mais de uma placa para serem modeladas, ou mesmo é necessário considerar efeitos de rochas encaixantes condutivas que podem interferir no dado (Nabighian \& Macnae, 1991).

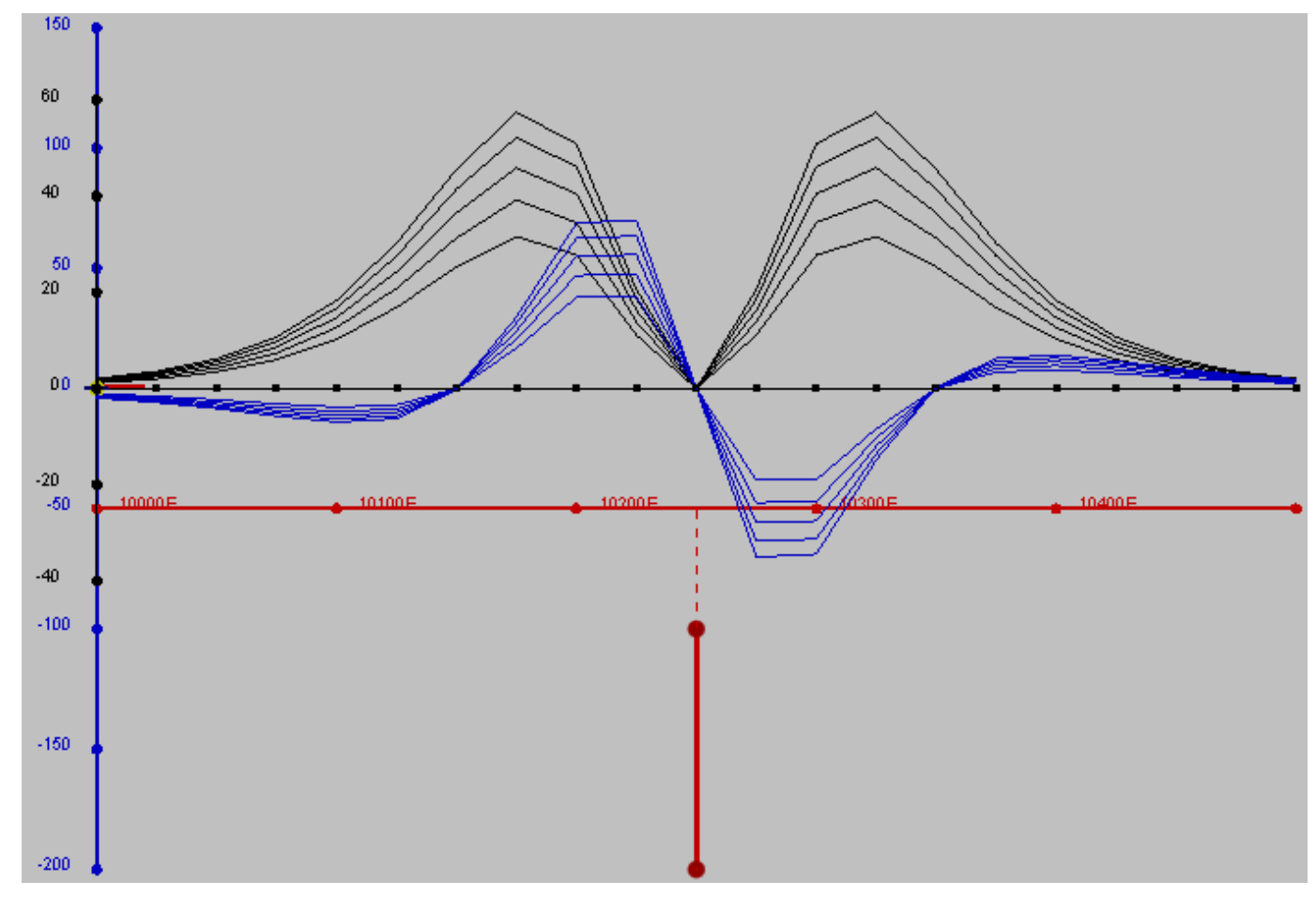

Figura 18: Modelo direto para uma placa vertical com 100x100 m e $100 \mathrm{~m}$ de profundidade para as componentes Z (preto) e X (azul). 


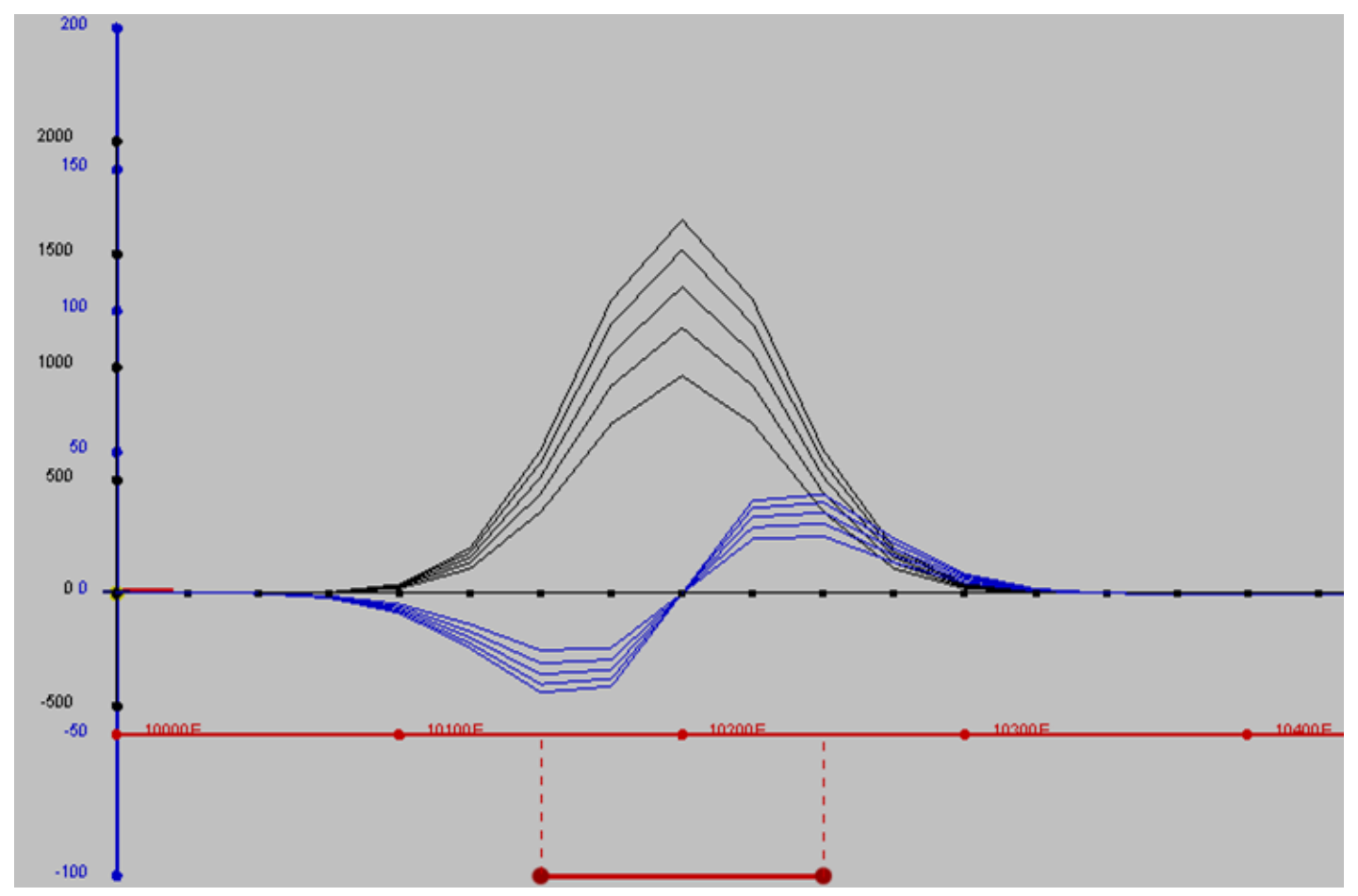

Figura 19: Modelo direto para uma placa horizontal com 100x100 m e $100 \mathrm{~m}$ de profundidade para as componentes $\mathrm{Z}$ (preto) e X (azul).

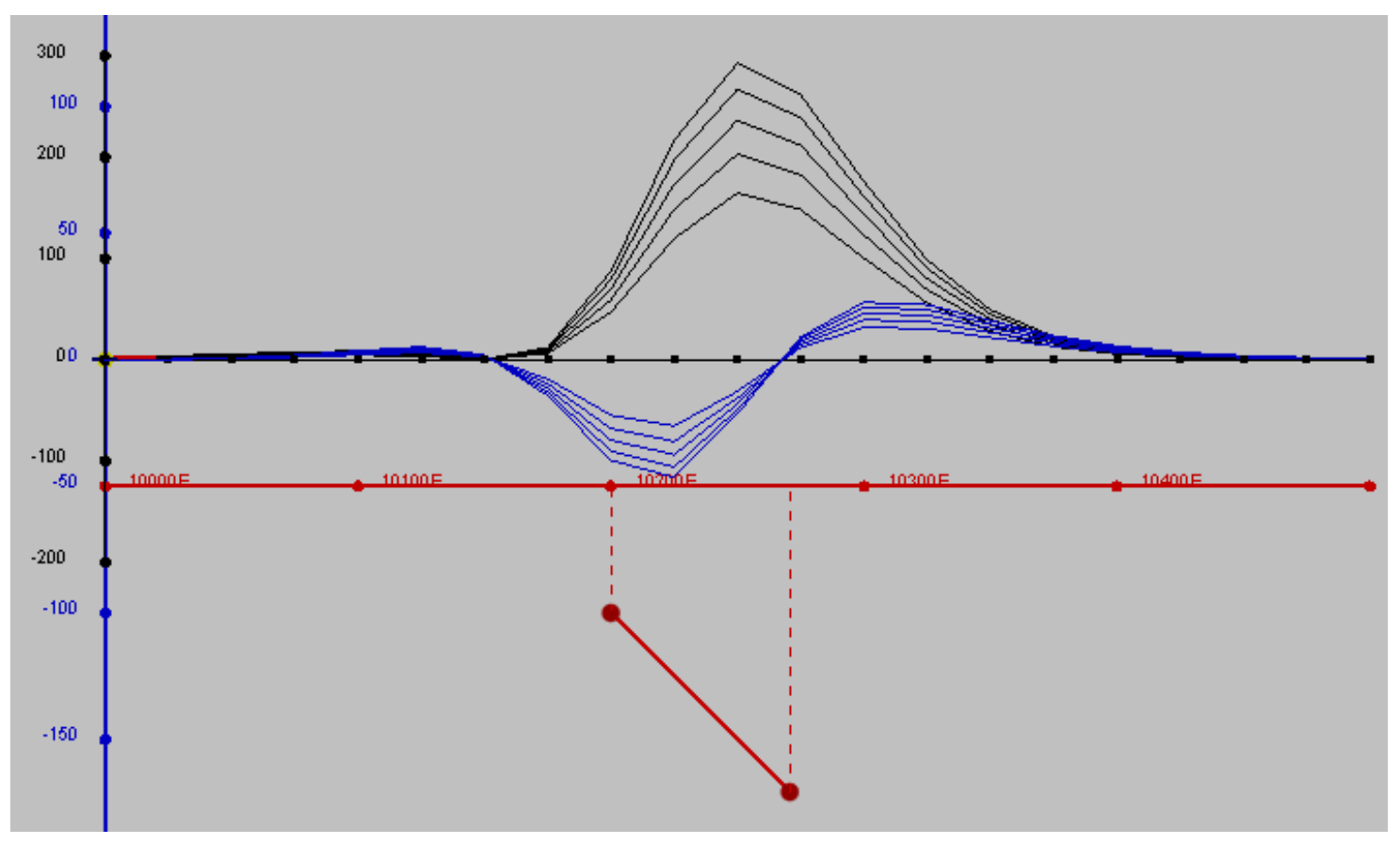

Figura 20: Modelo direto para uma placa sub-vertical com 100x100 m, $100 \mathrm{~m}$ de profundidade e $45^{\circ}$ de mergulho para as componentes $\mathrm{Z}$ (preto) e $\mathrm{X}$ (azul). 


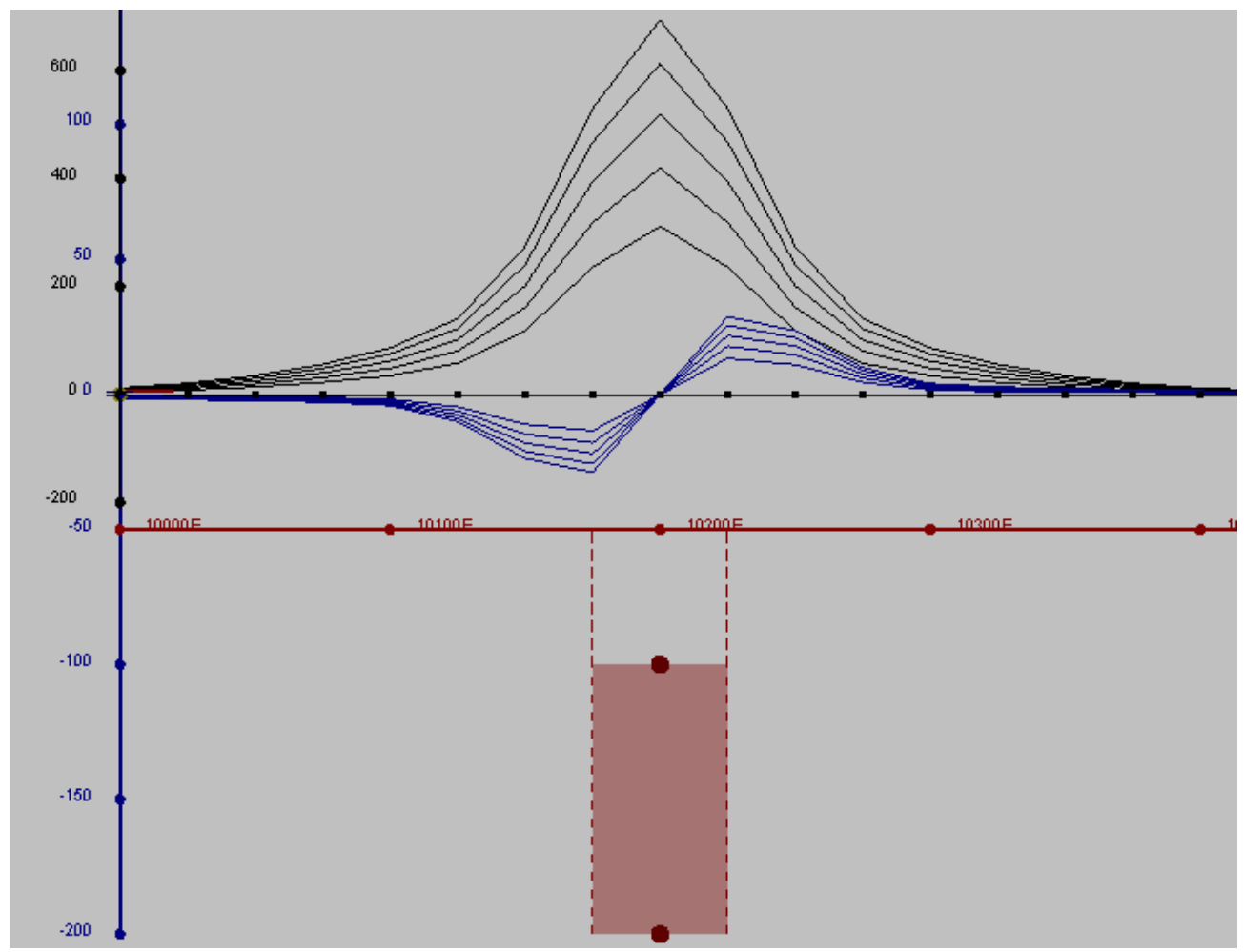

Figura 21: Modelo direto para uma placa vertical espessa com 100x100 m, $100 \mathrm{~m}$ de profundidade para as componentes $\mathrm{Z}$ (preto) e $\mathrm{X}$ (azul).

\subsection{Seleção das Anomalias}

Para selecionar as anomalias a serem modeladas, diversas precauções e parâmetros foram levados em consideração, a fim de obtermos uma anomalia que possivelmente seja causada por uma zona mineralizada. Buscou-se, principalmente, anomalias que fossem próximas às mineralizações conhecidas ou minas ativas da região, porém em algumas regiões a alta presença de ruído dificultou o processo da modelagem. Os parâmetros utilizados na escolha das anomalias são apresentados a seguir:

- Seleção no mapa dos dados HTEM (Canal 7);

- Localização (Google Earth);

- Monitoramento de fontes de acoplamentos galvânico ou capacitivo;

- Dados de magnetometria;

- Dados de gamaespectrometria; 
- Geologia da região e parâmetros estruturais/geomêtricos;

- Polígonos de direitos minerários da base de dados SIGMINE do DNPM (http://sigmine.dnpm.gov.br/webmap/).

Todos os canais HTEM foram analisados e o canal 7 (off-time) foi escolhido para ser utilizado na seleção das anomalias, pois é um canal intermediário, onde as anomalias possuem uma resposta mais nítida. Anomalias com maior condutividade, ou maior dB/dt, são priorizadas pois nesta região podem estar relacionadas a zonas sulfetadas.

O segundo passo seguiu-se com a utilização do software Google Earth para verificar a localização da anomalia. Assim como identificar linhas de transmissão ou estruturas metálicas, principalmente das minas em funcionamento, presentes na área de estudo, que podem estar associadas às fontes de acoplamentos capacitivo ou galvânico (Danielsen et al., 2003).

A integração dos métodos geofísicos é de extrema importância na exploração aurífera, uma vez que geralmente o ouro ocorre em baixo grau, sua detecção direta é impraticável (Doyle, 1990). Os mapas de magnetometria são importantes pois possibilitam mapear horizontes estratigráficos, litologias e estruturas que podem ser mineralizadas. $\mathrm{Na}$ área de estudo, as mineralizações estão hospedadas em estruturas como zonas de cisalhamento que, quando associadas a minerais magnéticos, podem ser definidas pela magnetometria. Já os mapas de gamaespectrometria podem auxiliar no mapeamento da geologia superficial e na identificação de zonas onde ocorreram alteração hidrotermal, processo essencial na formação de depósitos de ouro orogênico no QF, conforme discutido em (Lobato et al., 1998).

Em seguida, foram levados em consideração os parâmetros geológicos e estruturais disponíveis na literatura para modelagem dos depósitos. Segundo Lobato et al. (2001b), em geral, as mineralizações auríferas na área de estudo possuem os seguintes parâmetros estruturais e geométricos:

- strike: $\mathrm{N} 45^{\circ} \mathrm{E}$;

- direção de mergulho: $80^{\circ}$ a $135^{\circ}(\mathrm{SE})$;

- mergulho: $20^{\circ}$ a $80^{\circ}$;

- espessura: 0,5 a 20 m; 
- comprimento: 10 a $300 \mathrm{~m}$;

- comprimento em profundidade: 100 a $5.000 \mathrm{~m}$.

Os dados da ANM (Agência Nacional de Mineração) mostram em que fase de licenciamento encontra-se a área pesquisada (Fig. 22). A maior parte da região de estudo está ou em fase de pesquisa ou já foi concedida para lavra. Portanto, a confirmação de uma anomalia em uma área requisitada por empresas de mineração fornece maior importância econômica dos modelos, bem como justifica a escolha das anomalias a serem modelada.
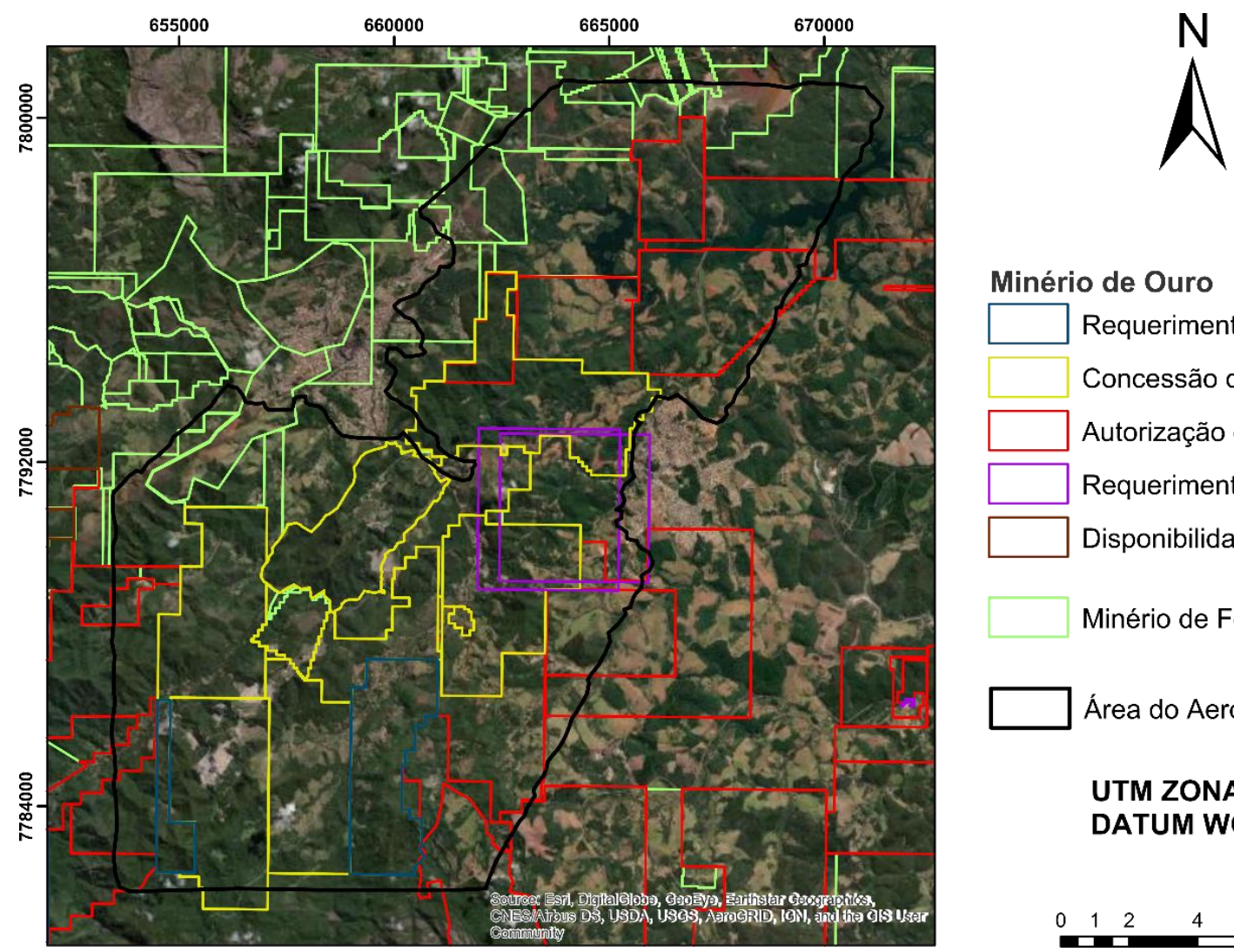

\section{Minério de Ouro}

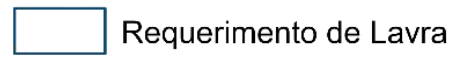

Concessão de Lavra

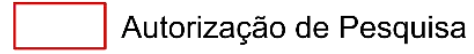

$\square$ Requerimento de Pesquisa

Disponibilidade

Minério de Ferro

Área do Aerolevantamento

UTM ZONA 23 S

DATUM WGS 84

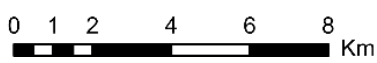

Figura 22: Dados da fase de requerimento para mineração (Retirado de http://www.anm.gov.br/assuntos/ao-minerador/sigmine).

Para a seleção das anomalias, um mapa de "pickings" (Fig. 23) foi gerado, de acordo com a classificação pela condutância das anomalias no mapa HTEM - Canal 7 (off-time). As condutâncias foram calculadas segundo o critério estabelecido pela empresa que adquiriu o dado. Segundo o relatório, as estimativas da condutância (off-time) foram calculadas com base em um modelo de uma placa horizontal, para os pontos ao longo da linha de voo, onde a amplitude de resposta foi suficiente para produzir uma estimativa aceitável. Cada condutor foi 
classificado de acordo com um conjunto de sete faixas de valores calculados de condutância (off-time). Condutores que não forneceram uma estimativa aceitável de condutância, devido a uma resposta de amplitude reduzida, foram classificados como uma fonte de baixa condutância (CPRM, 2012).
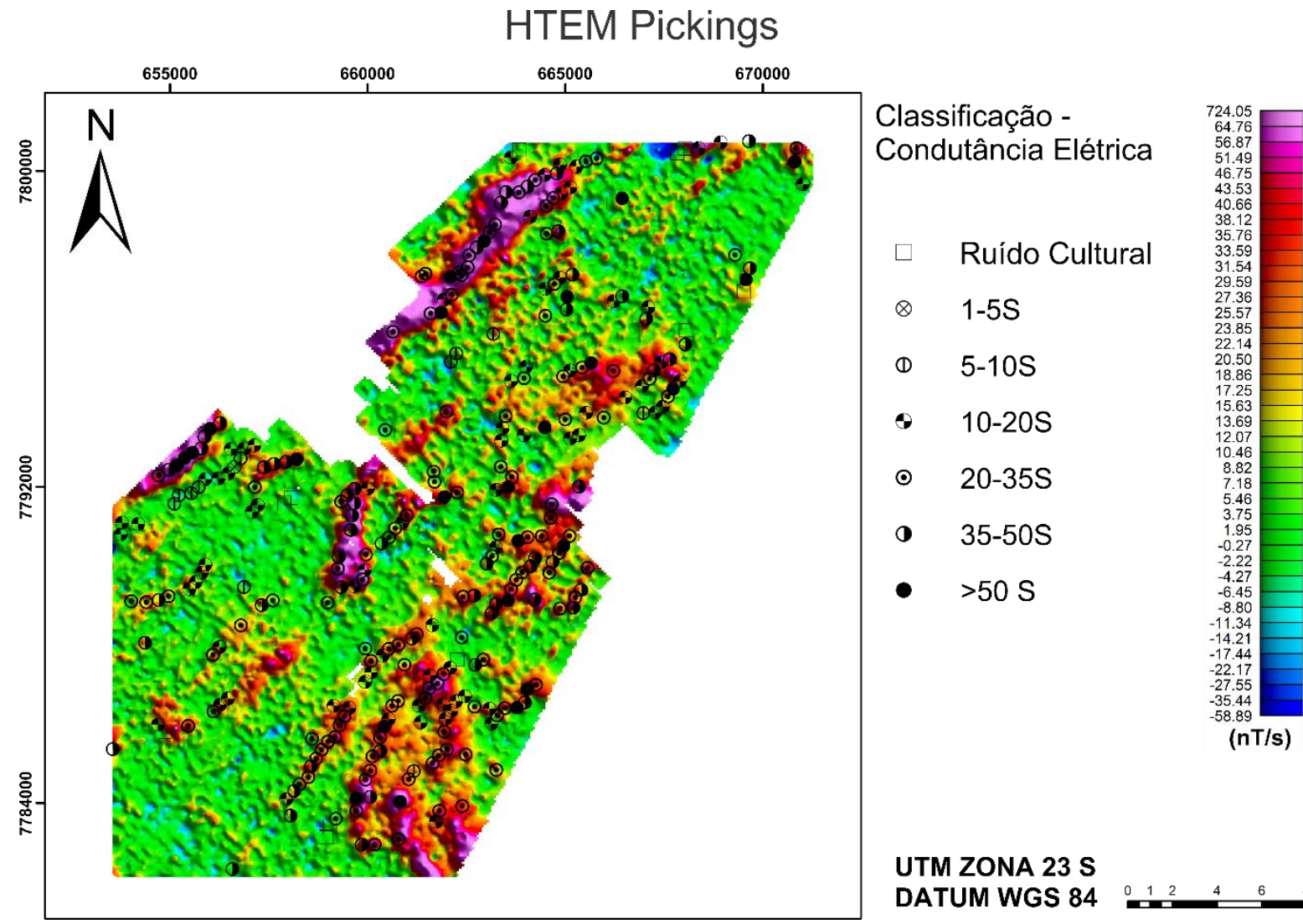

UTM ZONA $23 \mathrm{~S}$

DATUM WGS $84 \quad$\begin{tabular}{llllll}
0 & 1 & 2 & 4 & 6 & 6 \\
\hline
\end{tabular}

Figura 23: Mapa dos "pickings" das anomalias de condutividade dos dados HTEM (Adaptado de Couto Jr. et al., 2017). 


\section{Resultados}

Neste capítulo são discutidos os resultados dos dados aéreos de magnetometria, gamaespectrometria, eletromagnético e os modelos resultantes dos dados HTEM. Os resultados dos métodos de magnetometria e gamaespectrometria deram suporte, embasaram a escolha das anomalias modeladas para interpretação e discussão dos modelos dos dados HTEM.

\subsection{Magnetometria}

Os dados aéreos de magnetometria foram usados para uma interpretação conjunta dos resultados e para orientar a seleção das anomalias a serem modeladas. O método pode contribuir para a identificação e modelagem das rochas hospedeiras (principalmente BIF's), como também para análise estrutural. Os dados do campo magnético total (TMI - Total Magnetic Field) foram interpolados utilizando o software Oasis Montaj (Seequent). A intensidade do campo magnético total (Fig. 24-b) apresenta boa correlação com as litologias presentes na área de estudo (Fig. 24-a). Os complexos granito-gnáissicos e a associação vulcânica máfica ultramáfica na parte SE e NE do aerolevantamento exibem anomalias de baixa intensidade. Já na parte central e sudoeste, as anomalias são dipolares, com alta intensidade e possuem uma forma linear, seguindo a orientação $\mathrm{N}^{\circ} 5^{\circ} \mathrm{E}$ das principais estruturas presentes na região. 


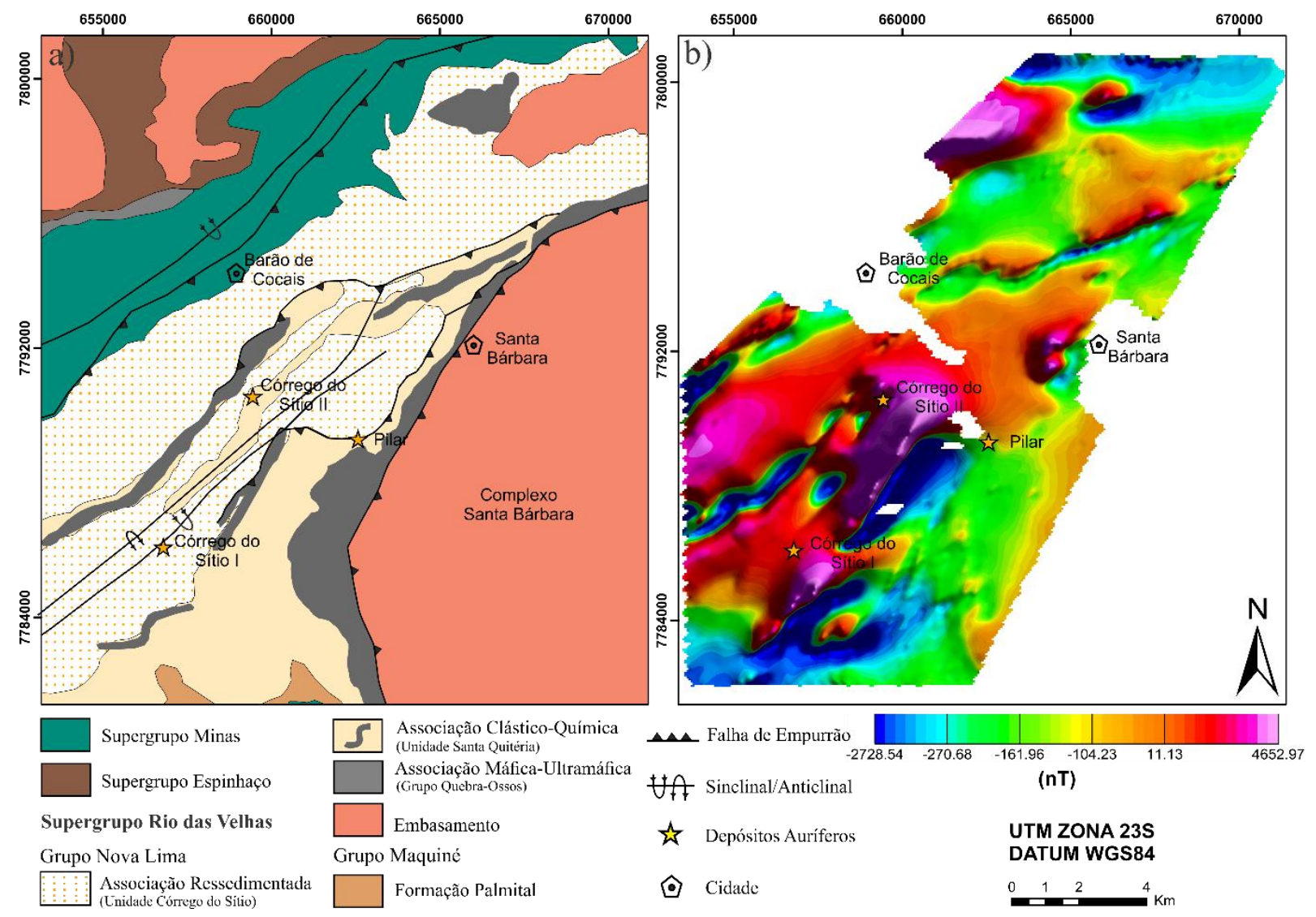

Figura 24: a) Geologia da área de estudo (Adaptado de Lobato et al., 2001b). b) Mapa da intensidade do campo magnético total.

Em seguida, foi aplicado o filtro da amplitude do sinal analítico (ASA 3D, Fig. 25-a) com o objetivo de delimitar as anomalias da região. O ASA 3D definiu a geometria em planta dos corpos magnéticos que, em sua maioria, são lineares, com quilômetros de extensão e seguem um trend principal de direção NE-SW, sobretudo na parte sudoeste do aerolevantamento, com orientação NNE-SSW. As anomalias magnéticas de alta intensidade possivelmente estão associadas às BIF's magnéticas que estão hospedadas nas zonas de cisalhamento. A fase do sinal analítico (TILT Derivative) foi utilizada com o objetivo de delimitar os principais lineamentos da área de estudo (Fig. 25-b). 


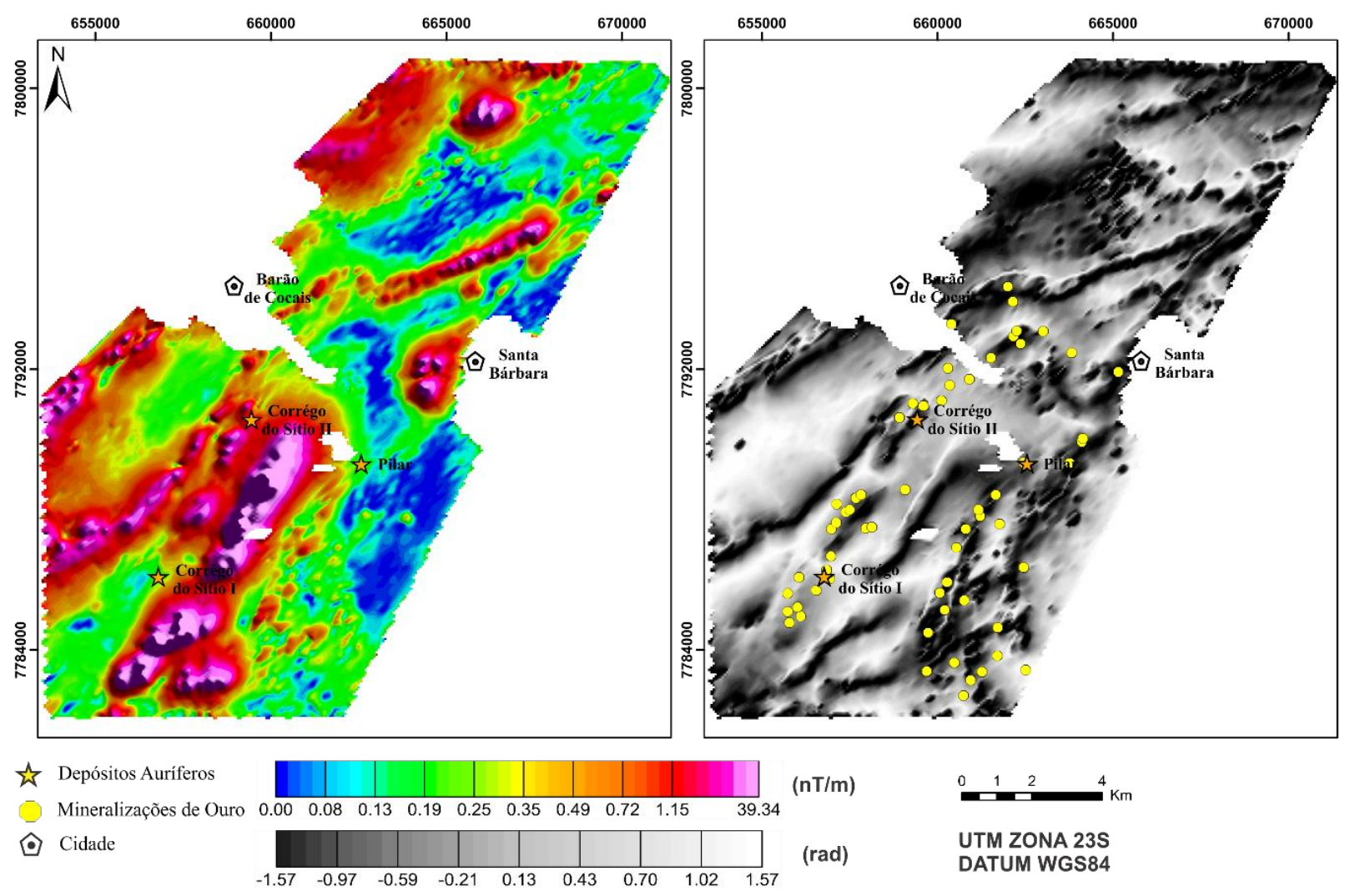

Figura 25: a) Mapa da amplitude do sinal analítico (ASA 3D). b) Mapa da fase da amplitude do sinal analítico (TILT Derivative).

Estes alinhamentos dos corpos magnéticos podem estar associados aos importantes lineamentos estruturais presentes na região, como os lineamentos São Bento-Donana, Cristina e Córrego do Sítio (Lima, 2012) (Fig. 26). Estes lineamentos estruturais representam zonas de cisalhamento associadas a falhas de empurrão, preenchidas por rochas sedimentares ou máficas-ultramáficas com intercalações de BIF's, o que explica as fortes anomalias magnéticas nos dados (Oliveira, 2014). As ocorrências auríferas estão correlacionadas com estes lineamentos magnéticos e estão localizadas principalmente no lineamento Córrego do Sítio, onde está situado o complexo de minas com o mesmo nome. No quadrante SE existe um lineamento magnético com direção NE-SW que pode possuir relação com lineamento Córrego do Sítio (Couto Jr. et al., 2017) e está associado a uma BIF de acordo com o mapa de geologia local (Fig. 7). Além disso, é possível reconhecer o alinhamento Brumal (Fig. 26), também associado a uma BIF (Oliveira, 2014) onde mineralizações estão localizadas, e a zona de cisalhamento Água Quente (Dorr, 1969) que separa o Grupo Quebra Ossos do complexo Santa Bárbara. 


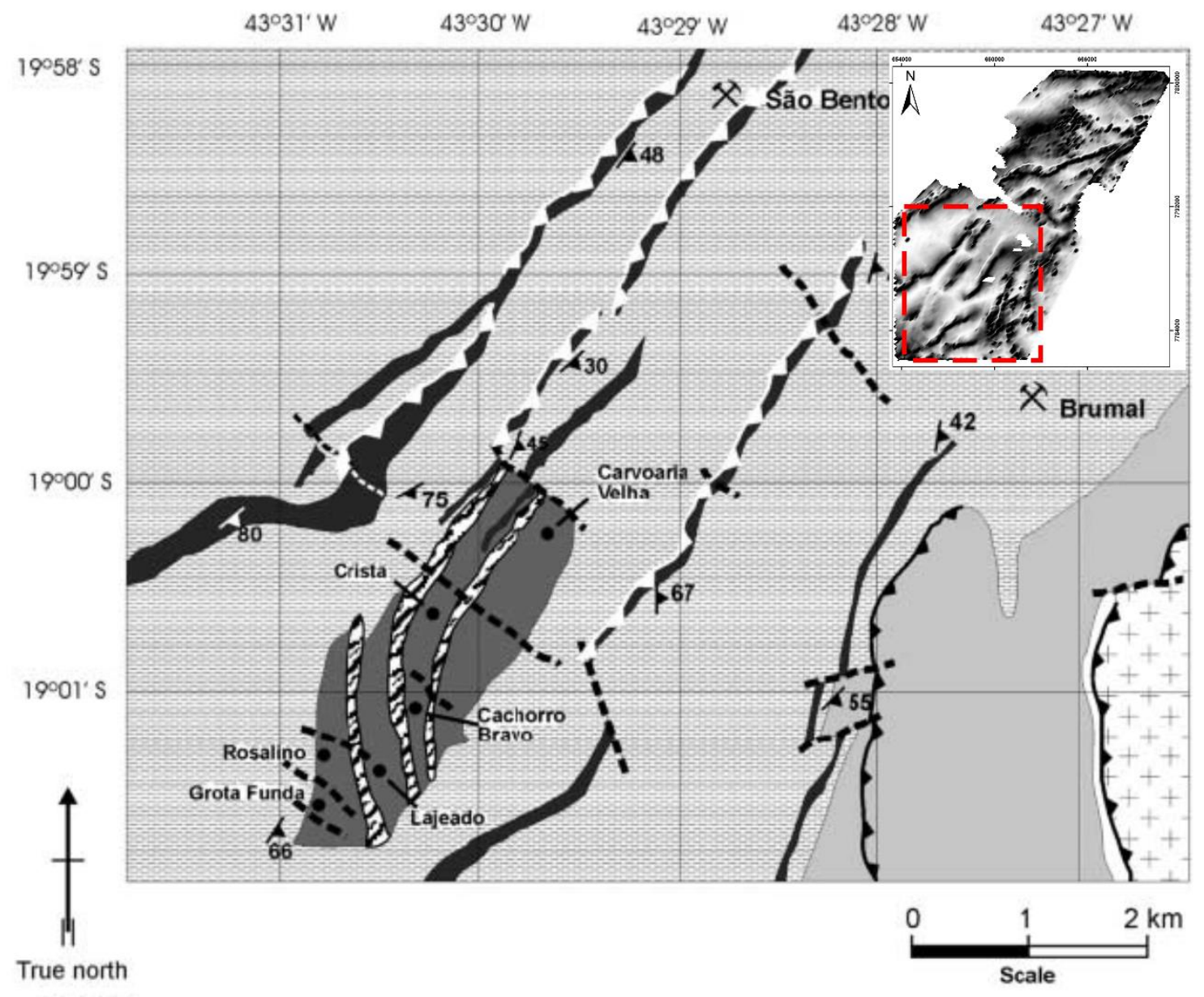

LEGEND

Minas Supergroup

BIF

RIO DAS VELHAS SUPERGROUP

NOVA LIMA GROUP

Resedimented association

pelite and greywacke with intercalated BIF \pm eheritcarbonaceous phyllite

Mafic-ultramafic volcanic association

komatiitic peridotite with intercalated BIF

Undivided Nova Lima Group

mainly rocks of the resedimented and clastic-chemical associations

Santa Bárbara complex

J3:. Diabase dyke

- Location of orebody

i. Shear zone

Thrust fault

Strike and dip of foliation

父 Gold deposit

Figura 26: Geologia do lineamento Córrego do Sítio e mapa da fase da amplitude do sinal analítico (Adaptado de Lobato et al., 2001b). 


\subsection{Gamaespectrometria}

Os dados de gamaespectrometria foram utilizados com o objetivo de entender e reconhecer as assinaturas radiométricas associadas às rochas hospedeiras das mineralizações auríferas. Estes dados, principalmente o canal do potássio, foram utilizados para o mapeamento geológico e definição das litologias do SGRV por Baltazar \& Zuchetti (2007).

Dickson \& Scott (1997) mostra que a assinatura de dados gamaespectrométricos aéreos para depósitos de ouro é variada, sendo o potássio o indicador mais valioso. Os halos de alteração hidrotermal ao redor de metais base e metais preciosos são há muito conhecidos por estudos geoquímicos. O metassomatismo potássico associado a sistemas de mineralização pode dobrar a concentração deste elemento, mesmo em rochas hospedeiras potássicas (Hoover \& Pierce, 1990).

Os dados foram interpolados no software Oasis Montaj (Seequent). O mapa do canal Potássio (Fig. 27-b) apresenta uma boa correlação com as litologias mineralizadas (Fig. 27-a) presentes na área de estudo, com extensas faixas anômalas (concentração da ordem de 60\%) com direção geral de (NE-SW), associadas à rochas félsicas que contém mica branca da unidade Córrego do Sítio. Nas partes SE e SW do aerolevantamento, o grupo Quebra Ossos e a unidade Santa Quitéria possuem uma baixa resposta para o K (concentração da ordem de $15 \%$ ). As coberturas lateríticas estão associadas também a uma baixa contagem, especialmente nas porções NW e NE da região. 


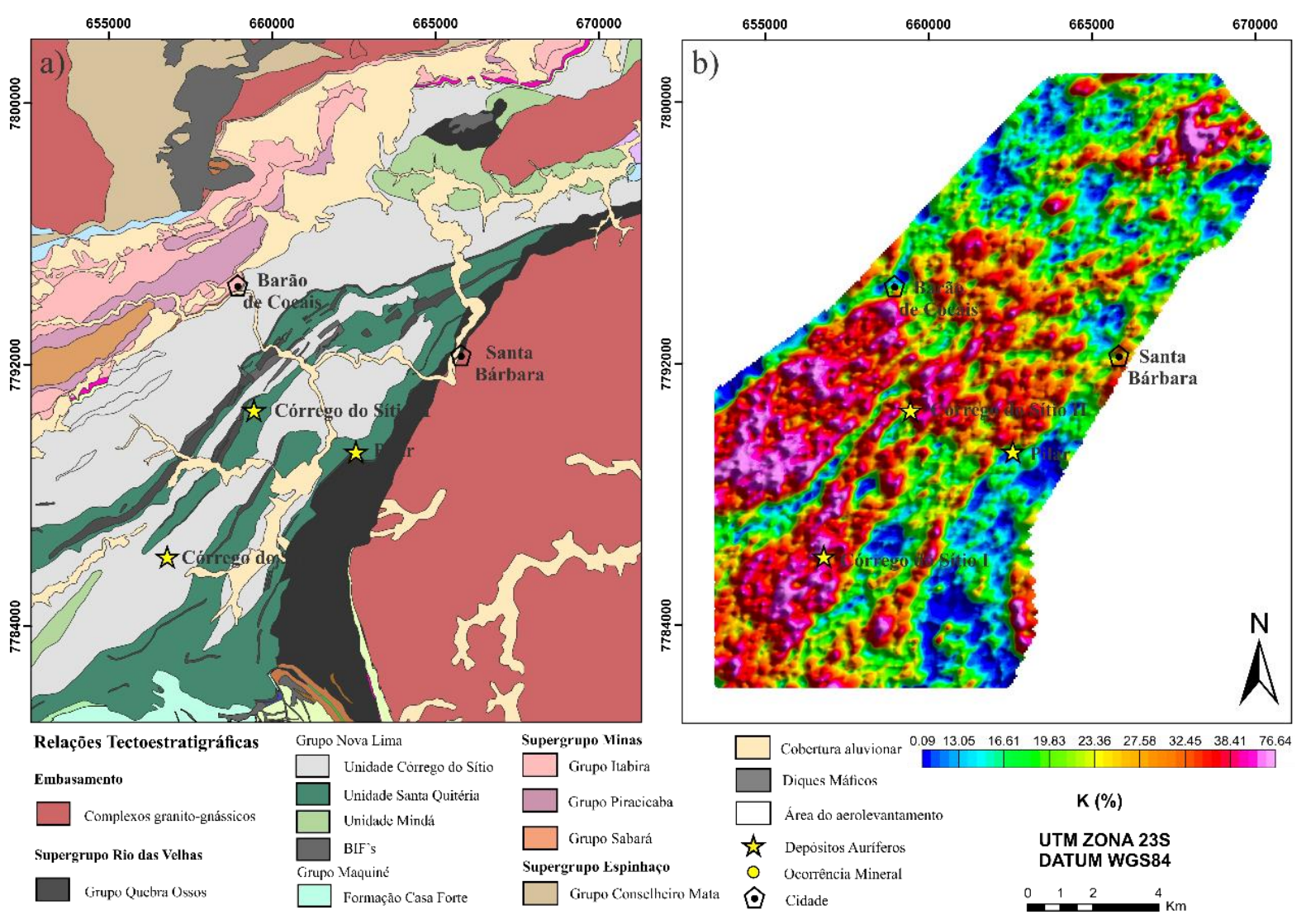

Figura 27: a) Mapa da geologia da área de estudo (CPRM). b) Mapa do canal do potássio.

O mapa ternário RGB dos dados gamaespectrométricos (Fig. 28-b) mostra uma boa correlação com as litologias da região de estudo e com a topografia. O granito Peti, na parte nordeste do aerolevantamento apresenta uma alta contagem (cor branca) para os três elementos em seu centro e alta concentração de eTh em suas bordas, indicando um granitoide bem evoluído. Na parte sudeste, o grupo Quebra Ossos (Fig. 28-a) exibe uma resposta bem definida com baixa contagem (cor preta) para todos os elementos. Já na porção sudoeste, existe uma gradação entre os elementos potássio e urânio (cor rosada), entre as unidades Córrego do Sítio e Santa Quitéria, com maior conteúdo de potássio na unidade Córrego do Sítio e maior concentração de eTh na unidade Santa Quitéria. As baixas concentrações com forma linear e concordantes com a direção dos principais lineamentos da região $\left(\mathrm{N} 45^{\circ} \mathrm{E}\right)$ estão associadas principalmente às BIF's pertencentes a unidade Santa Quitéria. Além disso, ainda existe uma correlação do mapa ternário com o relevo (Fig. 29-a, 30) da região. As drenagens presentes na área são controladas segundo a orientação geral da geologia estrutural e promovem a deposição de material erodido nos baixos topográficos, mascarando o contato entre algumas unidades. Porém, não possuem dimensões relevantes para representarem uma resposta no dado aerogeofísico (Oliveira, 2014). Um represamento é visível na parte nordeste do aerolevantamento como um baixo nos dados. 

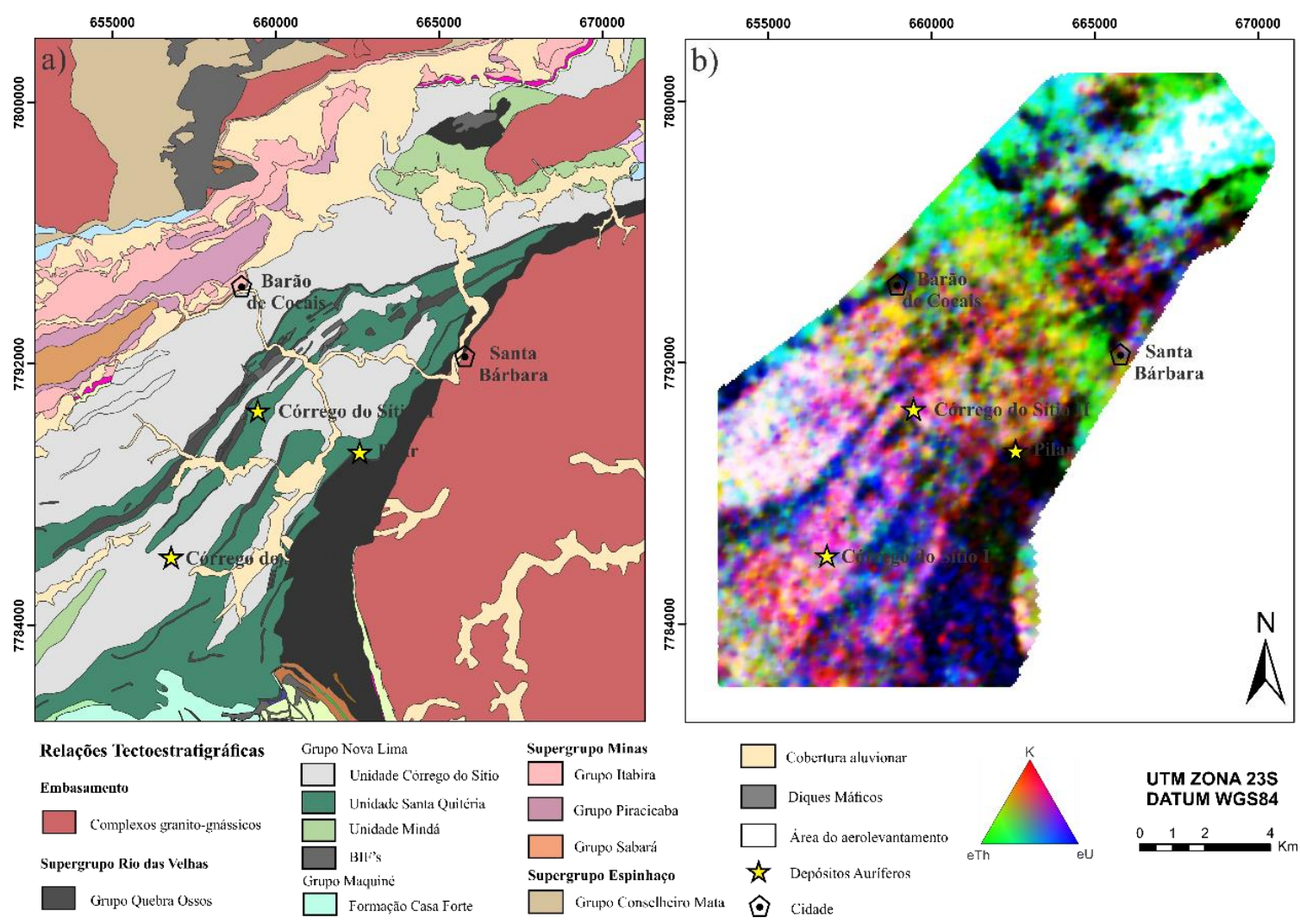

Figura 28: a) Mapa da geologia da área de estudo (CPRM). b) Mapa ternário (RGB) dos elementos eU (azul), eTh (verde) e K (vermelho).
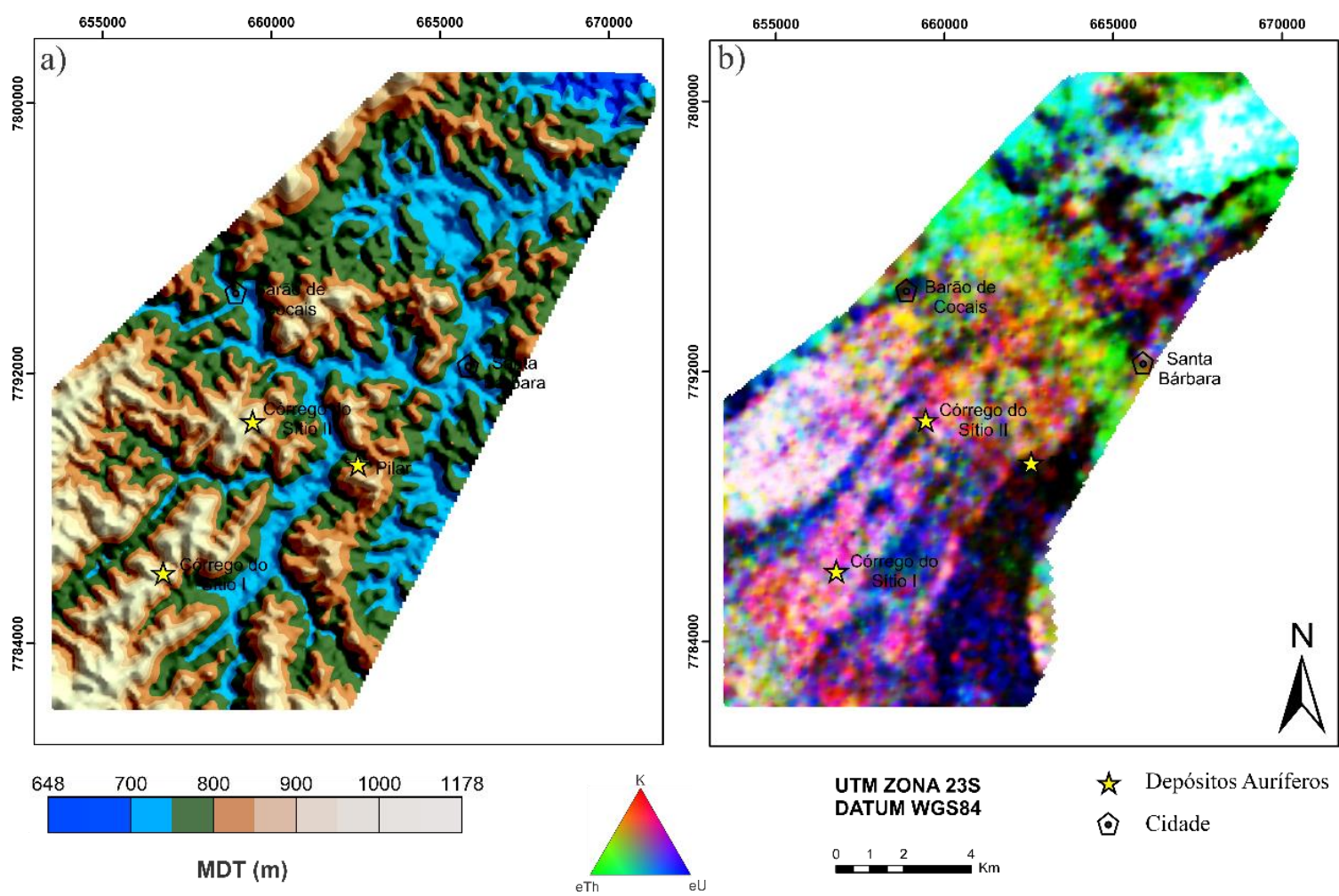

Fig. 29: a) Modelo Digital do Terreno (MDT). b) Mapa ternário dos radioelementos eU, eTh e K da área de estudo. 


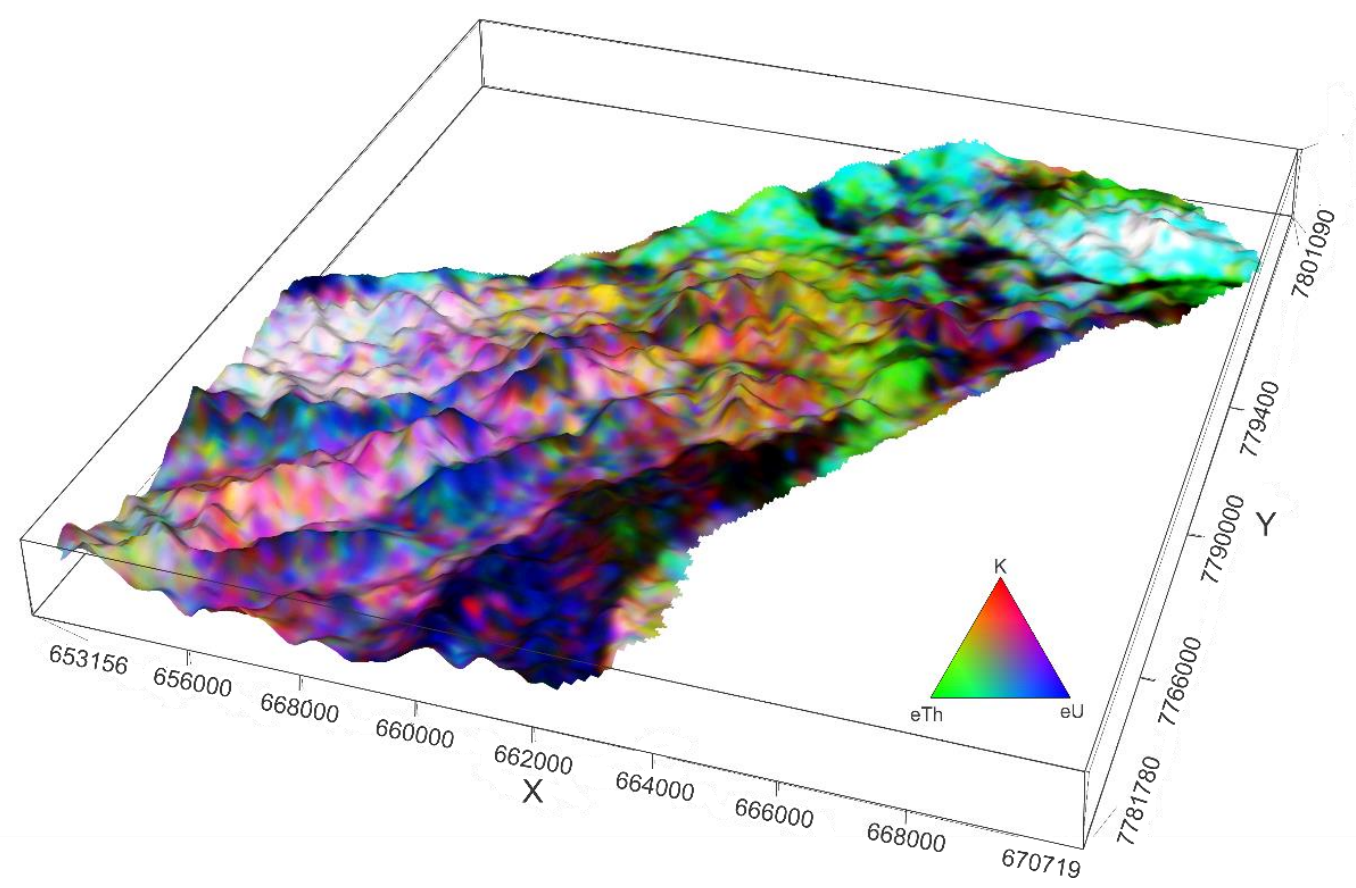

Figura 30: Mapa ternário sobre a topografia (MDT) da área de estudo.

As razões são utilizadas na interpretação dos dados gamaespectrométricos com o objetivo de realçar o enriquecimento ou empobrecimento de um canal em relação ao outro. Isso facilita a visualização da contribuição relativa dos radioelementos. Esta técnica pode auxiliar na identificação de regiões com forte alteração hidrotermal do tipo potássica ou sílica (dois tipos de alteração com maior concentração do elemento potássio, Ribeiro et al., 2013). O hidrotermalismo provoca mudanças nos minerais acessórios hospedeiros dos radioelementos de acordo com seu comportamento químico. O conteúdo de eTh sofre alteração em menor grau em relação ao K e eU. Portanto, as anomalias nos mapas das razões entre os canais, pode indicar áreas alteradas por hidrotermalismo, onde podem ocorrer associações com processos hidrotermais relacionados aos depósitos auríferos.

O mapa da razão entre os elementos eTh e K (Fig. 31-a) apresenta faixas de anomalias (altos: alta concentração de eTh e baixa concentração de K) e lineares na região SW da área de estudo, provavelmente geradas pelas BIF's da Unidade Santa Quitéria (Fig. 31-c). Já os baixos de K estão concentradas na Unidade Córrego do Sítio. Na porção mais ao Norte existem altos que apontam para maiores concentrações de eTh em relação ao K, possivelmente devido aos corpos graníticos presentes, como o granito Peti e mais a NW está relacionado ao formações ferríferas dos Itabiritos da Formação Cauê.

Já a técnica do Fator F (Gnojek \& Prichysta, 1985) é também utilizada para a identificação de zonas de ocorrência de alteração hidrotermal, devido à maior facilidade de 
movimentação do K e eU em relação ao eTh, ocasionando no acúmulo e enriquecimento desses elementos através dos fluidos hidrotermais em determinadas regiões. O mapa do Fator F (Fig. 31-b) se mostrou mais efetivo no reconhecimento de regiões com possíveis halos de alteração hidrotermal já que mostra intensas anomalias (altos) na parte SW da área de estudo, localizadas principalmente na Unidade Córrego do Sítio (Fig. 31-c). As ocorrências de ouro mostradas nos mapas estão, em sua maioria, concentradas nas Unidades Córrego do Sítio e Santa Quitéria. Na Unidade Córrego do Sítio o ouro está relacionado principalmente a processos como remobilização metamórfica dos fluidos hidrotermais que resultou na mineralização do ouro em veios de quartzo (Oliveira, 2014). Segundo CPRM (1996), os corpos de minério associados a veios de quartzo estão intimamente relacionados a alteração hidrotermal ao longo de antigas e extensas zonas de cisalhamento dúctil, como por exemplo, o lineamento São Vicente. Já na Unidade Santa Quitéria o ouro está associado a sulfetação, tipo de alteração hidrotermal que resultou na acumulação de ouro associado, predominantemente a pirita, arsenopirita e calcopirita nas BIF's. 

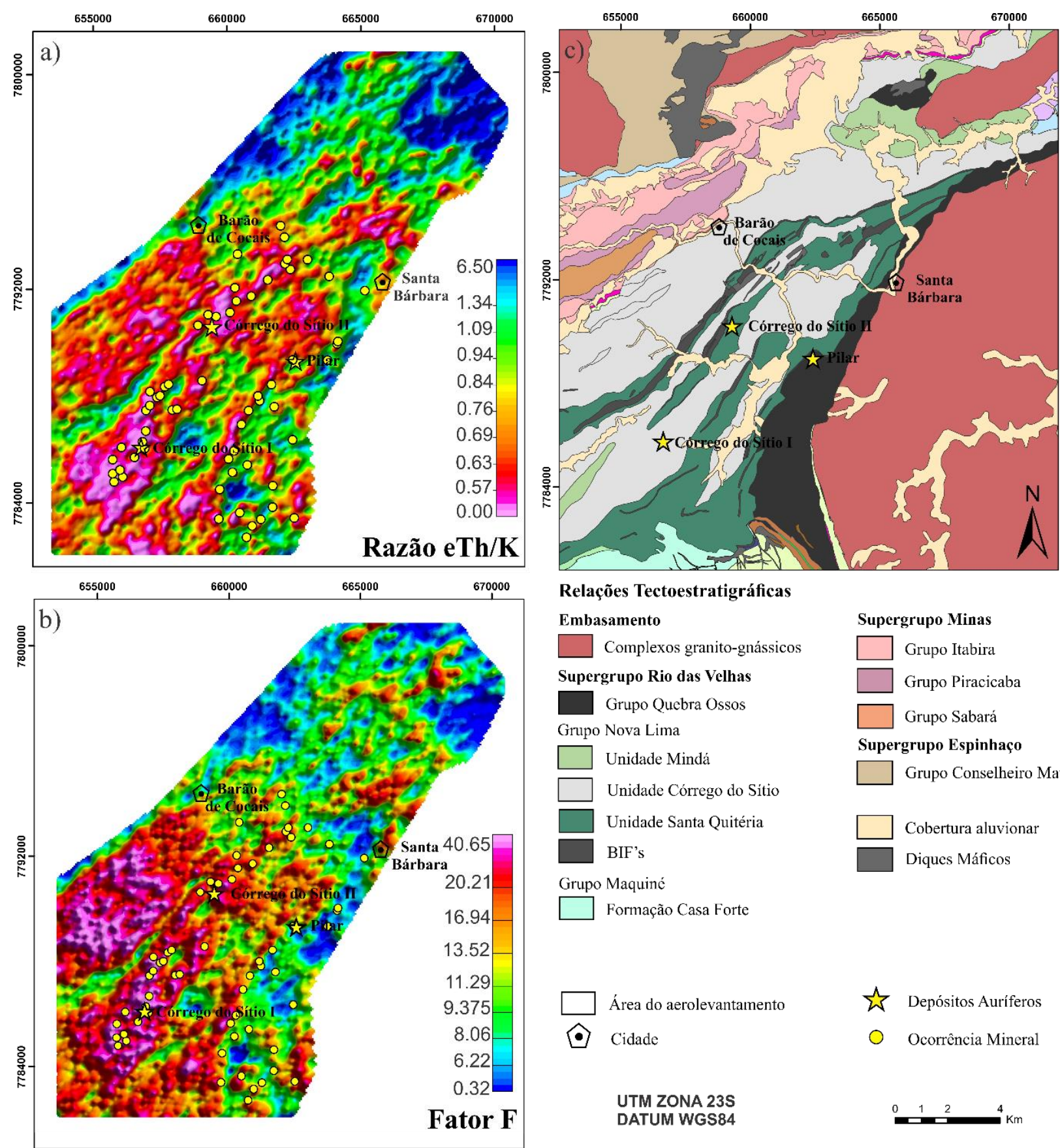

\section{Relações Tectoestratigráficas}

Embasamento

$\square$ Complexos granito-gnássicos

Supergrupo Rio das Velhas

$\square$ Grupo Quebra Ossos

Grupo Nova Lima

$\square$ Unidade Mindá

$\square$ Unidade Córrego do Sitio

Unidade Santa Quitéria

BIF's

Grupo Maquiné

Formação Casa Forte



UTM ZONA 23S

DATUM WGS84
Supergrupo Minas

$\square$ Grupo Itabira

$\square$ Grupo Piracicaba

Grupo Sabará

Supergrupo Espinhaço

$\square$ Grupo Conselheiro Mata

$\square$ Cobertura aluvionar

Diques Máficos

¿ Depósitos Auríferos

Ocorrência Mineral

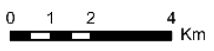

Figura 31: a) Mapa da razão entre eTh e K. b) Mapa do Fator F. c) Geologia da região de estudo (CPRM). 


\subsection{HTEM}

Os dados de HTEM foram interpolados utilizando o software Oasis Montaj (Seequent). Para uma melhor visualização dos corpos condutores presentes em superfície os resultados são apresentados em três canais diferentes: early, intermediate e late times (Fig. 32, 33, e 34). Espera-se que maiores amplitudes no tempo do campo magnético secundário estejam correlacionadas com zonas de maior condutividade elétrica, considerando que a atenuação das correntes induzidas ocorre em intervalos de tempo maiores no interior de corpos condutores, do que em relação ao ambiente resistivo.

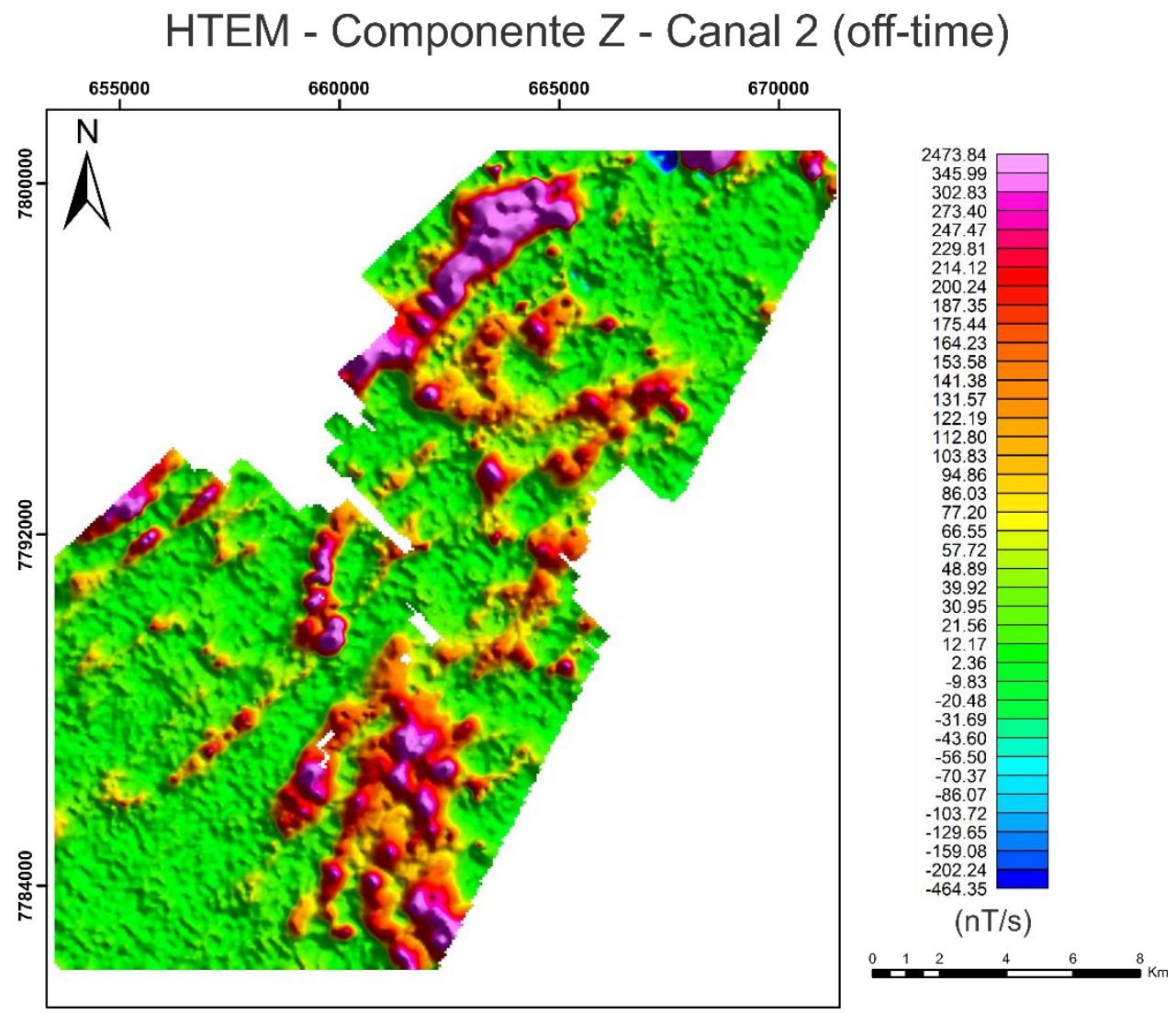

Figura 32: Resultado dos dados HTEM para o canal 2 (early times). 


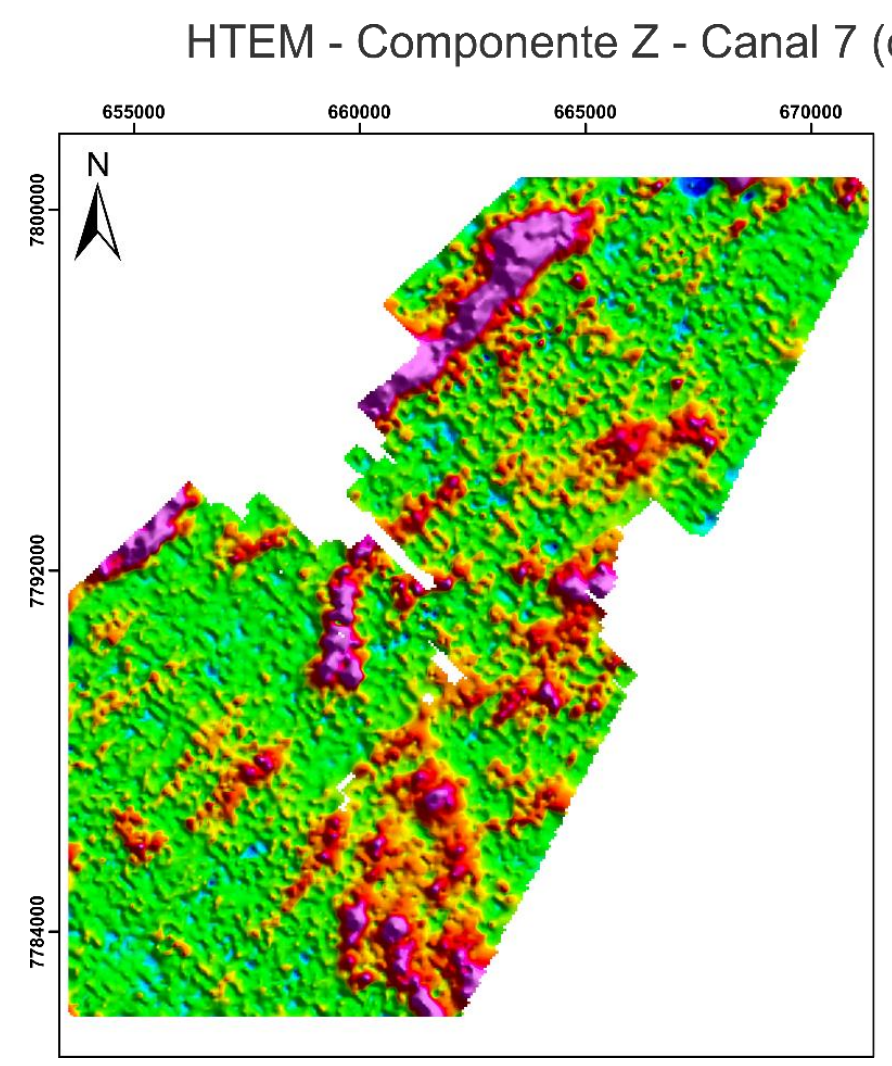

off-time)

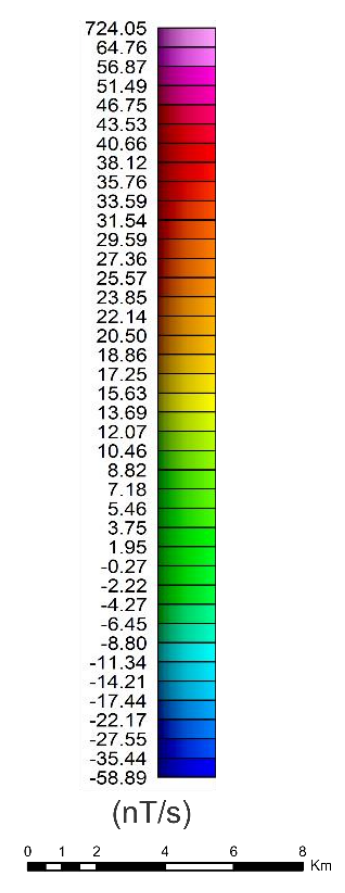

Figura 33: Resultado dos dados HTEM para o canal 7 (intermediate times).

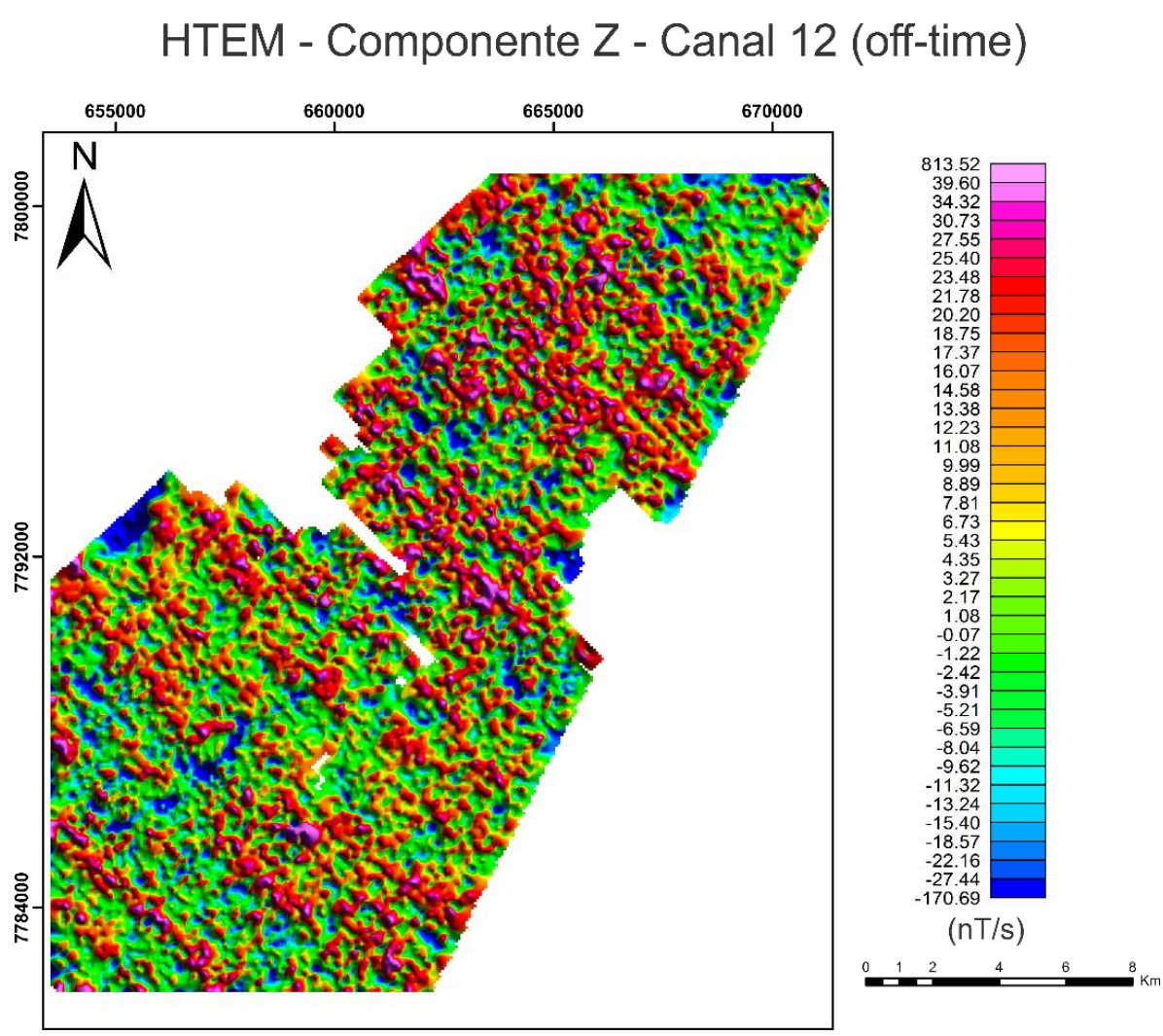

Figura 34: Resultado dos dados HTEM para o canal 12 (late times). 
Nas figuras acima, podem ser observadas diversas anomalias, principalmente nos canais 2 e 7. Na resposta "off-time", fracos condutores produzem grandes respostas nos "early times" que rapidamente decaem para zero. Já bons condutores produzem respostas de maior intensidade nos "intermediate/late times" com um decaimento mais lento (i.e., maiores valores de amplitude para $\mathrm{dB} / \mathrm{dt}$ ). Portanto, bons condutores tendem a produzir anomalias com maior amplitude nos canais de amostragem do sistema TDEM (Allard, 2007). A partir do canal 12, a razão sinal-ruído possui valores demasiadamente altos, inviabilizando, portanto, os late times para o processo de modelagem dos dados.

Assim como nos mapas de magnetometria e gamaespectrometria, os canais 2 e 7 (HTEM) (Fig. 35-b) também apresentam uma tendência linear das anomalias em algumas regiões, coerentes com o trend estrutural principal NE-SW. Anomalias de alta amplitude na parte SW do aerolevantamento estão alinhadas segundo a direção $\mathrm{N} 45^{\circ} \mathrm{E}$ e podem estar associadas ao processo de sulfetação metálica nas BIF’s da associação Clástico-Química (Fig. 35-a). Na porção NE as anomalias ainda seguem o mesmo trend, indicando uma possível continuação destes lineamentos. As litologias presentes na área de estudo não apresentam resposta eletromagnética significativa, com exceção de duas, (1) a associação ClásticoQuímica que possui sulfetos metálicos em sua composição (majoritariamente, pirita, arsenopirita, calcopirita e pirrotita), tornando-a mais condutiva, e (2) das rochas do grupo Quebra Ossos que exibe uma resposta moderada, provavelmente devido a serpentinização das rochas ultramáficas existentes. As intensas anomalias nas porções Norte e NW dos dados está possivelmente relacionada aos itabiritos da formação Cauê, um dos depósitos de ferro mais importantes do QF (Oliveira, 2014). 


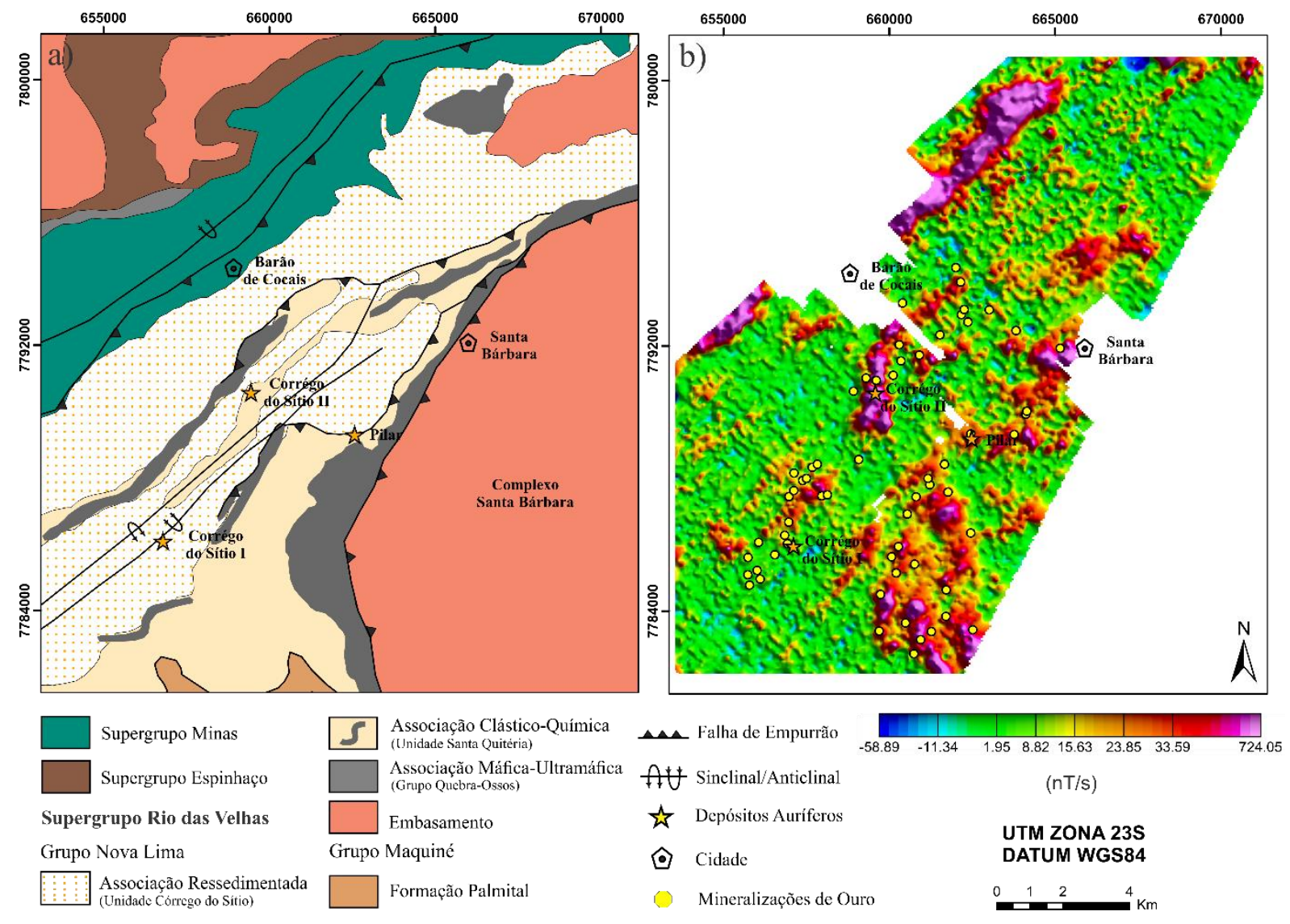

Figura 35: a) Geologia da área de estudo (Adaptado de Lobato et al., 2001b). b) Canal 7 (offtime) dos dados HTEM. 
Todas as questões e parâmetros mencionados anteriormente foram levados em consideração para a escolha das anomalias a serem modeladas. Devido à baixa razão sinal/ruído, a modelagem foi realizada com enfoque na componente $Z$, enquanto a componente $\mathrm{X}$ foi utilizada como um guia da posição e geometria do condutor. Porém, quando possível, em alguns casos, a componente $\mathrm{X}$ também foi modelada. A componente $\mathrm{X}$ pode ser, na maioria dos casos, difícil de modelar, pois é mais sensível as perturbações e ruídos da aquisição do que a componente Z. Portanto, para os propósitos desta pesquisa, será dada maior importância na interpretação e ajuste da componente Z. Selecionou-se anomalias com maior condutância para modelagem, conforme discutido no capítulo 5.3, pois maiores concentrações de ouro podem estar associadas à maiores zonas de concentração de sulfetos metálicos e, portanto, podem apresentar maiores valores de condutância. A Figura 36, abaixo, apresenta as anomalias que foram selecionadas para modelagem, destacada pelos retângulos em preto.
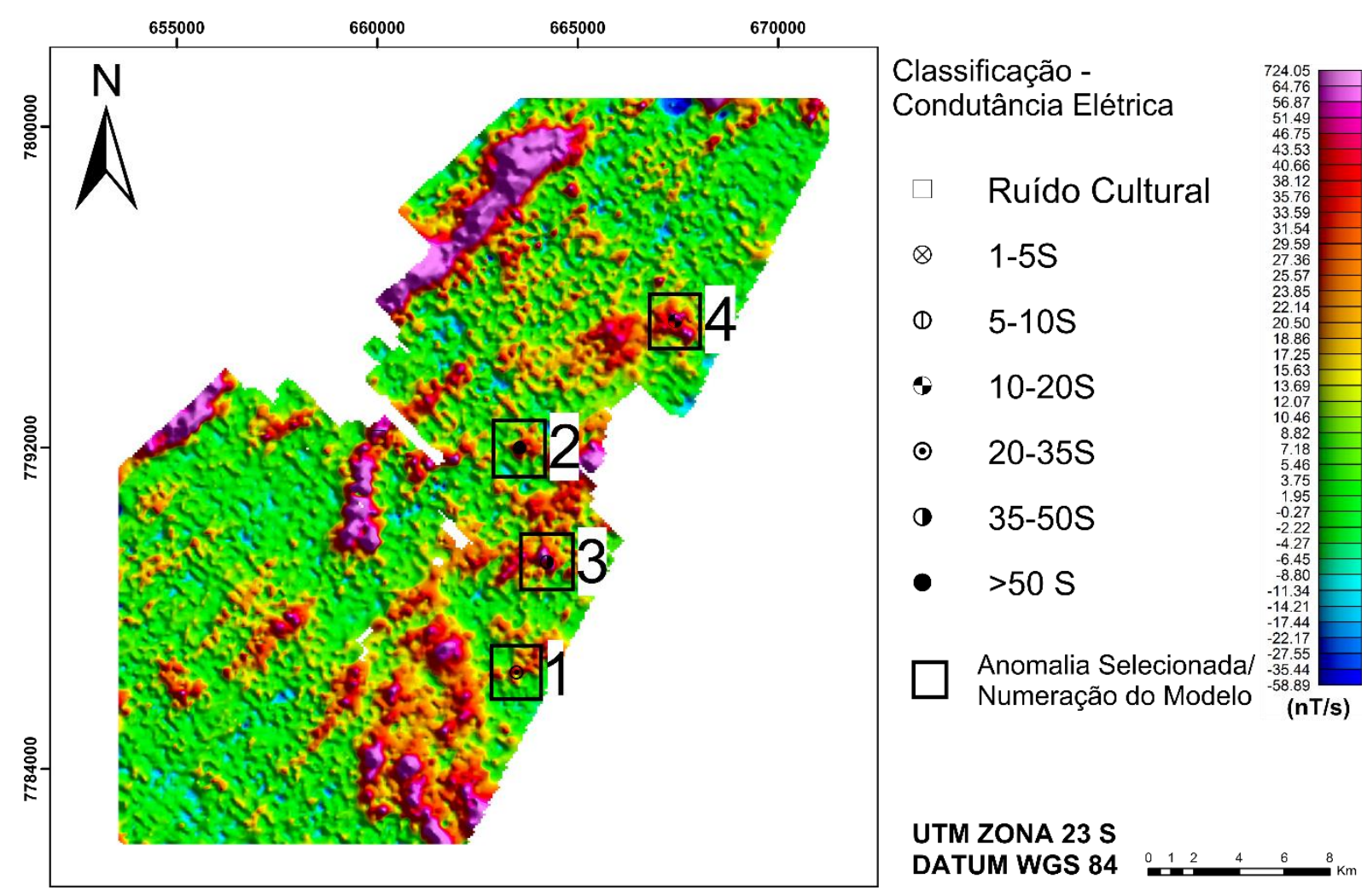

UTM ZONA $23 \mathrm{~S}$

DATUM WGS 84

Figura 36: Anomalias selecionas nos dados HTEM - Canal 7 (off-time) para modelagem destacadas pelo retângulo em preto. 


\section{Modelo 1}

O modelo 1 da anomalia da linha de voo (L30400) está localizado na parte sudeste do aerolevantamento. Sua forma caracteriza uma fonte retangular e sub-vetical e a polaridade inversa da componente $\mathrm{X}$ indica uma placa espessa. A amplitude da anomalia é moderada (150 nT/s) e segundo a geologia da região, a anomalia está situada em uma zona de contato entre o Grupo Quebra Ossos e o complexo Santa Bárbara. Foram modeladas as componentes Z e X (Fig. 37) dos canais 4 a 9 (off-time) que representam os "intermediate times". Foi obtido um bom ajuste entre o dado observado (curvas em preto) e o dado modelado (curvas em vermelho) para ambas as componentes. De acordo com os dados da ANM a área já foi requisitada para pesquisa. A Figura 38 apresenta uma visão 3D do modelo e os parâmetros da placa são resumidos na Tabela 4.
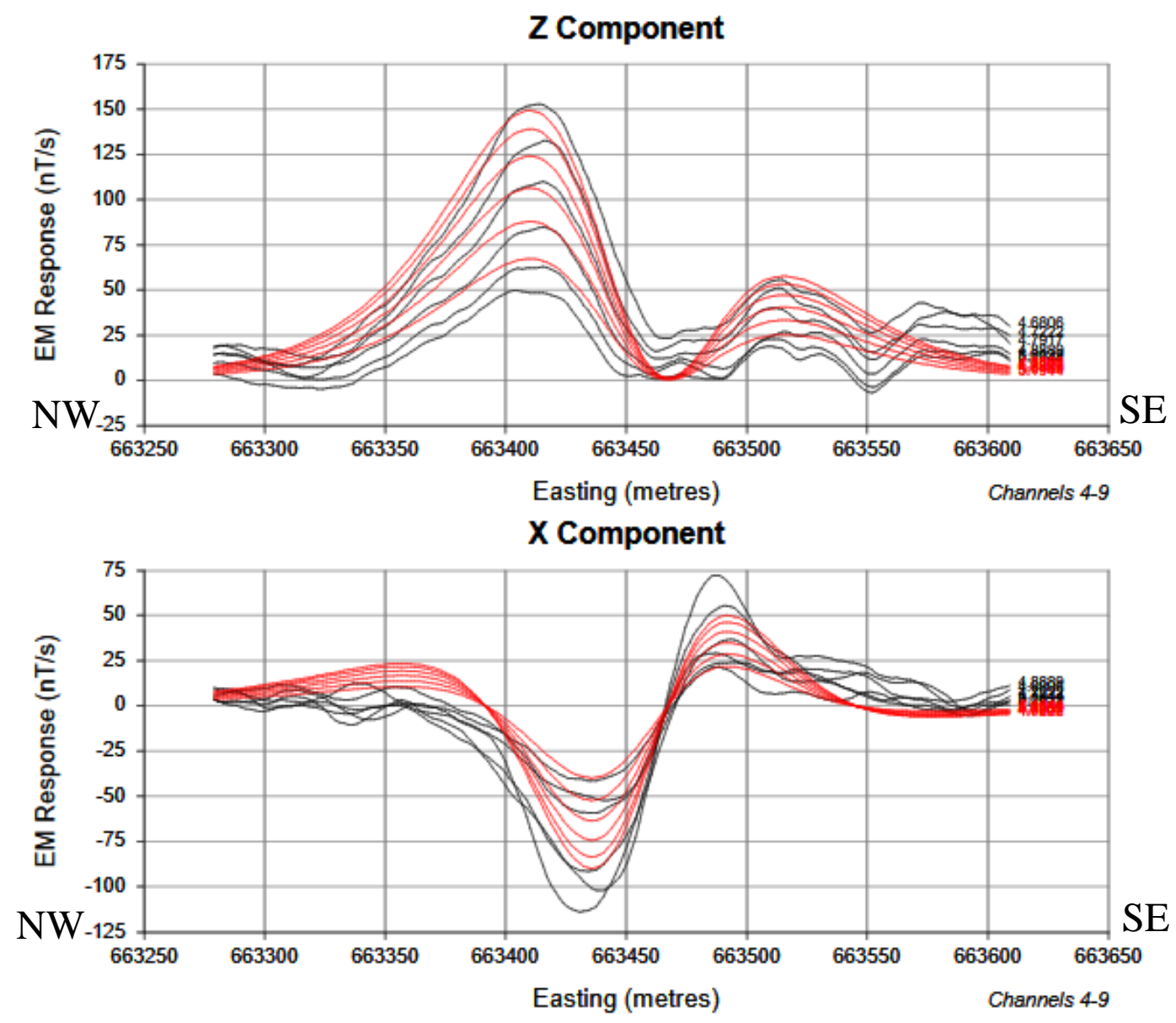

Figura 37: Resultado da modelagem para as componentes Z e X para os canais 4-9 (off-time). 

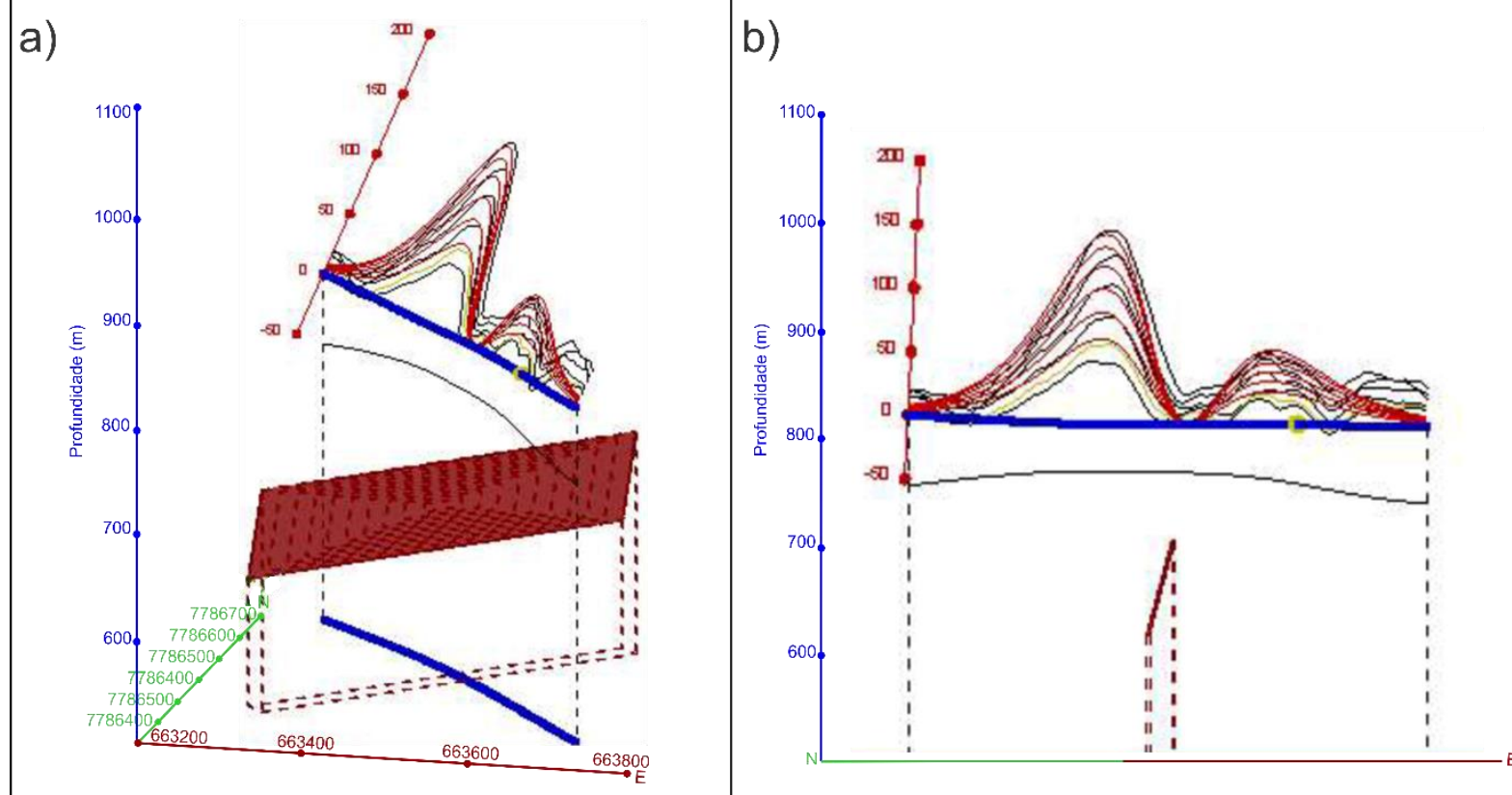

Figura 38: Resultados da modelagem da componente Z para os canais 4 a 9 (off-time). a) visão tridimensional do modelo. b) visão NW-SE do modelo.

Tabela 4: Parâmetros do modelo 1.

\begin{tabular}{|c|c|c|c|c|c|c|c|c|}
\hline $\mathbf{X}(\mathbf{m})$ & $\mathbf{Y ~ ( m )}$ & Depth(m) & DD $\left(^{\circ}\right)$ & D $\left(^{\circ}\right)$ & SL (m) & DE(m) & Th (m) & $\boldsymbol{\sigma}(\mathbf{S} / \mathbf{m})$ \\
\hline 663445 & 7786390 & $-63,5$ & 315 & 75 & 400 & 92 & 3 & 20 \\
\hline
\end{tabular}

O modelo de placa apresenta strike $\mathrm{N} 45^{\circ} \mathrm{E}$ e mergulho de $75^{\circ} \mathrm{NW}$. Possui dimensões de 400x92 m, espessura de $3 \mathrm{~m}$ e está a aproximadamente $63,5 \mathrm{~m}$ de profundidade. A placa modelada mergulha na direção NW, discordante com a direção SE apresentada por Lobato et al. (2001b). No entanto, segundo Canale (1999) existem relatos de inversões de mergulho de estruturas, como no caso dos depósitos Grota Funda, Rosalino, Lajeado, Cachorro Bravo, Crista, Candeia e Cristina (minas do Complexo Córrego do Sítio). As estruturas primárias do acamamento S0 foram sobrepostas por uma xistosidade regional com orientação de $100^{\circ}$ 120\%45-55NE, com inversões localizadas para NW, devido ao evento deformacional D1.

A região onde encontra-se o modelo, entre o Grupo Quebra Ossos e o complexo Santa Bárbara, está associada a um alto no mapa da razão eTh/K (Fig. 31-a) indicando uma maior concentração de eTh em relação ao conteúdo de K, característico de BIF’s (Oliveira, 2014). O 
eTh possui afinidade com óxidos de ferro o que pode explicar a maior condutividade $(20 \mathrm{~S} / \mathrm{m})$ da placa em relação aos demais modelos. No mapa da fase do ASA 3D (Fig. 25-b) é possível identificar a zona de cisalhamento Água Quente (Dorr, 1969), conforme discutido no capítulo 6.1, que separa o Grupo Quebra Ossos do Complexo Santa Bárbara. Este sistema constitui uma série de falhas ramificadas com direções N-S, E-W e NW-SE. O Sistema de Falhas Água Quente apresenta importantes mineralizações de ouro muito exploradas no passado, tanto em veios de quartzo como em formações ferríferas (Ferreira Filho \& Fonseca, 2001). Logo, esta estrutura e suas ramificações podem ser a hospedeiras deste modelo de mineralização.

De acordo com Lobato et al. (2001b), depósitos de ouro em rochas máficas e ultramáficas são menores em relação a outros tipos de depósito no QF e são representados pelos depósitos Santana (desativado) e Juca Vieira. Cisalhamento dúctil e alteração hidrotermal são características desses tipos de depósitos. O depósito de Juca Vieira localizado na porção norte do QF está inserido em rochas vulcânicas máficas e ultramáficas subordinadas, com intercalações de xistos carbonáceos e BIF's. A mineralização é estruturalmente controlada por uma zona de cisalhamento dúctil (NNW-SE) e é hospedada em veios quartzo-carbonato-sulfeto \pm albita. Os parâmetros geométricos apresentados para os corpos de minério por (Vial et al., 2007) são espessuras que variam de 2 a 40 m e continuidade de pelo menos 400 m na direção do mergulho nos eixos de dobras.

Segundo os dados da CPRM as mineralizações próximas a anomalia estão relacionadas a processos metamórficos hidrotermais. O ouro está associado à pirita e óxidos de ferro e hospedado em veios de quartzo ou BIF's. As rochas encaixantes são BIF's, veios de quartzo, xistos, serpentinitos ou quartizitos ferruginosos.

Portanto, a geometria deste modelo concorda com o controle estrutural proposto por Lobato et al. (2001b) e os parâmetros geométricos proposto por Vial et al. (2007) e Ferreira Filho \& Fonseca (2001). 


\section{Modelo 2}

A anomalia 2 (linha de voo L30560) encontra-se na parte central do aerolevantamento e está inserida na associação ressedimentada. Segundo os dados dos processos minérios da ANM (Sigmine), a região já foi concedida para lavra. A anomalia possui amplitude considerável (com pico da ordem de $325 \mathrm{nT} / \mathrm{s}$ ), caracteriza uma fonte retangular e sub-vertical. A Figura 39 apresenta o resultado da modelagem para as componentes $\mathrm{Z}$ e X dos canais 5-10 (off-time). Com apenas uma placa, foi possível obter um bom ajuste para componente Z. Já para componente X, levando em consideração a baixa razão sinal/ruído, o ajuste foi razoável.
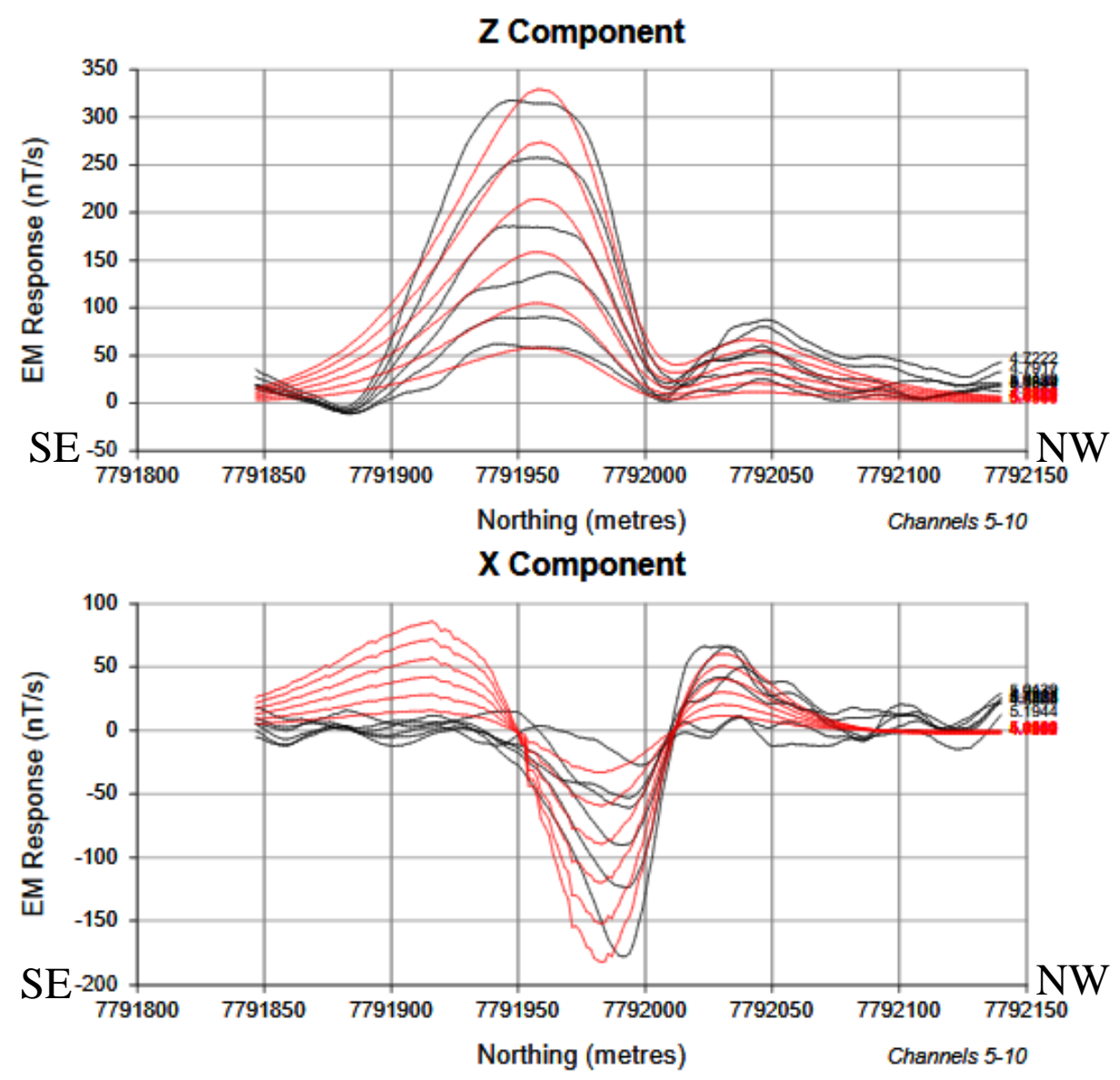

Figura 39: Resultado da modelagem para as componentes Z e X para os canais 4-10 (off-time).

A placa resultante da modelagem (Fig.40) possui atitude (Tab. 5) de N31 ${ }^{\circ} \mathrm{E} / 43^{\circ} \mathrm{SE}$ e está localizada a cerca de $35 \mathrm{~m}$ de profundidade. Apresenta dimensões de aproximadamente $153 \times 157 \mathrm{~m}$ e $11 \mathrm{~m}$ de espessura. Sua condutividade ajustada é baixa, sendo de $3.2 \mathrm{~S} / \mathrm{m}$. 


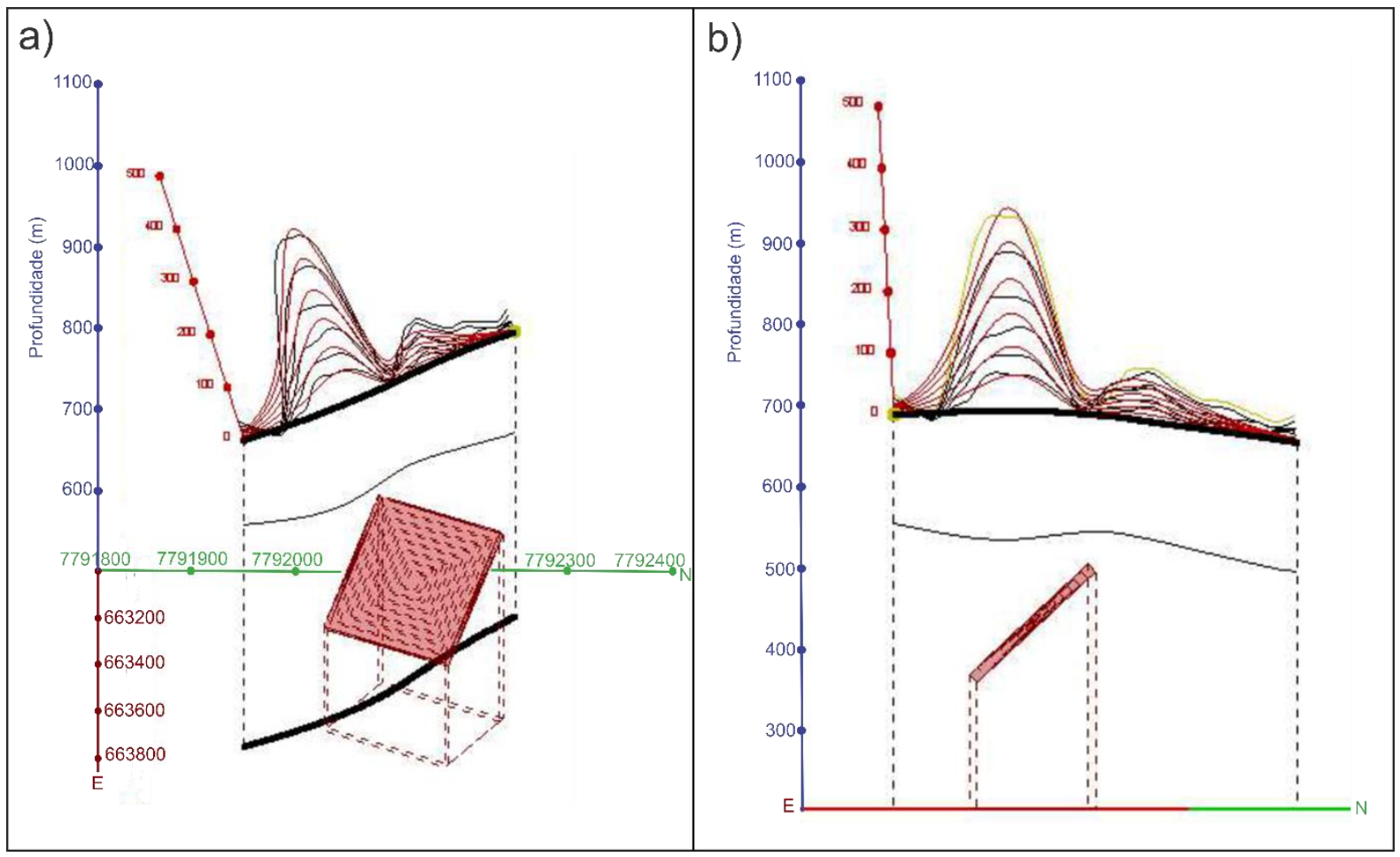

Figura 40: Resultados da modelagem da componente Z para os canais 4 a 10 (off-time). a) visão tridimensional do modelo. b) visão NW-SE do modelo.

Tabela 5: Parâmetros do modelo 2.

\begin{tabular}{|c|c|c|c|c|c|c|c|c|c|}
\hline Placa & $\mathbf{X}(\mathbf{m})$ & $\mathbf{Y}(\mathbf{m})$ & $\mathbf{D e p t h}(\mathbf{m})$ & $\mathbf{D D}\left(^{\circ}\right)$ & $\mathbf{D}\left({ }^{\circ}\right)$ & $\mathbf{S L}(\mathbf{m})$ & $\mathbf{D E}(\mathbf{m})$ & $\mathbf{T h}(\mathbf{m})$ & $\boldsymbol{\sigma}(\mathbf{S} / \mathbf{m})$ \\
\hline H1 & 663615 & 7792030 & -35.2 & 121 & 43 & 153 & 157.2 & 11 & 3.2 \\
\hline
\end{tabular}

A região onde encontra-se o modelo apresenta anomalia associada ao enriquecimento de potássio de acordo com os mapas da razão eTh/K (Fig. 31-a) e Fator F (Fig. 31-b), indicando que no local pode ter ocorrido o processo de alteração hidrotermal do tipo potássica. Já o mapa de magnetometria (TMI) (Fig. 24-b) apresenta resposta de intensidade moderada de magnetização.

A anomalia está inserida na associação ressedimentada (Unidade Córrego do Sítio). Nesta unidade, segundo Canale (1999) e Lima (2012) as mineralizações, em sua maioria, estão relacionadas a concentração metálica em veios de quartzo-carbonato-sulfetos ( \pm sufossais). As mineralizações são alongadas subparalelamente ao strike das rochas encaixantes e encontramse disseminadas nos sulfetos. São estruturalmente controladas por zonas de cisalhamento com direção em média de $\mathrm{N} 30-50^{\circ} \mathrm{E}$ e mergulho de $60-75^{\circ}$ para SE. Os parâmetros geométricos 
propostos para os corpos de minério são espessura de até 10 m, 50 a 250 m de largura e 100 a $1.200 \mathrm{~m}$ de comprimento. A associação ressedimentada é basicamente composta por filitos e xistos micáceos/carbonosos com mineralogia constituída predominantemente por clorita, quartzo e mica branca, minerais resistivos (Telford, 1990) o que contribui para a baixa condutividade do modelo.

\section{Modelo 3}

As anomalias do modelo 3 (linha de voo L30500), com quase $2 \mathrm{~km}$ de comprimento, encontram-se na parte sudeste do aerolevantamento e estão inseridas no contato entre três litologias diferentes: a associação Clástico Química, o Grupo Quebra Ossos e o complexo Santa Bárbara. As anomalias possuem amplitudes variadas e caracterizam uma série de fontes retangulares, sub-verticais e finas. A linha de voo possui nível de ruído relativamente alto, especialmente como apresentado na componente X (Fig. 41), provavelmente devido ao terreno acidentado da área de estudo e consequente dificuldade de estabilização da aeronave e também devido a geologia complexa da área. Segundo as informações da ANM a região está sob dois polígonos de concessão: requerimento de pesquisa e concessão de lavra. Foram modelados os canais 4-7 para as componentes $\mathrm{Z}$ e X (off-time). 

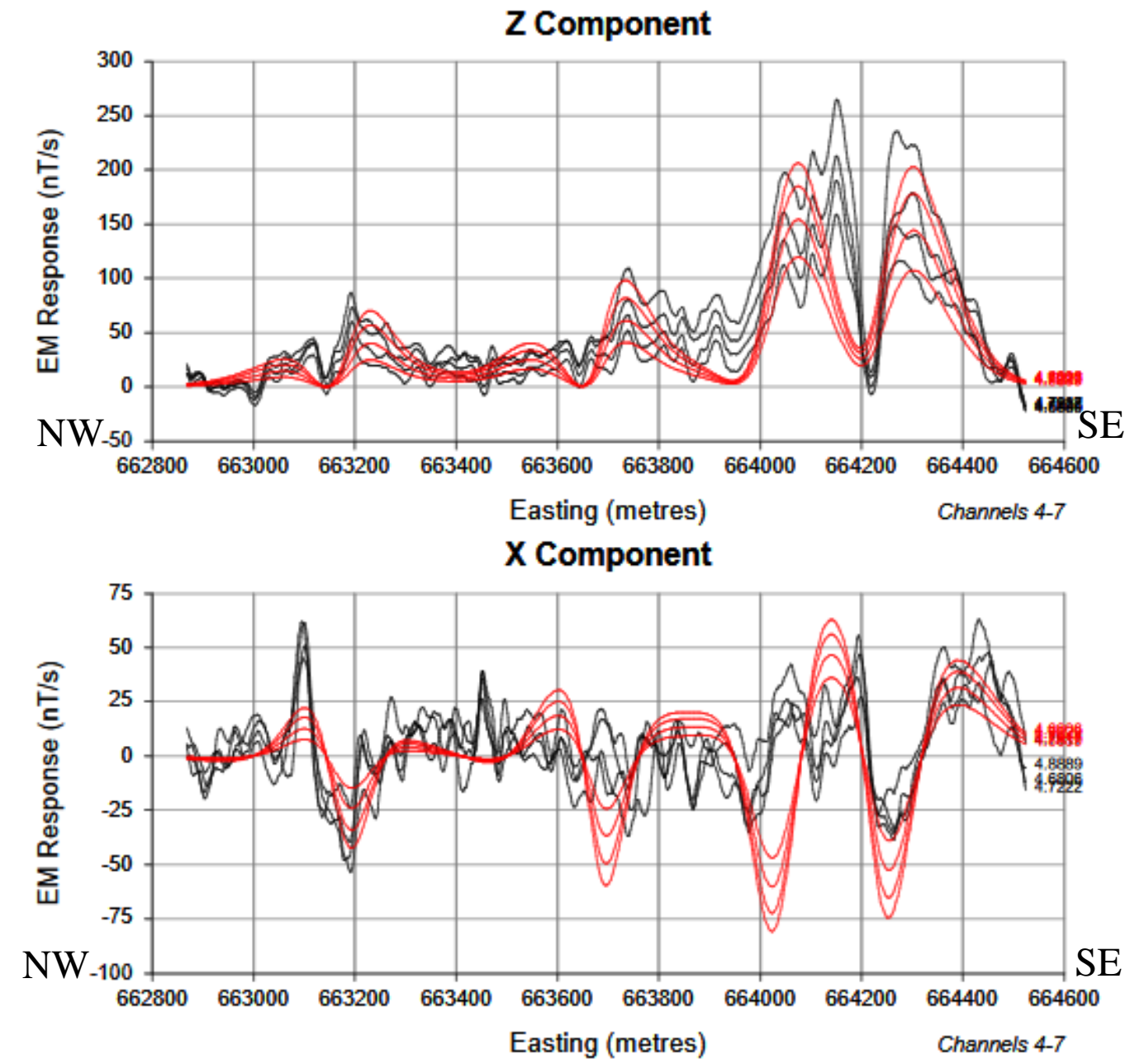

Figura 41: Resultado da modelagem para as componentes Z e X para os canais 4-7 (off-time). 


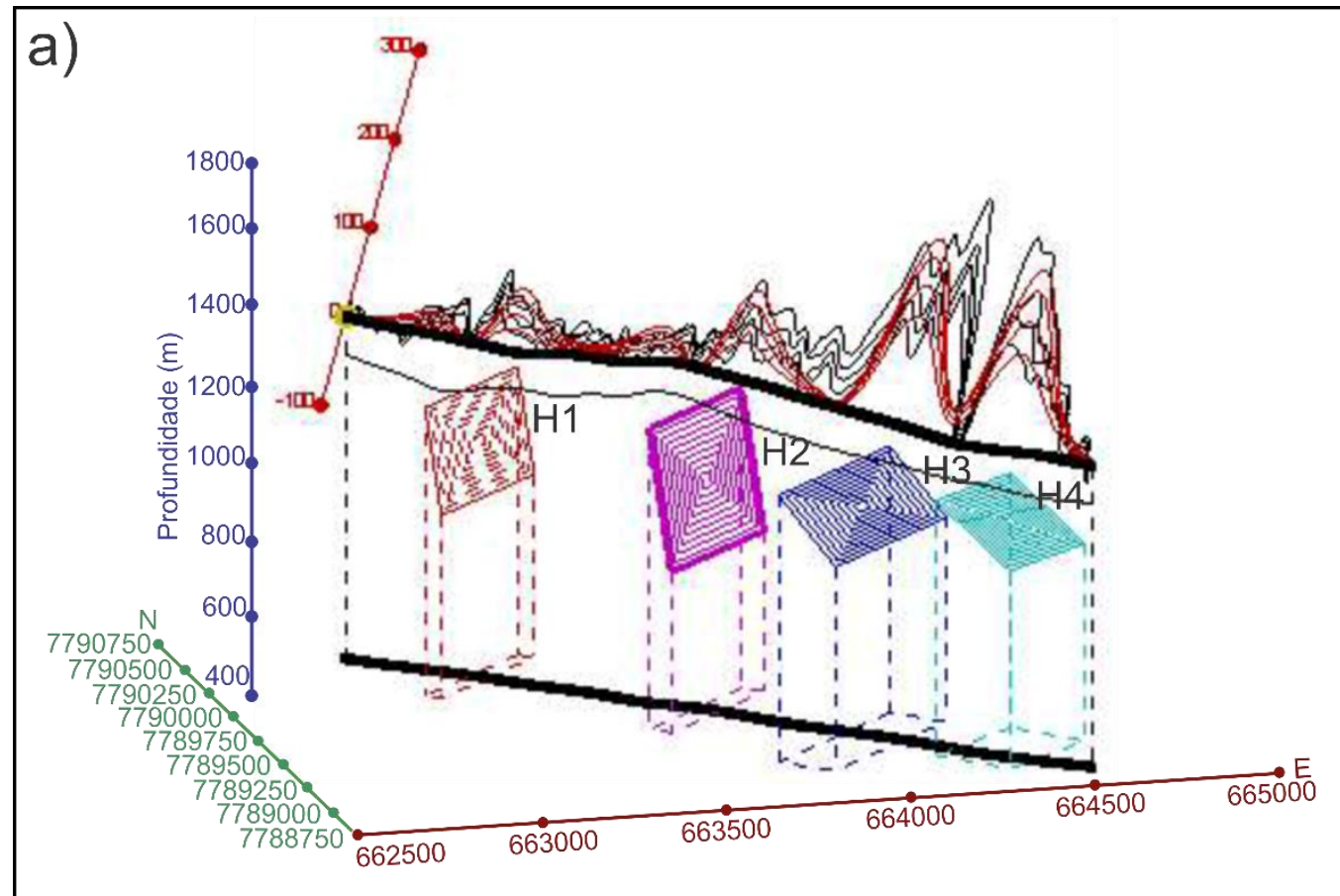

b)

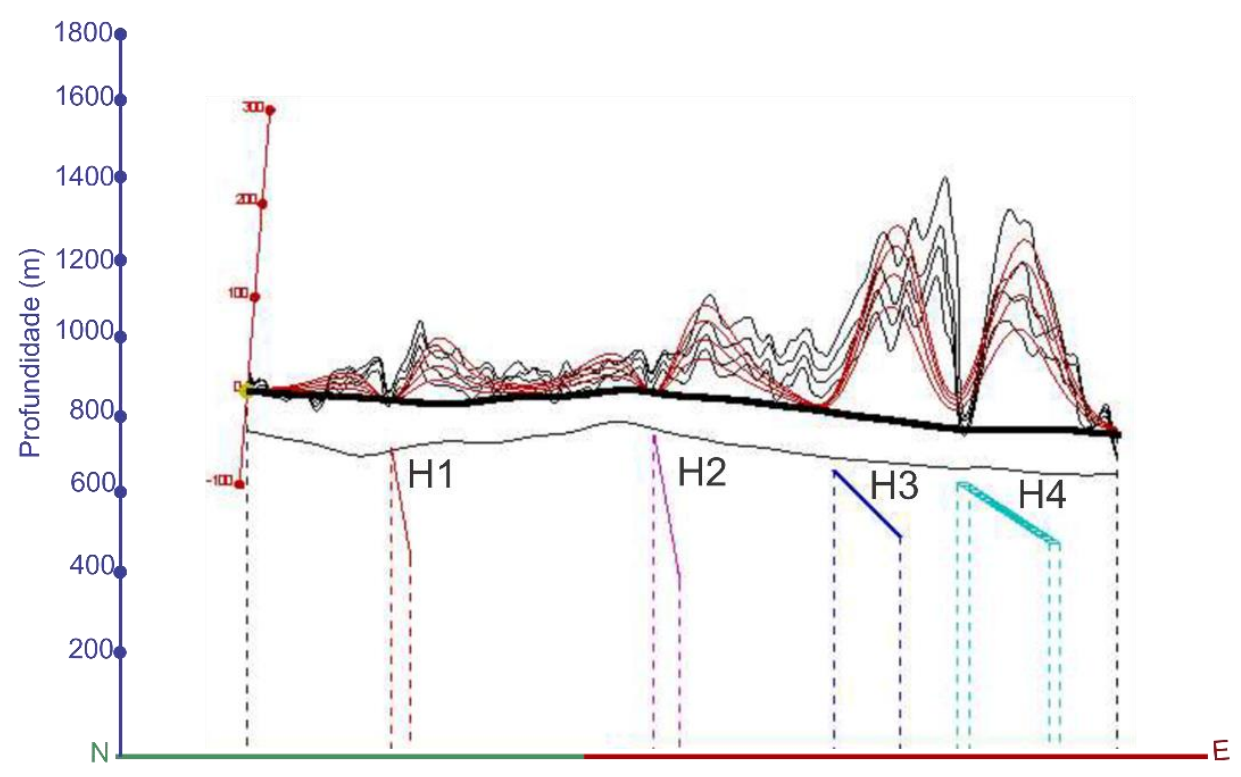

Figura 42: Resultados da modelagem da componente $\mathrm{Z}$ para os canais 4 a 7 (off-time). a) visão tridimensional do modelo. b) visão NW-SE do modelo.

Tabela 6: Parâmetros modelo 3.

\begin{tabular}{|c|c|c|c|c|c|c|c|c|}
\hline Placa & $\mathbf{X}(\mathbf{m})$ & $\mathbf{Y}(\mathbf{m})$ & Depth(m) & DD( $\left.{ }^{\circ}\right)$ & $\mathbf{D}\left(^{\circ}\right)$ & SL(m) & DE(m) & CT (S) \\
\hline H1 & 663150 & 7790240 & 8.4 & 135 & 80 & 500 & 300 & 6 \\
\hline H2 & 663645 & 7789745 & -16 & 135 & 80 & 500 & 400 & 6 \\
\hline H3 & 663930 & 7789355 & -33.5 & 135 & 45 & 600 & 250 & 13 \\
\hline H4 & 664282 & 7789220 & -41 & 140 & 33 & 350 & 291 & 11 \\
\hline
\end{tabular}


O modelo 3 (Fig. 42), resultante das anomalias da linha de voo (L30500), apresenta 4 placas sub-verticais finas. As placas estão orientadas na mesma direção $\mathrm{N} 45^{\circ} \mathrm{E}$, concordando com a direção geral das principais estruturas da região proposta por Lobato et al. (2001b) e Silva (2007) e possuem mergulhos com diferentes valores (Tab. 6). Possuem dimensões e profundidades próximas, cerca de 500x300 m e 30 m, respectivamente. A condutância dos modelos é baixa, em média cerca de $10 \mathrm{~S}$. A anomalia resultante da placa H4 (amplitude de $225 \mathrm{nT} / \mathrm{s}$ ) é a que obteve melhor ajuste ao dado real e também a que possui menor nível de ruído. As demais anomalias possuem um nível de ruído considerado alto, o que dificultou o processo de modelagem.

O condutor H4 está localizado entre o grupo Quebra Ossos e o complexo Santa Bárbara. Para essa região, o mapa da eTh/K (Fig. 31-a) mostra um alto associado ao eTh, resposta característica para o tipo de litologia da região (associação com BIF’s). Já o mapa do Fator F (Fig. 31-b) apresenta uma anomalia moderada para área. O condutor modelado está localizado sob à zona de cisalhamento Água Quente, como visto no mapa do TILT (Fig. 25-b), dessa forma, esta estrutura pode ter funcionado como o controle estrutural para essa possível mineralização.

Esse condutor está a cerca de 1,5 km do depósito Pilar. Segundo Silva (2007) o padrão estrutural da região do depósito Pilar é caracterizado regionalmente, por um sinforme de estilo fechado e isoclinal, relativo ao evento deformacional D1 (Capítulo 2.2) e superposta por uma zona de cisalhamento de empurrão, com planos axiais orientados para NE-SW, com a direção variando entre $20^{\circ}$ e $50^{\circ}$, mergulhos variáveis para SE e espessamento da charneira. A lineação do eixo da dobra é um dos principais controles estruturais da mineralização aurífera. O principal estilo é stratabound que ocorre preferencialmente na BIF, e é relacionado à presença de veios quartzo-carbonáticos e bandas de sulfetos maciços posicionados em zonas tabulares e confinadas, preferencialmente nos contatos entre bandas e nas charneiras das dobras deste litotipo. Os parâmetros estruturais/geométricos para os corpos mineralizados são alongamento segundo a foliação principal S1, padrão anastomosado, espessura entre 2 e $5 \mathrm{~m}$, podendo alcançar até $10 \mathrm{~m}$ em zonas de espessamento. Segundo Vial et al. (2007) os corpos de minério podem chegar a até $600 \mathrm{~m}$ de comprimento na direção do mergulho. Outro tipo de mineralização ocorre em zonas de cisalhamento orientadas segundo a direção NE-SW com mergulhos para SE, com instalação de veios de quartzo-carbonato-sulfeto, hospedados em xistos máficos (Lima, 2012). 


\section{Modelo 4}

A anomalia do modelo 4 (linha de voo L30770), possui cerca de $700 \mathrm{~m}$ de comprimento ao longo da linha de voo, está localizada na parte nordeste do aerolevantamento em uma região com poucas mineralizações mapeadas. A anomalia possui amplitude de $250 \mathrm{nT} / \mathrm{s}$, sua forma caracteriza placas sub-verticais e finas e está inserida no contato Associação Clástico-Química, o Grupo Quebra Ossos. Foram modelados os canais 4-8 (off-time) das componentes Z e X. O modelo foi construído priorizando o ajuste da anomalia com maior amplitude na componente Z. O ajuste (Fig. 43) foi considerável, porém, mais oeste da linha de voo, o dado está contaminado com bastante ruído, provavelmente devido a geologia complexa da região.
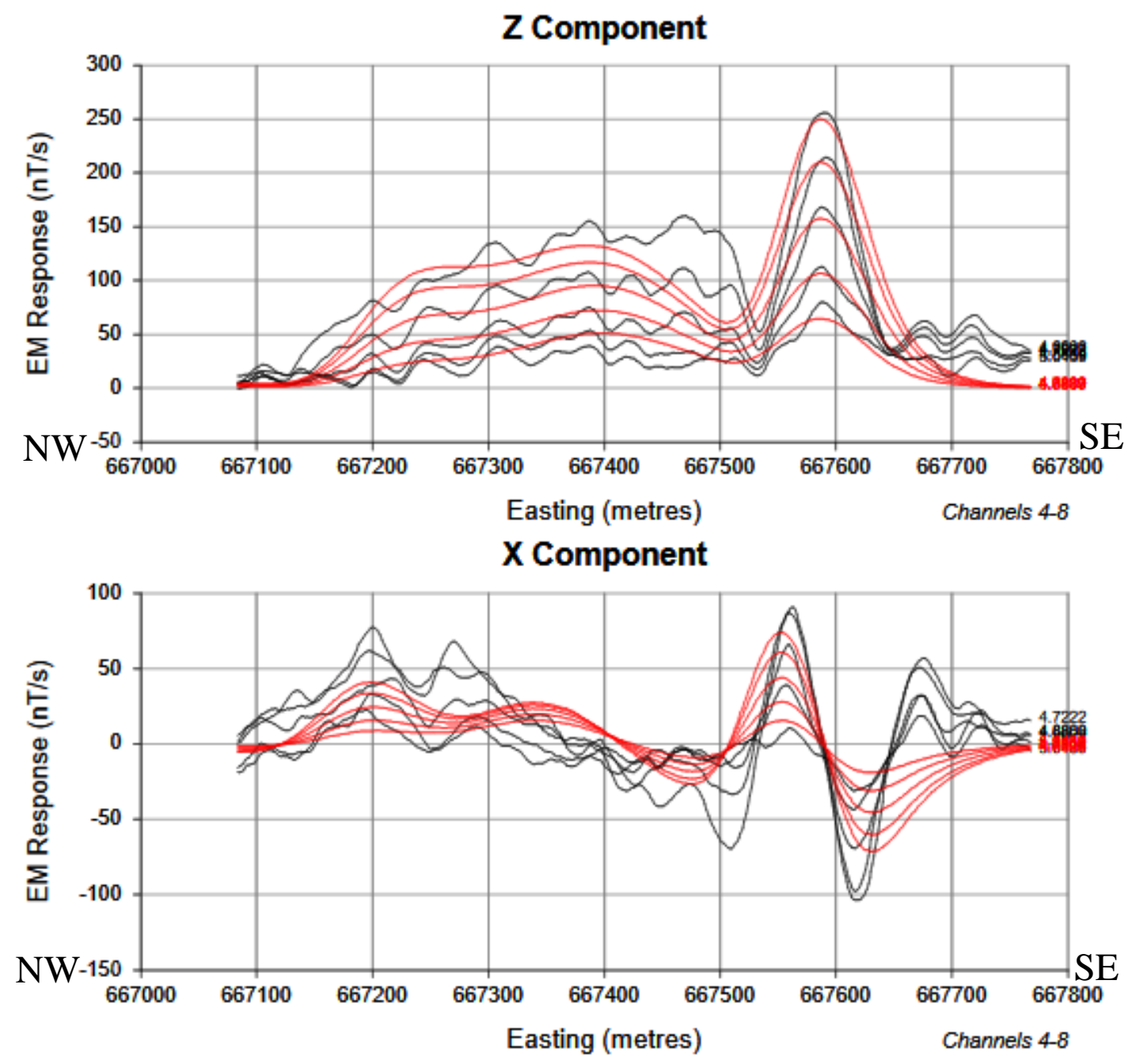

Figura 43: Resultado da modelagem para os canais 4-8 (off-time) das componentes Z e X. 


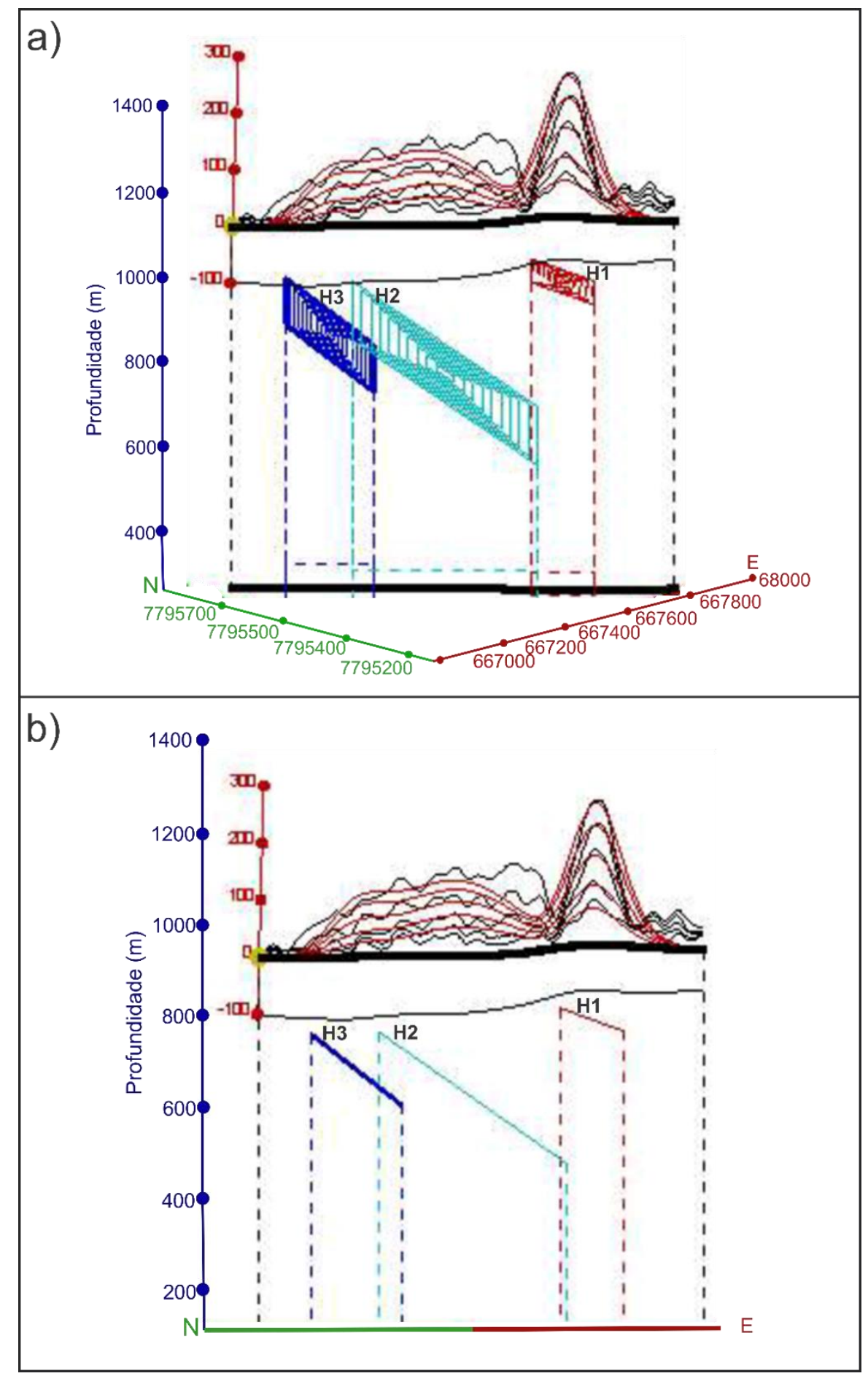

Figura 44: Resultados da modelagem da componente $\mathrm{Z}$ para os canais 4 a 8 (off-time). a) visão tridimensional do modelo. b) visão NW-SE do modelo. 
Tabela 7: Parâmetros do modelo 4.

\begin{tabular}{|c|c|c|c|c|c|c|c|c|}
\hline Placa & $\mathbf{X}(\mathbf{m})$ & $\mathbf{Y}(\mathbf{m})$ & $\mathbf{D e p t h}(\mathbf{m})$ & $\mathbf{D D}\left(^{\circ}\right)$ & $\mathbf{D}\left(^{\circ}\right)$ & $\mathbf{S L}(\mathbf{m})$ & $\mathbf{D E}(\mathbf{m})$ & $\mathbf{C T}(\mathbf{S})$ \\
\hline $\mathbf{H 1}$ & 667575 & 7795388 & -27.4 & 135 & 20 & 200 & 150 & 15 \\
\hline $\mathbf{H 2}$ & 667200 & 7795570 & -35.3 & 135 & 35 & 500 & 500 & 8 \\
\hline $\mathbf{H 3}$ & 667165 & 7795745 & -36.5 & 135 & 38 & 400 & 250 & 8 \\
\hline
\end{tabular}

A anomalia com maior amplitude foi modelada utilizando uma placa fina (Tab. 7, H1), semi-vertical, com cerca de $27 \mathrm{~m}$ de profundidade, orientada na direção $\mathrm{N} 45^{\circ} \mathrm{E}$ e mergulho de $20^{\circ} \mathrm{SE}$, dimensões de $200 \times 150 \mathrm{~m}$ e condutância de $15 \mathrm{~S}$, produzindo um bom ajuste para a anomalia.

A região da placa H1 está sob um alto no mapa da razão eTh/K (Fig. 31-a) e possui uma resposta moderada no mapa do Fator F (Fig. 31-b). Além disso, o mapa da geologia local (Fig. 7) indica que o condutor está posicionado sob uma BIF, que apresenta forte resposta magnética, como visto no mapa do TILT (Fig. 25-b).

Nesta região não há mineralizações mapeadas, no entanto, segundo os dados da ANM, a área já foi requisitada para pesquisa. Os depósitos relacionados ao lineamento Córrego do Sítio e a Associação Clástico-Química estão inseridos em uma sequência homoclinal com orientação de $\mathrm{N} 30^{\circ}$ para $40 / 45^{\circ} \mathrm{E}$ para $55^{\circ} \mathrm{SE}$ e são hospedados em BIF's fortemente magnéticas, como no caso do depósito São Bento (BIF São Bento, Pereira et al., 2007). O mapa TMI (Fig. 24-b) marca uma anomalia dipolar assim como as anomalias na região do complexo de minas Córrego do Sítio geradas por BIF's magnéticas, o que indica que a mineralização deste modelo pode estar hospedada em uma BIF. 


\section{Discussões}

O QF possui um grande potencial aurífero com depósitos, desde pequenos aos de classe mundial, relacionados a diferentes tipos de rochas hospedeiras. As maiores mineralizações estão hospedadas nas BIF's e em rochas hidrotermalizadas ("Lapa Seca"). No entanto, os depósitos relacionados aos veios de quartzo também representam uma parcela significativa na exploração de ouro. A geologia complexa da região, produto do intenso histórico de eventos deformacionais e metamórficos, fez do QF um desafio a ser explorado com métodos geofísicos, em vista de limitações e ambiguidades inerentes aos métodos.

$\mathrm{O}$ aspecto mais importante deste trabalho foi utilizar o conjunto de dados aéreos HTEM do Projeto Rio das Velhas - Etapa 2 (CPRM, 2012) para modelagem dos depósitos auríferos da região entre Barão de Cocais e Santa Bárbara, no QF, e assim definir suas geometrias, propriedades físicas e parâmetros estruturais. Além disso, os resultados encontrados com os métodos: magnético, gamaespectrométrico e eletromagnético no domínio do tempo, integrados, ajudaram a delinear um conjunto de assinaturas geofísicas que podem auxiliar em futuras campanhas de exploração e prospecção de ouro, no QF e em terrenos do tipo Greenstone Belt.

$\mathrm{Na}$ região de estudo, os dados magnéticos mostraram intensas anomalias lineares regionais, orientadas na direção NE-SW, especialmente na região de Santa Bárbara, que seguem a direção das principais zonas de cisalhamento propostas na literatura por Lobato et al. (2001b). Os dados magnéticos, como visto no mapa do ASA 3D (Fig. 25-a), são dominados pelo efeito das BIF's intensamente magnéticas da associação Clástico-Química e relacionadas aos depósitos de ouro das minas Córrego do Sítio II (antiga São Bento) e Pilar. O mapa do TILT (Fig. 26-b) definiu estes lineamentos que representam zonas de cisalhamento preenchidas por BIF's hospedeiras dos depósitos de ouro, os quais são conhecidos como Cristina, Córrego do Sítio e São Bento-Donana (Lima, 2012). Ainda foi possível identificar o alinhamento Brumal (Oliveira, 2015) e a zona de cisalhamento Água Quente (Dorr, 1969), que são estruturas hospedeiras de importantes depósitos auríferos.

Os dados de gamaespectrometria auxiliaram no reconhecimento de regiões onde pode ter ocorrido o processo de alteração hidrotermal e consequente enriquecimento de K. O mapa da eTh/K (Fig. 31-a) mostrou altos lineares com direção NE-SW onde existe maior conteúdo de eTh em relação ao K, como no caso das BIF's da associação Clástico-Química, visto que o 
eTh possui afinidade com óxidos de ferro, como hematita e magnetita que compõem as BIF's. O mapa do Fator F (Fig. 31-b) foi mais efetivo na identificação de zonas candidatas à alteração hidrotermal, já que destacou anomalias que indicam enriquecimento de $\mathrm{K}$, sugerindo remobilização do elemento. As anomalias de K que formam os halos de alteração hidrotermal estão concentradas principalmente na associação ressedimentada, onde depósitos relacionados a veios de quartzo, como Córrego do Sítio I, estão hospedados. De acordo com CPRM (1996), mineralizações hospedadas em veios de quartzo estão intimamente ligadas a alteração hidrotermal ao longo das zonas de cisalhamento. Siricitização, carbonatação e sulfetação são os tipos de alteração hidrotermal associados a mineralizações em veios de quartzo (Lima, 2012). As mineralizações mapeadas na região estão alinhadas a esses halos de alteração, sobretudo na parte NW da área de estudo.

Embora os dados eletromagnéticos aéreos não terem apresentado uma boa razão sinal/ruído em grandes porções da área de estudo, muito provavelmente devido a geologia complexa da região e estruturas metálicas/construções, principalmente associadas à infraestrutura das minas em funcionamento, foi possível extrair importantes informações para intepretação dos mesmos. Os dados do canal 7 - HTEM (Fig. 35) revelaram condutores, sobretudo, associados a associação Clástico-Química (Unidade Santa Quitéria), devido ao conteúdo de sulfetos (pirrotita, arsenopirita e pirita) das BIF's (Pereira et al., 2007). As anomalias condutivas seguem um trend linear com orientação geral de NE-SW e também são associadas as mineralizações das minas existentes na região. Além disso, existem condutores associados ao Grupo Quebra Ossos devido à serpentinização das rochas ultramáficas, que as tornaram mais condutivas, e nos itabiritos da formação Cauê.

Os dados do canal 7 (off-time) HTEM foram utilizados para modelagem e interpretação qualitativa. Os modelos mostraram, em sua maioria, direções de NE-SW e orientação de $\mathrm{N} 45^{\circ} \mathrm{E} / 20^{\circ}-80^{\circ} \mathrm{SE}$, com reversões para $\mathrm{NW}$, que concordam com as orientações propostas em trabalhos anteriores (Lobato et al., 2001b; Silva, 2007; Lima, 2012) e em mapeamentos geológicos dos depósitos de ouro (CPRM, 1992) na região de estudo.

O modelo 1 (Fig. 38) obteve o melhor ajuste ao dado real em relação aos demais modelos para as componentes $\mathrm{Z}$ e X. A placa foi modelada com orientação $\mathrm{N} 45^{\circ} \mathrm{E}$, de acordo com a orientação das principais estruturas hospedeiras de mineralizações descrita na literatura, como em Lobato et al. (2001b). O mergulho resultante da modelagem para o condutor foi para NW, porém, devido aos diversos eventos deformacionais que ocorreram nas rochas no SGRV é 
possível que inversões no mergulho das camadas ocorram, como discutido em Canale (1999). As mineralizações conhecidas próximas ao modelo estão relacionadas a corpos de minério hospedados em veios de quartzo ou BIF's. De acordo com o mapa da razão eTh/K (Fig. 31-a) existe um alto relacionado ao maior conteúdo de eTh em relação ao K, o que pode caracterizar uma BIF, segundo Oliveira (2014). O condutor está localizado bem próximo à zona de cisalhamento regional Água Quente, como visto no mapa do TILT (Fig. 25-b). Esta estrutura pode ter funcionado como hospedeira para a mineralização desse depósito.

O modelo 2 possui as menores extensões, $153 \times 157 \mathrm{~m}$ e $11 \mathrm{~m}$ de espessura, em relação aos demais modelos, porém apresenta a maior amplitude de $\mathrm{dB} / \mathrm{dt}$ na ordem de $325 \mathrm{nT} / \mathrm{s}$. O condutor está inserido na associação ressedimentada e associado a enriquecimento de $\mathrm{K}$ de acordo com o mapa do Fator F (Fig. 31-b). Segundo Canale (1999) e Lima (2012), as mineralizações em rochas dessa região (unidade Córrego do Sítio) são caracterizadas por enriquecimento de sulfetos em veios de quarto-carbonato-sulfeto. Os sulfetos encontram-se na forma disseminada, sendo a arsenopirita o principal sulfeto, o que pode explicar a baixa condutividade desse modelo $(3.2 \mathrm{~S} / \mathrm{m})$. A orientação do condutor foi modelada com $\mathrm{N} 31^{\circ} \mathrm{E} / 43^{\circ} \mathrm{SE}$, seguindo o trend das principais estruturas da região. Portanto, levando em consideração as dimensões do modelo, o condutor pode estar associado a um modelo de depósito do tipo ouro hospedado em veio de quartzo.

As anomalias do modelo 3, com quase $1700 \mathrm{~m}$ de comprimento ao longo da linha de voo, foram modeladas com 4 placas finas. $\mathrm{O}$ ajuste do modelo ao dado bruto foi considerado razoável para componente $\mathrm{Z}$, dentro do nível de ruído dos dados. Porém, para componente X o ajuste não foi adequado devido ao alto nível de ruído, provavelmente em razão da topografia acidentada da região o que dificulta a estabilização da aeronave e da geologia complexa. As anomalias estão localizadas no contato entre a associação Clástico-Química, o grupo QuebraOssos, sob a zona de cisalhamento Água Quente e foram modeladas com parâmetros estruturais de orientação $\mathrm{N} 45^{\circ} \mathrm{E}$, de acordo com a direção dessa zona de cisalhamento (Dorr, 1969) e mergulhos de $33^{\circ}$ podendo chegar a até $80^{\circ}$ para SE. A placa $\mathrm{H} 4$, com amplitude de $225 \mathrm{nT} / \mathrm{s}$, obteve o melhor ajuste ao dado real. Possui dimensões de 350x291 m, profundidade de $40 \mathrm{~m}$ e $11 \mathrm{~S}$ de condutância. Mineralizações próximas aos condutores modelados, como o depósito de Pilar à cerca de 1,5 km de distância, são hospedadas em BIF’s Silva (2007) e relacionadas a zonas de cisalhamento de mesma orientação. O mapa da eTh/K (Fig. 31-a) mostra um alto de eTh na região das anomalias, o que pode indicar a presença de BIF como discutido no capítulo 
6.2. Uma mineralização mapeada a cerca de $500 \mathrm{~m}$ da anomalia está associada a ouro em BIF. Portanto, especialmente em razão das dimensões e assinaturas geofísicas mencionadas anteriormente, esses condutores podem estar associados a um modelo de mineralização de ouro em BIF.

Por fim, o modelo 4, situado em uma zona de contato entre a associação Clástico Química e o Grupo Quebra Ossos na porção NE da área de estudo, apresentou parâmetros estruturais que concordam com parâmetros estruturais propostos por Pereira et al. (2007) para mineralizações com as mesmas características do condutor, sendo de direção $\mathrm{N}^{\circ} 5^{\circ} \mathrm{E}$ e mergulho de $20^{\circ}$ para SE. De acordo com os dados do mapa do TILT (Fig. 25-b), eTh/K (Fig. 31-a) e da geologia da área de estudo, aliados aos parâmetros encontrados na modelagem, o modelo de mineralização desse condutor pode ser do tipo ouro hospedado em BIF, como no caso do depósito São Bento. Como não existem mineralizações mapeadas nessa região, este modelo oferece um novo alvo para mapeamento e futura exploração.

Os modelos revelaram, em geral, valores de condutância entre 6 e $15 \mathrm{~S}$ e de condutividade entre 3.2 e $20 \mathrm{~S} / \mathrm{m}$. De acordo com Palacky (1991) os ranges de condutividade para as rochas do SGRV são pequenos, o que é uma característica típica de terrenos PréCambrianos. Silva et al. (2003) mostra através de dados AEM no domínio da frequência, que as rochas máficas e ultramáficas do Grupo Quebra Ossos e as rochas da associação ClásticoQuímica são mais condutivas do que as rochas da associação ressedimentada, como pôde ser visto nos dados HTEM e nas modelagens. 


\section{Conclusões e Recomendações}

Esta dissertação de mestrado mostrou que a modelagem $2.5 \mathrm{D}$ de condutores como placas finas ou prismas no software Maxwell, recuperou de forma significativa os parâmetros geométricos, estruturais e físicos das mineralizações. Os resultados encontrados da integração dos três métodos adicionados aos modelos, para a exploração brownfield, forneceram mais conhecimento sobre os depósitos auríferos conhecidos, e podem auxiliar na melhoria da base de informação e planejamento da mina. Já na exploração greenfield, os modelos oferecem parâmetros para novos alvos exploratórios e podem assistir nos testes e furos de sondagem.

Os modelos mais distantes de minas ativas, como as minas do Complexo Córrego do Sítio, apresentaram melhor ajuste, devido ao baixo nível de ruído, fator que facilitou o processo de modelagem. Apesar de ter sido realizada várias tentativas de modelar condutores sob mineralizações conhecidas, não foi possível obter modelos com um bom ajuste devido ao alto nível de ruído das anomalias. Os modelos apresentados nesta pesquisa revelaram baixas condutividades/condutâncias e parâmetros estruturais e geométricos consistentes com as informações disponíveis na literatura.

Os condutores modelados oferecem parâmetros estruturais, geométricos e físicos que podem auxiliar o setor de exploração mineral no reconhecimento de novos alvos para serem investigados. Seguindo o exemplo de Oliveira (2014) e com base nos resultados e discussões apresentados nesta pesquisa, criou-se uma lista de alvos exploratórios a partir da modelagem e interpretação dos condutores. A prioridade de exploração foi dada em função do ajuste dos dados obtido na modelagem e da interpretação geofísica e geológica atribuída aos modelos. 
Tabela 8: Lista dos alvos modelados segundo o contexto geofísico e geológico e prioridade para exploração.

\begin{tabular}{|c|c|c|c|}
\hline Modelo & Contexto Geofísico & Contexto Geológico & Prioridade \\
\hline 1 & $\begin{array}{c}\text { Anomalia EM e magnética } \\
\text { moderada. } \\
\text { Maior conteúdo de Th em relação } \\
\text { ao K. }\end{array}$ & $\begin{array}{c}\text { Associado a rochas } \\
\text { vulcânicas máficas e } \\
\text { ultramáficas. } \\
\text { Próximo a zona de } \\
\text { cisalhamento Água Quente } \\
\text { (NE/SW). }\end{array}$ & 1 \\
\hline 2 & $\begin{array}{c}\text { Anomalia EM forte e } \\
\text { magnetização moderada. } \\
\text { Enriquecimento potássico. }\end{array}$ & $\begin{array}{l}\text { Rochas metassedimenares e } \\
\text { metamórficas da associação } \\
\text { Ressedimentada. }\end{array}$ & 2 \\
\hline 3 & $\begin{array}{c}\text { Anomalia EM moderada e } \\
\text { associação com lineamento } \\
\text { magnético. } \\
\text { Maior conteúdo de Th em relação } \\
\text { ao K. }\end{array}$ & $\begin{array}{c}\text { Contato entre o Grupo } \\
\text { Quebra Ossos e o complexo } \\
\text { Santa Bárbara. } \\
\text { Zona de cisalhamento Água } \\
\text { Quente (NE/SW). }\end{array}$ & 2 \\
\hline 4 & $\begin{array}{c}\text { Anomalia EM moderada, } \\
\text { associação com lineamento } \\
\text { magnético e maior conteúdo de Th } \\
\text { em relação ao K. }\end{array}$ & $\begin{array}{c}\text { Contato entre a associação } \\
\text { Clástico-Química e o Grupo } \\
\text { Quebra Ossos. } \\
\text { BIF (NE/SW). }\end{array}$ & 1 \\
\hline
\end{tabular}

Devido ao grande potencial de exploração de ouro e também de ferro no QF, recomendase que sejam realizados novos levantamentos aéreos e terrestres com equipamentos mais modernos para melhorar os resultados de modelagens futuras, com o objetivo de confirmar os alvos indicados (follow-up), além de buscar novos alvos, obtendo-se uma base de dados de melhor qualidade.

$\mathrm{O}$ sistema que foi utilizado na aquisição dos dados desta pesquisa (AeroTEM ${ }^{\mathrm{HD}}$ ) é considerado um sistema de baixa potência com frequência base de $30 \mathrm{~Hz}$. Na última década, sistemas mais modernos com melhor resolução nos early e late times foram desenvolvidos. Novas frequências bases e momentos de dipolo vêm sendo empregados para aumentar a profundidade de investigação e a potência desse sistema. No entanto, um sistema mais moderno vem sendo bastante utilizado nos últimos anos na busca por depósitos de sulfeto maciço com grande sucesso, como os sistemas VTEM (Geotech Ltd.). O VTEM Max utiliza uma configuração in-loop com o loop Tx de $960 \mathrm{~m}^{2}$ de área e momento de dipolo magnético que pode chegar a até 866000 NIA. As frequências base são 25 ou $30 \mathrm{~Hz}$ e o sistema faz medição 
do $\mathrm{dB} / \mathrm{dt}$ para as componentes $\mathrm{X}, \mathrm{Y}$ e Z, proporcionando maior profundidade de investigação e maior resolução, resultado de níveis de razão sinal/ruído de alta qualidade. Outros sistemas que poderiam ser utilizados na região são os SkyTEM (SkyTEM Aps - Dinamarca). Embora inicialmente tenham sido desenhados para exploração de água subterrânea, veem sendo melhorados nos últimos anos e aplicados com sucesso na exploração mineral. O sistema SkyTEM306 HP pode ser operado em high ou low moment. O loop transmissor possui $324 \mathrm{~m}^{2}$ de área e em high moment pode chegar a até cerca de 500000 NIA, com pico de corrente de 220 - 250 A e em low moment, o momento de dipolo é de cerca de 3000 NIA, com 9 A de corrente. A frequência base é de $25 \mathrm{~Hz}$. Este sistema pode ser utilizado para recuperação de informações mais rasas, importantes para modelagem principalmente do solo polarizável. Logo, os sistemas poderão ser uma boa opção para aquisição de novos dados HTEM, com maior qualidade, no SGRV.

As metodologias terrestres como TDEM, IP (Induced Polarization), ER (Electroresistivity Method) e magnetometria podem auxiliar na confirmação dos alvos modelados, em uma escala menor e maior detalhe (follow up geofísico). Estas informações servirão como guia para as empresas de mineração nos testes e furos de sondagem.

A exploração mineral demanda muitas etapas onerosas e através de métodos geofísicos, como os aerolevantamentos eletromagnéticos, pode-se delimitar alvos de prospecção com maior precisão, otimizando o processo de pesquisa mineral e reduzindo custos. 


\section{Referências Bibliográficas}

Alkmim, F. F., \& Noce, C. M. (2006). São Francisco craton. Paleoproterozoic Supercontinents e Global Evolution, 116.

Alkmim, F. F., \& Marshak, S. (1998). The Transamazonian orogeny in the Quadrilátero Ferrífero, Minas Gerais, Brazil: Paleoproterozoic collision and collapse in the Southern São Francisco Craton region. Precambrian Research, 90, 29-58.

Alkmim, F. F., Jordt-Evangelista, H., Marshak, S., \& Brueckner, H. (1994). Manifestações do evento Trans-Amazônico no Quadrilátero Ferrífero, MG. 38th Congresso Brasileiro de Geologia. Sociedade Brasileira de Geologia, Camboriú, 75-76.

Allard, M. (2007). On the origin of HTEM species. In "Proceedings of Exploration 07: Fifth Decennial International Conference on Mineral Exploration” edited by B. Milkereit, 355374.

Almeida, F. F. M., \& Hasui, Y. (1984). O pré-Cambriano do Brasil. São Paulo, Edgar Blücher Ltda, 378.

Almeida, F. F. M. (1967). Origem e evolução da plataforma brasileira. Rio de Janeiro, Departamento Nacional da Produção Mineral, Divisão de Geologia e Mineralogia. Boletim, 241, 36 .

Almeida, E. R., Porsani, J. L., dos Santos, F. A. M., \& Bortolozo, C.A. (2017). 2D TEM Modeling for a Hydrogeological Study in the Paraná Sedimentary Basin, Brazil. International Journal of Geosciences, 8, 693-710.

Annan, A. P. (1974). The equivalent source method for electromagnetic scattering analysis and its geophysical application: PhD Thesis. Memorial University of Newfoundland.

Auken, E., Jørgensen, F., \& Sørensen, K. I. (2003). Large-scale TEM investigation for groundwater. Exploration Geophysics, 34, 188-194.

Balch, S. J., Boyco, W. P., \& Paterson, N. R. (2003). The AeroTEM airborne electromagnetic system. The Leading Edge, 22, 562-566. 
Baltazar, O. F. (1998a). Geologia Estrutural.apud Zucchetti, M.; Baltazar, O. F (Eds.). Projeto Rio das Velhas: Texto explicativo do mapa geológico integrado, escala 1: 100.000. $2^{\mathrm{a}}$ ed. Belo Horizonte: DNPM/CPRM.

Baltazar, O., \& Zucchetti M. (2007). Lithofacies associations and structural evolution of the Archean Rio das Velhas greenstone belt, Quadrilátero Ferrífero, Brazil: A review of the setting of gold deposits. Ore Geology Reviews, 32, 471-499.

Bortolozo, C. A., Couto, M. A., Porsani, J. L., Almeida, E. R., \& Santos, F. A. M. (2014). Geoelectrical Characterization Using Joint Inversion of VES/TEM Data: A Case Study in Paraná Sedimentary Basin, São Paulo State, Brazil. Journal of Applied Geophysics, 111, $33-46$.

Bournas, N., Plastow, G., Prikhodko, A., \& Legault, M. J. (2015). VTEM interpretation results and implications for graphite, $\mathrm{Cu}-\mathrm{Ni}$ and $\mathrm{Cr}$ mineralization-a case study from the Mazeze area, north-eastern Mozambique. Conference Paper, 1-5.

Campaña, J. D. R., Porsani, J. L., Bortolozo, C. A., Oliveira, G. S., \& Santos, F. A. M. (2017). Inversion of TEM Data and Analysis of the 2D Induced Magnetic Field Applied to the Aquifers Characterization in the Paraná Basin, Brazil. Journal of Applied Geophysics. $138,233-244$.

Canale, A. L. (1999). Geologia do Depósito Córrego do Sitio, Quadrilátero Ferrífero (MG), e Caracterização Mineralógica do Minério Sulfetado. Dissertação de Mestrado, Universidade Federal de Rio Grande do Sul, Porto Alegre, RG.

Cardador, M. H., Cuevasc, A. L., Watanabed, H., Saitoe, A., Wadae, K., Ishikawae, \& H., Okuzumie, K. (2003). Experimental evaluation of hydrocarbon detection with the LongOffset Time-Domain Electromagnetic Method in the Cretaceous carbonates of the Tampico-Misantla basin, Mexico. Journal of Applied Geophysics, 52, 103-122.

Carlos, D. U. (2013). Aplicação de processamento e inversão geofísica 3d de dados de aerogradiometria da gravidade na estimação da estrutura do minério de ferro no Sinclinal Gandarela - Quadrilátero Ferrífero - Minas Gerais. Tese de Doutorado. Observatório Nacional, Rio de Janeiro, RJ, Brasil.

Carson, M. C. (2003). The airborne Survey Industry - Struggling with Change. PDAC Forum. 
Chemale Jr., F., Rosière, C. A., \& Endo, I. (1994). The Tectonic evolution of the Quadrilátero Ferrífero, Minas Gerais, Brazil. Precambrian Research, 65, 25-54.

Chemale Jr., F., Rosiére, C. A., \& Endo, I. (1991). Evolução Tectônica do Quadrilátero Ferrífero, Minas Gerais - um modelo. Pesquisas da Universidade Federal do Rio Grande do Sul, 18, 104-127.

Christiansen, A. V., Auken, E., \& Sørensen, K. (2006). The transient electromagnetic method. In Groundwater Geophysics - A tool for Hydrogeology. Kirsh, R. (1ed). Springer-Verlag, Berlin.

Couto, M. A., Fiandaca, G., Maurya, P. K., Christiansen, A. V., Porsani, J. L., \& Auken, E. (2019). AEMIP robust inversion using maximum phase angle Cole-Cole model reparameterisation applied for HTEM survey over Lamego gold mine, Quadrilátero Ferrífero, MG, Brazil. Exploration Geophysics, 1-14.

Couto, M. A., Aisengart, T., Barbosa D., Ferreira C. R. Ferreira, Baltazar O. F., Marinho M. S., Cavalcanti, J. A. D., \& Araújo, J. C. S. (2017). Magnetization Vector Inversion Application in Quadrilatero Ferrifero Region, MG, Brazil. 15th International Congress of the Brazilian Geophysical Society \& EXPOGEF, 523-528.

Couto, M. A. (2015). Caracterização Hidrogeoelétrica na Região de Termas de Ibirá, Bacia do Paraná, por meio de Inversão Conjunta 1D de Sondagens TDEM/SEVs. Dissertação de Mestrado, IAG, Universidade de São Paulo, São Paulo, SP, Brasil.

CPRM - Serviço Geológico do Brasil (2012). Relatório Final do Levantamento e Processamento dos Dados Magnetométricos e Eletromagnetométricos: Projeto Aerogeofísico Rio das Velhas - Etapa 2. (Relatório Técnico). Belo Horizonte, MG.

CPRM - Serviço Geológico Do Brasil (1996). Programa Estudos de Distritos Mineiros. Projeto Rio das Velhas. Mapa Geológico Integrado. Escala 1:100.000: Texto Explicativo. (Relatório Técnico). Belo Horizonte, MG.

Danielsen, J. E., Auken, E., Jørgensen, F. S., Søndergaard, V. H., \& Sørensen, K. I. (2003). The application of the transient electromagnetic method in hydrogeophysical surveys. Journal of Applied Geophysics, 181-198. 
Dickson, B. L., \& Scott, K. M. (1997). Interpretation of aerial gamma-ray surveys - adding the geochemical factors. AGSO J. Australia Geology \& Geophysics. 17(2):187-200.

Dyck, A. V., Bloore, M., \& Vallee, M. A. (1980). Programs PLATE and SPHERE. Research in Applied Geophysics, $n^{\circ} 10$. University of Toronto, Canada.

DNPM - Departamento Nacional da Produção Mineral (1992). Levantamento Aéreo Magnetométrico, Gamaespectrométrico e Eletromagnético. Projeto Rio das Velhas. (Relatório Técnico). Belo Horizonte, MG.

Dorr II, J. V. N. (1969). Physiographic, stratigraphic and structural development of the Quadrilátero Ferrífero, Minas Gerais, Brazil. Geological Survey Professional Paper, 641A, 1-110.

Doyle, H. A. (1990). Geophysical exploration for gold - a review. Geophysics, 55, 134-146.

Electromagnetic Imaging Technology (2015). Maxwell Manual.

Farina, F., Albert, C., Martínez Dopico, C., Aguilar Gil, C., Moreira, H., Hippertt, J. P., \& Lana, C. (2016). The Archean-Paleoproterozoic evolution of the Quadrilátero Ferrífero (Brazil): Current models and open questions. Journal of South American Earth Sciences, $68,4-21$.

Ferreira Filho, F. A., \& Fonseca, M. A. (2001). Partição da deformação em regimes contracionais com obsctáculos no antepaís: exemplo a partir do Sistema de Falhas Água Quente, borda leste do Quadrilátero Ferrífero, MG. Revista Brasileira de Geociências., 31 (3), 267-278.

Fitterman, D. V., \& Stewart, M. T. (1986). Transient electromagnetic sounding for groundwater. Geophysics, 51, 995-1005.

Geosoft (1997a). Microleveling using FFT decorrugation. Geosoft Tech. Note.

Gnojek, I., \& Prichystal, A. (1985). A new zinc mineralization detected by airborne gammaray spectrometry in Northern Moravia (Czechoslovakia).

Grant, F. S., \& West, G. F. (1965). Interpretation theory in applied geophysics. McGraw-Hill. 
Groves, D. I., Goldfarb., R. J., Gebre-Mariam, M., Hagemann, S. G., \& Robert, F. (1998). Orogenic gold deposits: A proposed classification in the context of their crustal distribution and relationship to other gold deposit types. Ore Geology Reviews, 13, 7-27.

Guimarães, F. R. (2011). Análise espacial tridimensional e geoestatística de dados multi-fonte de superfície e subsolo aplicada à modelagem prospectiva de mineralizações auríferas no Quadrilátero Ferrífero - MG. Tese de doutorado, Universidade Estadual de Campinas, Campinas, São Paulo, Brasil.

Hamada, L. R., Porsani, J. L., Bortolozo, C. A., \& Rangel, C. R. (2018). TDEM and VES soundings applied to a hydrogeological study in the central region of the Taubate Basin, Brazil. First Break, 36, 49-54.

Herz, N. (1970). Gneissic and ignous rocks of the Quadrilatero Ferrifero, Minas Gerais, Brazil. Whashington, US Geological Survey. (pp.58).

Hoover, D. B., \& Pierce, H. A. (1990). Annotated Bibliography of Gamma-Ray Methods Applied to Gold Exploration. (Open-File Report). U.S.G.S. 90-203.

Johansson, L. (2017). Modelling and interpretation of VTEM data from Soppero, Sweden. Dissertação de Mestrado, Universidade de Tecnologia de Lulea, Lulea, Suécia.

Junqueira, P. A., (1997). Geologia do Depósito de Ouro da Mina de Raposos, Quadrilátero Ferrífero, com Ênfase na Alteração Hidrotermal. Tese de Doutorado. Inst. de Geociências, Universidade Federal de Minas Gerais, Belo Horizonte, (pp.130).

Kaufman, A. A., \& Keller, G. V. (1983). Frequency and Transient Soundings (1a ed). Elsevier.

Kirsch, R. (2006). Groundwater Geophysics (1a ed). Ed Springer.

Ladeira, E. A., Roeser, H. M. P., \& Tobschall, H. J. (1983). Evolução petrogenética do cinturão de rochas verdes, Rio das Velhas, Quadrilátero Ferríefero, Minas Gerais. Simpósio de Geologia de Minas Gerais, 2. Belo Horizonte. Anais. SBG/Núcleo Minas Gerais, 149-165.

Lamontagne, Y., Macnae, J., \& Polzer, B. (1988). Multiple conductor modeling using program MultiLOOP. SEG Technical Program Expanded Abstract (pp. 237-240). 
Lamontagne, Y., \& West, G. F. (1971). EM Response of a Rectangular Thin Plate. Geophysics, 36(6), 1204.

Leite, D. N., Bortolozo, C. A., Porsani, J. L., Couto, M. A., Campaña, J. D. R., dos Santos, F. A. M., Serejo, G., \& Stangari, M. C. (2018). Geoelectrical characterization with 1D VES/TDEM joint inversion in Urupês-SP region, Paraná Basin: Applications to hydrogeology. Journal of Applied Geophysics, 151, 205-220.

Leite, D. N. (2013). Caracterização geoelétrica por meio de inversão conjunta 1D de SEV/TDEM na região de Urupês-SP, Bacia do Paraná: Aplicações em Hidrogeologia. Dissertação de Mestrado, IAG, Universidade de São Paulo, São Paulo, Brasil.

Legault, J. M, Kaminski V., Kumar H., Orta M., \& Prikhodko A. (2010). Helicopter Electromagnetic (VTEM ${ }^{\mathrm{TM}}$ and ZTEM $^{\mathrm{TM}}$ ) Applications for Gold Exploration. Kegs-Pdac Symposium, Toronto, Canadá.

Lima, L. C. (2012). Depósito LODE Au-As-Sb Laranjeiras, em metaturbitos do Grupo Nova Lima, Quadrilátero Ferrífero, Minas Gerais. Dissertação de Mestrado, Instituto de Geociências, Universidade Federal de Minas Gerais, Belo Horizonte.

Lobato, L. M., Ribeiro-Rodrigues, L. C., \& Vieira, F. W. R. (2001a). Brazil's premier gold province: Part II. Geology and genesis of gold deposits in the Archean Rio das Velhas greenstone belt, Quadrilátero Ferrífero. Mineralium Deposita, 36, 249-277.

Lobato, L. M., Ribeiro-Rodrigues, L. C. \& Vieira, F. W. R. (2001b). Brazil's premier gold province. Part II: Geology and genesis of gold deposits in the Archean Rio das Velhas greenstone belt, Quadrilátero Ferrífero. Mineralium Deposita, 36, 249-277.

Lobato, L. M., Vieira, F. W. R., Ribeiro-Rodrigues, L. C., Pereira, L. M. M., Menezes, M. G., Junqueira, P. A., \& Martins-Pereira, S. L. (1998). Styles of hydrotermal alteration and gold mineralization associated with the Nova Lima group of the QF: part I, Description of selected gold deposits. Revista Brasileira de Geociências, 28 (3), 339-354.

Macnae, J., \& Nabighian, M. (2005). Electrical and EM methods, 1980-2005. The Leading Edge, 24, 42-45. 
McNeill, J. D. (1994). Principles and application of time domain electromagnetic techniques for resistivity soundings. Tech. Note TN-27 Geonics Ltd., Mississauga, Ontario, Canada.

Malouf, R. F., \& Corrêa Neto, A. V. (1996). O Supergrupo Rio das Velhas na Folha Conceição do Rio Acima: Projeto Rio das Velhas. Departamento Nacional de Produção Mineral/Companhia de Pesquisa de Recursos Minerais, Belo Horizonte, 17-23.

Marshak, S., Alkmim, F. F., \& Jordt Evangelista, H. (1992). Proterozoic crustal extension and the generation of dome-and-keel structure in an Archean granite-greenstone terrane. Nature, 397, 491-493.

Nabighian, M. N., \& Macnae, J. C. (1991). Time domain electromagnetic prospection methods. Investigations in Geophysics, no 3. Electromagnetic Methods in Applied Geophysics. Society of Exploration Geophysicists, Ed. Misac N. Nabighian, v.2, Application, Parts A and B.

Nabighian, M. N., \& Macnae, J. C. (1989). Time-domain electromagnetic prospecting methods, Ed., Electromagnetic Methods in Applied Geophysics. Society of Exploration Geophysicists, Ed. Misac N. Nabighian, v.2.

Nabighian, M. N., \& Macnae, J. C. (1988). Time Domain Electromagnetic Prospecting Methods. In: Nabighian M. N. (Ed.). Eletromagnetic Theory for Geophysics Application, Part A, Chapter 4.

Nabighian, M. N., Oppliger, G. L., Edwards, R. N., Lo, B. B. H., \& Cheesman, S. J. (1984). Cross-hole magnetometric resistivity (MMR). Geophysics, 49, 1313-1326.

Nabighian, M. N. (1979). Quasi-static transient response of a conducting half-space - An approximate representation. Geophysics, 44(10), 1700-1705.

Noce, C. M., Tassinari, C., \& Lobato, M. L. (2007). Geochronological framework of the Quadrilátero Ferrífero, with emphasis on the age of gold mineralization hosted in Archean greenstone belts. Ore Geology Reviews, 32, 500-510.

Noce, C. M. (2000). Geochronology of Quadrilátero Ferrífero: a review. Geonomos, Revista de Geociências, 7, 15-23. 
Oliveira, D. S. (2014). Interpretação de dados aerogeofísicos para exploração aurífera na área do Projeto Córrego do Sítio, NE do Quadrilátero Ferrífero. Dissertação de Mestrado, IAG, Universidade de São Paulo, São Paulo, Brasil.

Palacky, G. J. (1991). Resistivity characteristics of geologic targets. In: Electromagnetic Methods in Applied Geophysics. Society of Exploration Geophysicists, Tulsa, Oklahoma, $1,53-129$.

Pereira, S. L. M., Lobato, L. M., Ferreira, J. E., \& Jardim, E. C. (2007). Nature and origin of the BIF-hosted São Bento gold deposit, Quadrilátero Ferrífero, Brazil, with especial emphasis on structural controls. Oro Geology Reviews, 32, 571-595.

Porsani, J. L., Almeida, E. R., Bortolozo, C. A., \& Monteiro Santos, F. A. (2012a). TDEM survey in an area of seismicity induced by water wells in Paraná sedimentary basin, Northern São Paulo State, Brazil. Journal of Applied Geophysics, 82, 75-83.

Porsani, J. L., Almeida, E. R., \& Bortolozo, C. A., (2012b). TDEM Survey in an Area of Seismicity Induced by Water Wells in Paraná Sedimentary Basin, Northern São Paulo State, Brazil. Journal of Applied Geophysics, 82, 75-83.

Rangel, C. R., Porsani, J. L., Bortolozo, C. A., \& Hamada, L. R. (2018). Electrical Resistivity Tomography and TDEM Applied to Hydrogeological Study in Taubaté Basin, Brazil. International Journal of Geosciences, 9, 119-130.

Ribeiro Rodrigues, L. C., (1992). O contexto geológico-estrutural do Parque Natural do Caraça e adjacências, Quadrilátero Ferrifero, MG. Mapas e perfis. Dissertação de Mestrado. Instituto de Geociências da Universidade de Brasília, Brasília.

Ribeiro, V. B., Mantovanni, M. S. M., \& Louro, V. H. A. (2013). Aerogamaespectrometria e suas aplicações no mapeamento geológico. Terra e Didática, 10, 29-51.

Rolim, S. B. A. (2001). Resposta geofísica dos depósitos de ouro da porção central do Quadrilátero Ferrífero, MG. Tese de Doutorado, IG, Unicamp, Campinas, São Paulo, Brasil.

Schorscher, H. D. (1976). Polimetamorfismo do Pré-Cambriano na Região de Itabira, Minas Gerais. In: SBG, 29th Congresso Brasileiro De Geologia, Ouro Preto, MG, 194-195. 
Schrank, A., \& Machado, N. (1996a). Idades U-Pb em monazitas e zircões das minas de Morro Velho e Passagem de Mariana-Quadrilátero Ferrífero (MG). 39th Congresso Brasileiro de Geologia. Sociedade Brasileira de Geologia, Salvador, Brasil, 470-472.

Silva, A. M., McCafferty, A. E., \& Pires A. C. B. (2003). An Integrated Exploration Approach to Map BIF-Hosted Gold Deposits in the Rio das Velhas Greenstone Belt, Quadrilatero Ferrífero. Brazil. Revista Brasileira de Geociências, 33(2), 29-36.

Silva, A. M. (1999). Integração de dados geológicos e geofísicos utilizando-se uma nova técnica estatística para seleção de alvos para exploração mineral, aplicada ao Greenstone Belt Rio das Velhas, Quadrilátero Ferrífero. Tese de doutorado, Universidade de Brasília, Brasília, Brasil.

Silva, L. C. F. (2007). Depósito Pilar: contexto geológico, alteração hidrotermal e mineralização aurífera. Dissertação de Mestrado. Universidade Federal de Minas Gerais, Belo Horizonte, MG, Brasil.

Sørensen, K. I., Auken, E., Christensen, N. B., \& Pellerin, L. (2005). An Integrated Approach for Hydrogeophysical Investigations: New Technologies and a Case History. SEG NSG Vol II: Applications in Case Histories, 21.

Sørensen, K. I., Auken, E., \& Thomsem, P. (2000). TDEM in groundwater mapping - a continuous approach. Proceedings of the Symposium of the Application of Geophysics to Engineering and Environmental Problems, Virginia, USA.

Spies, B. R. (1989). Depth investigation in electromagnetic sounding methods. Geophysics, 54(7), 872-888.

Teixeira, W., Carneiro, M. A., Noce, C. M., Machado, N., Sato, K., \& Taylor, P. N. (1996). $\mathrm{Pb}, \mathrm{Sr}$ and $\mathrm{Nd}$ isotope constratains on the Archean evolution of gneissic - granitoid complexes in São Fransciso Craton, Brazil. Precambrian Research, 78, 151-164.

Telford, W. M., Geldart, L. P., \& Sheriff, R. E. (1990). Applied Geophysics (2a Ed). Cambridge University Press, England. 
Vial, D. S., Abreu, G. C., Schubert, G., \& Ribeiro Rodrigues, L. C. (2007a). Smaller gold deposits in the Archean Rio das Velhas greenstone belt, Quadrilátero Ferrífero, Brazil. Ore Geology Reviews, 32, 651-673.

Vial, D. S., DeWitt, E., Lobato, L., M., \& Thorman, C, H. (2007). The geology of the Morro Velho gold deposit in the Archean Rio das Velhas greenstone best, Quadrilátero Ferrífero, Brazil. Ore Geology Reviews, 32, 511-542.

Vieira, F. W. R., \& Oliveira, G. A. L. (1988). Geologia do Distrito Aurífero de Nova Lima, Minas Gerais. IN: Schobbenhaus, C., Coelho, C. ES. (coord.) Principais Depósitos Minerais do Brasil. Brasília, DNPM/CVRD, 3, 377-391. 